\title{
Em busca da sistematização do corpo teórico-conceitual da Ciência da Informação: uma abordagem hermenêutica
}

\author{
Versão corrigida
}

(original disponível na Escola de Comunicações e Artes)

\begin{abstract}
Tese apresentada como requisito para a obtenção do grau de Doutor ao Programa de Pós-Graduação em Ciência da Informação, área de concentração Cultura e Informação, linha de pesquisa Organização da Informação e do Conhecimento, Escola de Comunicações e Artes, Universidade de São Paulo.
\end{abstract}

Orientadora: Profa Dra Marilda Lopes Ginez de Lara

Coorientador: Prof. Dr. Michael Keeble Buckland 
Autorizo a reprodução e divulgação total ou parcial deste trabalho, por qualquer meio convencional ou eletrônico, para fins de estudo e pesquisa, desde que citada a fonte.

\author{
Catalogação na Publicação \\ Serviço de Biblioteca e Documentação \\ Escola de Comunicações e Artes da Universidade de São Paulo \\ Dados inseridos pelo(a) autor(a)
}

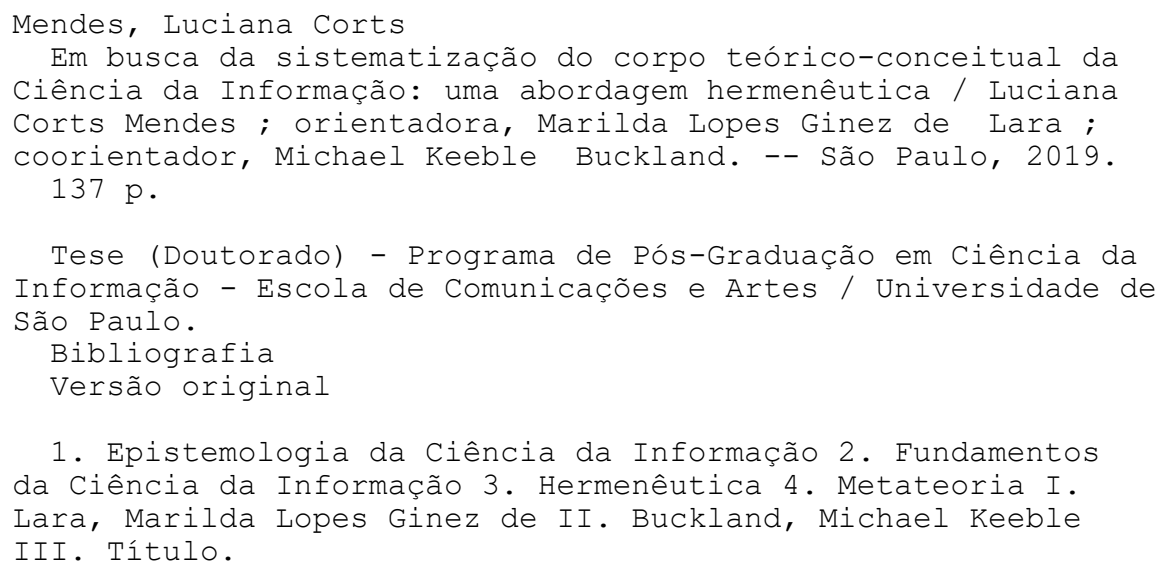

CDD 21.ed. - 020 


\section{Folha de Aprovação}

Nome: MENDES, Luciana Corts

Título: Em busca da sistematização do corpo teórico-conceitual da Ciência da Informação: uma abordagem hermenêutica.

Tese apresentada como requisito para a obtenção do grau de Doutor ao Programa de Pós-Graduação em Ciência da Informação, área de concentração Cultura e Informação, linha de pesquisa Organização da Informação e do Conhecimento, Escola de Comunicações e Artes, Universidade de São Paulo.

Data de aprovação:

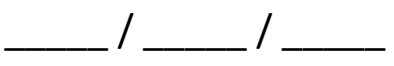

Banca Examinadora

Prof. Dr.

Instituição:

Julgamento:

Prof. Dr.

Instituição:

Julgamento:

Prof. Dr.

Instituição:

Julgamento:

Prof. Dr.

Instituição:

Julgamento: 
Prof. Dr.

Instituição:

Julgamento:

Prof. Dr.

Instituição:

Julgamento: 
À minha mãe, Elisabete de Brito Mendes. 



\section{Agradecimentos}

“Rendei graças ao SENHOR, porque ele é bom, porque a sua misericórdia dura para sempre."

À Profa. Dra. Marilda Lopes Ginez de Lara pela orientação dedicada, estimuladora e paciente durante os anos de doutorado. Muito obrigada pelos comentários e críticas, eles foram fundamentais para o desenvolvimento e amadurecimento desta pesquisa. Agradeço também o carinho e preocupação nos momentos de dificuldade.

Ao Prof. Dr. Michael Keeble Buckland por demonstrar interesse em minha pesquisa e se disponibilizar para me orientar durante o doutorado sanduíche. Muito obrigada pela orientação dedicada e estimuladora e também pelo acolhimento, carinho e preocupação enquanto eu estava sozinha longe de casa.

À minha mãe, Elisabete de Brito Mendes, pelas sugestões durante o desenvolvimento desta pesquisa, leituras e releituras desta tese e por ter me ensinado desde pequena a guardar informações, porque elas fariam sentido no futuro quando fossem associadas umas às outras.

A meu pai, Luis Enrique Corts Ibañez, por me ensinar logo nos primeiros anos do Ensino Fundamental como uma pesquisa deve ser feita e pelo estímulo ao conhecimento e à leitura.

À minha avó, Rosa de Brito Mendes (in memoriam), por me criar e me ensinar a importância de conhecer, estudar e ler, sendo um exemplo de vida.

Aos meus abuelos, Manuela Ibañez Cobo (in memoriam) e Luis Corts Espigol (in memoriam), pelo carinho e pelos cuidados, por me ensinarem um idioma e por estimularem o aprendizado e a leitura.

A meu tio, Fábio José de Brito Mendes, pelo carinho e por ter estimulado meu interesse no conhecimento desde criança com seus quizzes de conhecimento geral. 
À Amanda Emy Hatano Mendes e à Bruna Miho Hatano Mendes pelo carinho, diversão e paciência.

À Amanda Pacini de Moura pelas discussões sobre minha pesquisa e sobre a Ciência da Informação como um todo, mas sobretudo pela amizade e carinho.

À Luiza Cândido Fernandes, Tatiana Galdino dos Santos, Verônica Silva Rodriguez Marques e Viviane Prado da Cruz pela amizade, apoio, carinho e paciência durante os anos em que desenvolvi esta pesquisa.

À Joseneide Maria de Oliveira pelo carinho, companhia e cuidado comigo em tempos difíceis.

Aos amigos, colegas e funcionários da International House at the University of California, Berkeley, em especial Chetanya Jain, Jianwen Xu, Simon Friedrich Edel, Sunwoo Kim, Renata Avila e Ricardo García Martínez, pelo acolhimento, companhia, cuidados, passeios e refeições durante meu doutorado sanduíche.

À Coordenação de Aperfeiçoamento de Pessoal de Nível Superior (CAPES) pela bolsa de doutorado (Código de Financiamento 001) que permitiu minha dedicação exclusiva a esta pesquisa.

Ao Conselho Nacional de Desenvolvimento Científico e Tecnológico (CNPq) pela bolsa de doutorado sanduíche no exterior (processo 206495/2017-0) que permitiu o aprofundamento desta pesquisa com novos referenciais conceituais e metodológicos em um centro internacional de excelência acadêmica, a University of California, Berkeley. 


\section{Resumo}

MENDES, Luciana Corts. Em busca da sistematização do corpo teórico-conceitual da Ciência da Informação: uma abordagem hermenêutica. 2019. Tese (Doutorado em Ciência da Informação) - Escola de Comunicações e Artes, Universidade de São Paulo, São Paulo, 2019.

A pesquisa consiste no levantamento de elementos teórico-conceituais de cunho geral que sirvam de base para a sistematização futura de uma metateoria hermenêutica da Ciência da Informação. Desenvolveu-se a investigação através de levantamento, revisão e análise das literaturas da Ciência da Informação e da hermenêutica. A pesquisa partiu da identificação de que, sob uma perspectiva hermenêutica, os pontos centrais ao redor dos quais se estrutura a Ciência da Informação são o indivíduo que busca informação e dela faz uso e o registro de informação capaz de informar. A partir dessa constatação, levantaram-se elementos teóricoconceituais de cunho geral referentes ao comportamento informacional e ao armazenamento, organização e recuperação de documentos sob a ótica hermenêutica. Conclui-se que os fundamentos da hermenêutica perpassam toda a Ciência da Informação, servindo assim de base para a sistematização do corpo teórico-conceitual do paradigma hermenêutico da disciplina, e que o levantamento realizado se configura como um delineamento inicial para o desenvolvimento de uma metateoria hermenêutica da Ciência da Informação.

Palavras-chave: Epistemologia da Ciência da Informação. Fundamentos da Ciência da Informação. Hermenêutica. 



\begin{abstract}
MENDES, Luciana Corts. Em busca da sistematização do corpo teórico-conceitual da Ciência da Informação: uma abordagem hermenêutica. 2019. Tese (Doutorado em Ciência da Informação) - Escola de Comunicações e Artes, Universidade de São Paulo, São Paulo, 2019.

The research consists in raising theoretical and conceptual elements of a general nature that serve as the basis for a future systematisation of a hermeneutical metatheory of Information Science. The investigation was developed through bibliographic survey, revision and analysis of the literatures of Information Science and hermeneutics. The research departed from the identification that, from a hermeneutical perspective, the central points around which Information Science is structured are the individual that searches and uses information, and the information record capable of informing. This finding led to the raising of theoretical and conceptual elements of a general nature regarding information behaviour and document storage, organisation and retrieval from a hermeneutical point of view. It is concluded that the foundations of hermeneutics permeate the entirety of Information Science, thus serving as the basis for a systematisation of the theoretical and conceptual body of the hermeneutical paradigm of the discipline. It is also concluded that the results achieved configure an initial delineation of a hermeneutical metatheory of Information Science.
\end{abstract}

Keywords: Epistemology of Information Science. Foundations of Information Science. Hermeneutics. 



\section{Resumen}

MENDES, Luciana Corts. Em busca da sistematização do corpo teórico-conceitual da Ciência da Informação: uma abordagem hermenêutica. 2019. Tese (Doutorado em Ciência da Informação) - Escola de Comunicações e Artes, Universidade de São Paulo, São Paulo, 2019.

La investigación consiste en la identificación de elementos teórico-conceptuales de naturaleza general que sirvan de base para la sistematización futura de una metateoría hermenéutica de la Ciencia de la Información. Se desarrolló la investigación a través de encuesta, revisión y análisis de las literaturas de la Ciencia de la Información y de la hermenéutica. La investigación partió de la identificación de que, bajo una perspectiva hermenéutica, los puntos centrales alrededor de los cuales se estructura la Ciencia de la Información son el individuo que busca información y la utiliza y el registro de información capaz de informar. A partir de esa constatación, se identificaron elementos teórico-conceptuales de naturaleza general referentes al comportamiento informacional y al almacenamiento, organización y recuperación de documentos bajo la óptica hermenéutica. Se concluye que los fundamentos de la hermenéutica atraviesan toda la Ciencia de la Información, sirviendo así de base para la sistematización del cuerpo teórico-conceptual del paradigma hermenéutico de la disciplina, y que el resultado alcanzado se configura como un delineamiento inicial para el desarrollo de una metateoría de la Ciencia de la Información.

Palabras clave: Epistemología de la Ciencia de la Información. Fundamentos de la Ciencia de la Información. Hermenéutica. 



\section{Sumário}

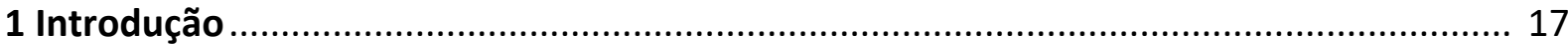

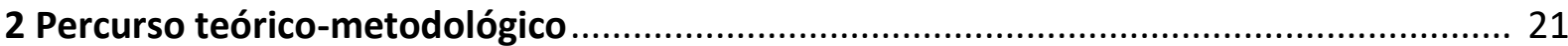

3 Comportamento informacional sob a ótica hermenêutica ........................................... 43

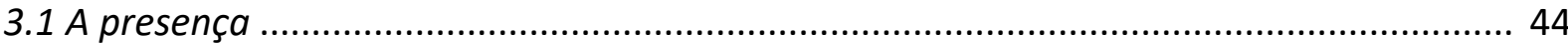

3.2 Compreensão, interpretação e círculo hermenêutico ........................................................ 53

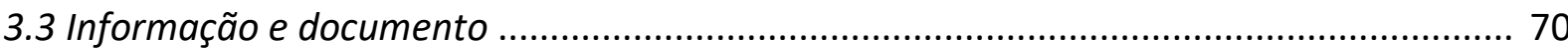

3.4 Presença e comportamento informacional .................................................................... 92

4 Armazenamento, organização e recuperação de documentos sob a ótica hermenêutica. 95

4.1 Análise de comunidade e avaliação de necessidades .................................................... 96

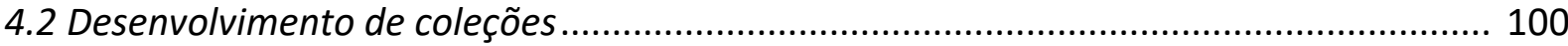

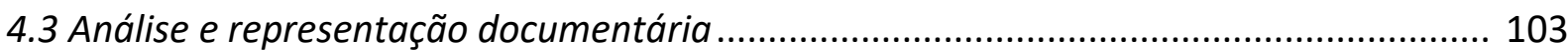

4.4 Busca e recuperação de documentos, serviço de referência e relevância ....................... 111

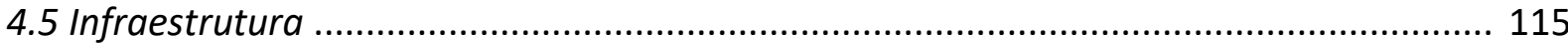

4.6 Sistemas de documentação sob a ótica da hermenêutica ................................................ 118

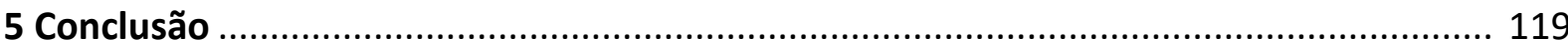

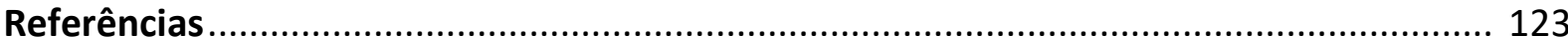





\section{Introdução}

A Ciência da Informação é entendida no contexto brasileiro como uma ciência social aplicada (ÁREAS..., [2018]). Esta área do conhecimento se preocupa com a informação e com o modo como o ser humano se relaciona com ela, abrangendo questões relativas à produção, circulação e consumo da informação. A disciplina trabalha tradicionalmente com informação registrada, pois esta é passível de permanência, portabilidade, coleção, armazenamento, organização, recuperação e acessibilidade no tempo e no espaço.

Dentro desse contexto foi desenvolvida esta pesquisa de doutorado, que teve como origem a identificação do problema da ausência da sistematização de uma estrutura teóricoconceitual integrada da Ciência da Informação. Desde o advento da Ciência da Informação existe a preocupação de que a disciplina não possui um corpo teórico-conceitual sistematizado. Como qualquer outra área científica, a Ciência da Informação precisa de um corpo teórico-conceitual estruturado para se desenvolver, uma vez que este permite o redimensionamento e a reorientação da área. Padecendo da falta de um corpo teóricoconceitual sistematizado, a Ciência da Informação se torna propensa a um desenvolvimento irregular e fragmentado, justificando-se a realização de pesquisas que visem sistematizar modelos, teorias e metateorias da área. Somente com um corpo teórico-conceitual sistematizado a Ciência da Informação pode se desenvolver coesamente, compreendendo suas limitações e possibilidades.

Uma vez identificado esse problema, perguntamo-nos: como seria possível a sistematização do corpo teórico-conceitual da Ciência da Informação? Em busca de uma resposta para nossa pergunta, desenvolvemos uma investigação de natureza teórica e exploratória por meio de levantamento, revisão e análise bibliográficos da literatura sobre epistemologia da Ciência da Informação, que evidenciou que os conceitos fundamentais com os quais a Ciência da Informação trabalha são imbuídos de bases teóricas que são passíveis de análise, ainda que estas bases estejam implícitas, através da revisão da literatura da área e de seu processo de constituição (GOMES, 2001; HJØRLAND, 1998; JAEGER, 2010; KOBASHI; TÁLAMO, 2003; TÁLAMO; SMIT, 2007; WERSIG, 1993; WERSIG; WINDEL, 1985). Este processo, detalhado no segundo capítulo desta tese - Percurso teórico-metodológico -, levou à formulação de duas hipóteses em resposta à nossa pergunta de pesquisa: 
a) a aplicação da hermenêutica na articulação, isto é, na combinação, na coordenação, no estabelecimento de relações entre os conceitos basilares da Ciência da Informação permitiria a sistematização do corpo teórico-conceitual de seu paradigma hermenêutico;

b) seria possível sistematizar o corpo teórico-conceitual do paradigma hermenêutico da Ciência da Informação através da sistematização de sua metateoria;

Partindo dessas hipóteses, formulamos nosso objetivo geral de pesquisa: levantar elementos teórico-conceituais de cunho geral que permitam a sistematização futura de uma metateoria hermenêutica da Ciência da Informação. A sistematização de uma metateoria é um processo que não pode ser reduzido ao desenvolvimento de uma única pesquisa de doutorado, contudo, visamos contribuir para essa sistematização através do levantamento de elementos teórico-conceituais de cunho geral que sirvam de base para o desenvolvimento de pesquisas futuras que levem à sistematização de uma metateoria hermenêutica da Ciência da Informação. Nossos objetivos específicos são:

a) levantar elementos teórico-conceituais de cunho geral referentes à relação entre indivíduo e informação, isto é, referentes ao comportamento informacional sob a ótica hermenêutica;

b) levantar elementos teórico-conceituais de cunho geral referentes aos modos como os registros de informação, ou documentos, são tratados para que possam ser recuperados e utilizados pelos indivíduos, ou seja, referentes ao armazenamento, organização e recuperação de documentos sob a ótica hermenêutica.

Esta tese está estruturada em cinco capítulos. O primeiro capítulo é a presente introdução. No segundo capítulo apresentamos nosso percurso teórico-metodológico. Iniciamos o capítulo com uma discussão sobre o estado da teoria na Ciência da Informação, analisando as ideias de que a disciplina não tem um corpo teórico-conceitual estruturado e de que essa estruturação é necessária. Em seguida discutimos como essa estruturação pode ser realizada e como propomos levantar elementos teórico-conceituais de cunho geral que sirvam de base para a sistematização de uma metateoria hermenêutica da Ciência da Informação. 
Nesta discussão justificamos a adoção de nossa abordagem hermenêutica e discutimos o conceito de metateoria.

A seguir temos o capítulo Comportamento informacional sob a ótica hermenêutica, que se constitui na primeira das duas partes em que organizamos nosso levantamento de elementos teórico-conceituais de cunho geral que sirvam de base para a sistematização de uma metateoria hermenêutica da Ciência da Informação. Nele discutimos o comportamento informacional de um ponto de vista hermenêutico, de modo a entendermos o que motiva alguém a buscar e utilizar informação sob a perspectiva da hermenêutica. Iniciamos o capítulo com uma discussão sobre o que é o ser humano no contexto da hermenêutica e sobre o modo como esse ser humano se encontra no mundo. Passamos então à discussão sobre os conceitos de informação e documento sob a perspectiva da hermenêutica.

O quarto capítulo desta tese, chamado Armazenamento, organização e recuperação de documentos sob a ótica hermenêutica, é a segunda das duas partes em que organizamos nosso levantamento de elementos teórico-conceituais de cunho geral que sirvam de base para a sistematização de uma metateoria hermenêutica da Ciência da Informação e discute o armazenamento, a organização e a recuperação de documentos de um ponto de vista hermenêutico. Nele são analisados os seguintes conceitos:
a) análise de comunidade e avaliação de necessidades;
b) desenvolvimento de coleções;
c) análise e representação documentária;
d) busca e recuperação de documentos, serviço de referência e relevância;
e) infraestrutura.

O quinto e último capítulo desta tese é a conclusão de nossa pesquisa de doutorado, onde refletimos sobre nossa investigação, avaliando se nossas hipóteses foram confirmadas e se nossos objetivos foram alcançados.

Passamos agora ao segundo capítulo desta tese, Percurso teórico-metodológico. 


\title{
2 Percurso teórico-metodológico
}

A motivação para o desenvolvimento desta pesquisa de doutorado surgiu durante a realização de nossa pesquisa de mestrado, onde buscávamos compreender a herança do Movimento Bibliográfico para a Ciência da Informação (MENDES, 2014). O desenvolvimento de nossa pesquisa de mestrado levou a que nos deparássemos com a necessidade de identificar os conceitos centrais da Ciência da Informação e compará-los a suas aproximações na literatura dos autores que selecionamos como nosso corpus de trabalho. No entanto, esta tarefa nos explicitou a ausência da sistematização de uma estrutura teórico-conceitual integrada da Ciência da Informação. A identificação deste problema, contudo, não é uma detecção exclusivamente nossa, tratando-se de uma percepção recorrente na história da disciplina, bem como das áreas na qual ela se enraíza, como pode ser ilustrado pela literatura:

\begin{abstract}
não existe uma ciência básica bem desenvolvida da qual a Biblioteconomia possa obter seus conhecimentos e princípios fundamentais. Que isto seja verdade não significa que essa ciência básica não seja possível, mas apenas que ela ainda não foi desenvolvida. Certamente, o problema de coordenar os recursos intelectuais das sociedades humanas é tão importante e tão passível de investigação científica como o problema de identificação de elementos não racionais no comportamento humano, com o qual os cientistas do comportamento têm estado tão enamorados durante as últimas décadas. Mas, até o desenvolvimento independente dessa ciência básica, bibliotecários provavelmente serão forçados a desenvolver estruturas teóricas apropriadas à parte que lhes cabe nesse problema mais geral [de coordenar os recursos intelectuais das sociedades humanas], e eles [os bibliotecários] devem ao menos iniciar pesquisa relevante ${ }^{1,2}$ (EGAN, 1956, p. 72).
\end{abstract}

A ênfase na palavra 'ciência' reflete não somente um desejo pelo status profissional, mas também a esperança de que será possível desenvolver fundamentos sólidos de teoria e fatos testados característicos de outras ciências ${ }^{3}$ (CUADRA, 1964, p. 289).

bibliotecários [...] nunca deram muita atenção aos fundamentos teóricos de seus procedimentos, nem desenvolveram um programa de pesquisa que avançasse essa

\footnotetext{
${ }^{1}$ As traduções dos textos em outros idiomas são de nossa responsabilidade. Os textos em idioma original se encontram em notas de rodapé na mesma página dos textos traduzidos.

2 [...] there is no well-developed basic science from which librarianship can draw its fundamental knowledge and principles. That this is true does not mean that such a basic science is not possible but merely that it has not yet been developed. Certainly, the problem of coordinating the intellectual resources of human societies is just as important, and just as amenable to scientific investigation, as the problem of identifying the non-rational elements in human behavior with which the behavioral scientists have been so enamored during the past few decades. But, pending the independent development of such a basic science, librarians are probably going to be forced to develop a theoretical structure appropriate to their own part of this more general problem, and they must make at least a beginning in relevant research.

3 The emphasis on the word "science" reflects not only a desire for professional status but also the hope that it will be possible to develop the solid underpinnings of theory and tested fact characteristic of the other sciences.
} 
teoria ou explicasse e aprimorasse suas aplicações. Bibliotecários sabem muito bem como fazer o que eles fazem, mas eles nunca se preocuparam muito com porquê eles fazem o que fazem. [...] Sua disciplina é uma vasta acumulação de detalhes técnicos em vez de um corpo organizado de princípios abstratos que podem ser aplicados a situações concretas, um corpo de conhecimento que é conhecido e compreendido por todos os membros da corporação e que os próprios bibliotecários criaram sozinhos ${ }^{4}$ (SHERA, 1967, p. 748, grifos do autor).

Um primeiro passo crucial é um comprometimento maior por parte dos educadores da Biblioteconomia e da Ciência da Informação com a busca por uma conceptualização adequada do domínio como um conjunto de problemas sobre um funcionamento social único dentro do contexto de um sistema holístico de interações multivariadas ${ }^{5}$ (SCHRADER, 1984, p. 228).

Quando a própria teoria parece ter uma estrutura ad hoc, há sempre a tentação de concluir que ela forma um complemento opcional. O resultado é um campo fragmentado que provavelmente continuará desse jeito. Os primeiros pioneiros da Ciência da Informação viram isto como a maior ameaça ao seu campo recémestabelecido. Eles acreditavam que uma base teórica acordada era necessária para a disciplina se desenvolver de um modo consistente e compreensível. Por um lado, eles temiam que a Ciência da Informação se tornaria um rótulo para uma coleção de habilidades práticas sem qualquer coerência teórica subjacente (Brookes, 1989) ${ }^{6}$. Pelo outro, eles sentiam que essa base teórica seria impossível de formular a menos que as atividades informacionais fossem estudadas e discutidas em seus próprios termos, não nos termos de suas possíveis aplicações (Fairthorne, 1967) ${ }^{7}, 8$ (SUMMERS et al., 1999, p. 1156).

O dilema atual da Ciência da Informação se enuncia, a meu ver, nos seguintes termos: temos muitos estudos de caso sobre o acesso à informação e a organização da informação, mas não organizamos a informação constitutiva da área num corpo conceitual próprio (SMIT, 2009, p. 65).

${ }^{4}$ [...] librarians [...] have never given much consideration to the theoretical foundations of their procedures, nor developed a research program that would advance such theory or explain and improve its applications. Librarians know very well how to do what they do, but they never concern themselves to any great extent with why they do it. [...] Their discipline is a vast accumulation of technical details rather than a body of organized abstract principles that can be applied in concrete situations, a body of knowledge that is known and understood by all members of the guild and one which the librarians themselves alone have created.

${ }^{5} \mathrm{~A}$ crucial first step is a stronger commitment by library and information science educators to the search for an adequate conceptualization of the domain as a set of problems about a unique social functioning within the context of a holistic system of multivariate interactions.

${ }^{6}$ BROOKES, Bertram C. (1989). Personal transferable skills for the modern information professional. Journal of Information Science, [East Grinstead], v. 15, n. 2, p. 115-117.

${ }^{7}$ FAIRTHORNE, Robert A. (1967). Morphology of information flow. Journal of the Association for Computing Machinery, [New York], v. 14, n. 4, p. 710-719.

${ }^{8}$ When theory itself seems to have an ad hoc structure, there is always a temptation to conclude that it forms an optional add-on. The result is a fragmented field that is likely to stay that way. The early pioneers of information science saw this as a major threat to their newly established field. They believed that an agreed theoretical base was necessary for the subject to develop in a consistent and comprehensible way. On the one hand, they feared information science would become a label for a collection of practical skills without any underlying theoretical coherence (Brookes, 1989). On the other, they felt that such a theoretical basis would be impossible to formulate unless information activities were studied and talked about in their own terms, not in terms of their possible applications (Fairthorne, 1967). 
A percepção desse problema e sua aparente irresolução até o presente nos levou a perguntar, como seria possível a sistematização do corpo teórico-conceitual da Ciência da Informação? Desta pergunta surgiu a proposição de uma pesquisa de doutorado conduzida no Programa de Pós-Graduação em Ciência da Informação da Escola de Comunicações e Artes da Universidade de São Paulo, sob orientação da Profa Drạ Marilda Lopes Ginez de Lara, com período sanduíche na Escola de Informação (School of Information) da Universidade da Califórnia, Berkeley (University of California, Berkeley - UC Berkeley), nos Estados Unidos, sob coorientação do Prof. Dr. Michael Keeble Buckland.

Em busca de uma resposta para nossa pergunta, ou seja, buscando saber como seria possível a sistematização do corpo teórico-conceitual da Ciência da Informação, desenvolvemos uma investigação de natureza teórica e exploratória por meio de levantamento, revisão e análise bibliográficos da literatura sobre epistemologia da Ciência da Informação. Ou seja, realizamos a pesquisa e seleção de textos na bibliografia da área que respondessem à nossa pergunta e procedemos à leitura e análise dos mesmos, apropriandonos dessa bibliografia em consonância com as ideias expostas pelos autores e cotejando-as entre si mediante a hermenêutica crítica.

A hermenêutica crítica é uma metodologia de interpretação dos significados dos fenômenos investigados que se preocupa com a historicidade do conhecimento, isto é, pressupõe que o entendimento somente pode ser atingido ao se ter como referência o momento histórico e o contexto sociocultural no qual esses fenômenos tomaram lugar (HJøRLAND, 1998; RADFORD, 1991). A hermenêutica crítica é uma metodologia que objetiva a teorização analítica e avaliativa, buscando não apenas descrever os fenômenos investigados e o mundo, mas também os criticar e modificar (RADFORD, 1991).

Através do processo descrito acima e com base em diversos autores (GOMES, 2001; HJØRLAND, 1998; JAEGER, 2010; WERSIG, 1993; WERSIG; WINDEL, 1985), concluímos que os conceitos fundamentais com os quais a Ciência da Informação trabalha são imbuídos de bases teóricas, ainda que estas estejam implícitas. Ademais, foi possível concluir que, mesmo não estando explícitas, as bases teóricas subjacentes à disciplina são passíveis de análise. Inferimos então que o exame dessas bases, dos conceitos fundamentais da disciplina e de suas interrelações e a subsequente proposição de modelos e teorias permitiriam a sistematização do corpo teórico-conceitual da Ciência da Informação e, consequentemente, possibilitariam uma melhor compreensão de suas limitações e possibilidades. 
Segundo Kobashi e Tálamo (2003) e Tálamo e Smit (2007), através das revisões sistemáticas da literatura da Ciência da Informação seria possível a revisão crítica de seu processo de constituição - teórica e pragmaticamente - e, consequentemente, o redimensionamento do campo e a sistematização de seu corpo teórico-conceitual. Partindo deste pressuposto, buscamos então traçar um panorama do desenvolvimento da área, com o mesmo método descrito anteriormente, de modo a nos guiar na detecção das bases teóricas subjacentes à Ciência da Informação.

A Ciência da Informação surgiu na década de 1950 procurando responder a questões relativas à gestão da enorme quantidade de registros informacionais que emergiram no período imediatamente posterior à Segunda Guerra Mundial, tendo como objetivo a pesquisa dedicada ao estabelecimento de sistemas de armazenamento, organização e recuperação da informação, seu desenvolvimento estando atrelado às novas tecnologias de comunicação e processamento da informação. No entanto, como afirma Brookes (1980, p. 125), "os problemas básicos da Ciência da Informação não são novos" ${ }^{\prime 9}$; as questões relativas à produção, circulação e consumo da informação não surgiram com a disciplina, mas sim com a emergência dos registros de informação.

Diversos autores (ABDALLA; KOBASHI, 2012; BATES, 1999; BUCKLAND, 1999, 2012b; BUCKLAND; LIU, 1995; CAPURRO, 2007; CAPURRO; HJØRLAND, 2003; HJØRLAND, 2014; ORTEGA, 2004, 2009a, 2009b; RAYWARD, [1983], 1985; SHAPIRO, 1995; SHERA, 1980, [1983]; SHERA; CLEVELAND, 1977; SILVA; RIBEIRO, 2012; SMIT; TÁLAMO; KOBASHI, 2004; VEGAALMEIDA; FERNÁNDEZ-MOLINA; LINARES, 2009; WERSIG, 1993) compartilham o entendimento de que as raízes da Ciência da Informação estão nas teorias, práticas e paradigmas de diferentes áreas, particularmente nas práticas e teorias da Biblioteconomia, Documentação e Information Retrieval, disciplinas estas que, apesar de suas especificidades, têm em comum o interesse pela informação, sua forma, estrutura e seus processos de organização para seu acesso e apropriação.

Apesar da pré-existência dessas disciplinas, a Ciência da Informação surge pelo fato de que "durante o século XX existia um forte desejo de que os serviços provedores de informação se tornassem científicos, de que progredissem da Biblioteconomia, Bibliografia e

\footnotetext{
${ }^{9}$ The basic problems of information science are not new.
} 
Documentação para uma Ciência da Informação"10 (BUCKLAND, 2012b, p. 1) - aqui, científico se refere ao modelo das ciências naturais.

A própria Ciência da Informação, segundo proposta recorrente na literatura da área (CAPURRO, 2007; SMIT, 2012; VEGA-ALMEIDA; FERNÁNDEZ-MOLINA; LINARES, 2009), se desenvolveu por meio de três paradigmas, o paradigma físico, o paradigma cognitivo e o paradigma social. Cada um desses paradigmas não rompe com o paradigma anterior, o que ocorre é "a incorporação de novos conceitos e uma priorização diferente de conceitos, desenhando assim tanto epistemologias diferentes do campo informacional como práticas diferenciadas" (SMIT, 2012, p. 88).

Smit (2012, p. 90) afirma que "o paradigma físico priorizou o objeto [a informação], o paradigma cognitivo enfatizou o sujeito, e o paradigma social enxerga o sujeito, contextualizado, em sua relação com o objeto-informação". O paradigma físico foi determinante para "a criação e consolidação da integridade e singularidade do novo campo de conhecimento, em um período histórico concreto, e definiu sua independência e autonomia"11; o paradigma cognitivo expressa e reflete "uma mudança social e intelectual mais radical"12, pois "se centra no sujeito como ente individual"13; e o paradigma social transcende o paradigma cognitivo ao enfatizar "a historicidade de todos os fenômenos sociais" 14 e por questionar "os elementos subjetivos dos modelos teóricos"15, aumentando "a probabilidade de que esses modelos sejam relevantes"16 e contribuindo para 0 "desenvolvimento orgânico da disciplina"17 (VEGA-ALMEIDA; FERNÁNDEZ-MOLINA; LINARES, 2009, online).

Este panorama do processo de constituição da Ciência da Informação nos permitiu concluir que ela não pode possuir um único corpo teórico-conceitual, mas que cada um de seus paradigmas de desenvolvimento possui seu próprio corpo teórico-conceitual. Enquanto esta conclusão pode parecer óbvia frente à crise enfrentada pela ciência moderna ao longo

\footnotetext{
${ }^{10}$ During the 20th century there was a strong desire for the provision of information services to become scientific, to move from librarianship, bibliography, and documentation to an information science.

11 [...] la creación y consolidación de la integridad y singularidad del nuevo campo del conocimiento, en un período histórico concreto, y definió su independencia y autonomía.

12 [...] un cambio social e intelectual más radical [...].

13 [...] centrarse en el sujeto como ente individual.

14 [...] la historicidad de todos los fenómenos sociales [...].

15 [...] los elementos subjetivos de los modelos teóricos [...].

16 [...] la probabilidad de que esos modelos sean relevantes [...].

17 [...] desarrollo orgánico de la disciplina.
} 
do século XX - a crise de um modelo global e totalitário fundado na racionalidade científica e no cientificismo devido à identificação de seus limites e insuficiências estruturais, bem como dos desusos da ciência (SANTOS, 2010) -, ou seja, pode parecer óbvio que não exista uma única possibilidade global e totalitária de sistematização do corpo teórico-conceitual da Ciência da Informação, e fôssemos conscientes desta realidade, nossa conclusão destacou a necessidade de definir um ponto de vista a partir do qual buscar a sistematização do corpo teórico-conceitual da disciplina.

Dada nossa percepção de que não existe uma única possibilidade global e totalitária de sistematização do corpo teórico-conceitual da Ciência da Informação, selecionamos o paradigma social da disciplina como nosso objeto de pesquisa devido à sua abrangência diante das questões relativas à produção, circulação e consumo da informação, uma vez que ele "enxerga o sujeito, contextualizado, em sua relação com o objeto-informação" (SMIT, 2012, p. 90).

Capurro (2007) afirma que o paradigma social da Ciência da Informação pode também ser chamado de paradigma hermenêutico da Ciência da Informação, uma perspectiva que esse autor fundamenta em grande parte no pensamento do filósofo Martin Heidegger (1889-1976) expresso na obra Ser e Tempo. Capurro explica que a

\begin{abstract}
hermenêutica do existir humano [...] parte da premissa de que não precisamos buscar uma ponte entre o sujeito e o objeto localizado em um 'mundo exterior', já que existir significa já estar sempre 'fora' e socialmente envolvido em uma rede de relações e significados que Heidegger chama 'mundo'. Sua famosa fórmula 'ser-nomundo' explicita justamente esta situação fática do 'ser aí' ('Dasein') do existir humano. Porém é mais que isso, dito envolvimento é para Heidegger originariamente também um 'ser aí' em uma relação social primordialmente prática ('Sorge') com os outros ('Mitsein') e com as coisas ${ }^{18}$ (CAPURRO, 2007, p. 20).
\end{abstract}

A identificação por parte de Capurro (2007) de que o paradigma social, que considera o caráter contextual dos processos de produção, circulação e consumo da informação, não isolando estes processos ao indivíduo, se relaciona à hermenêutica, levou a que nos voltássemos para este ramo da filosofia, de modo a melhor compreender a caracterização do

\footnotetext{
18 [...] la hermenéutica del existir humano [...] parte de la premisa de que no necesitamos buscar un puente entre el sujeto y el objeto ubicado en un "mundo exterior" puesto que existir significa estar ya siempre "afuera" y socialmente involucrado en una red de relaciones y significados que Heidegger llama "mundo". Su famosa fórmula "ser-en-el-mundo" hace explícita justamente esta situación fáctica del "estar allí" ("Dasein") del existir humano. Pero es más, dicho involucramiento es para Heidegger originariamente también un "estar allí" en una relación social primordialmente práctica ("Sorge") con los otros ("Mitsein") y con las cosas.
} 
paradigma social feita pelo autor. Buscamos explicitar o conceito de hermenêutica primordialmente através das obras de Heidegger e Hans-George Gadamer (1900-2002) - este último considerado "a figura decisiva no desenvolvimento da hermenêutica do século XX"19 (MALPAS, 2018, online) -, mas também em obras que discutem a filosofia desses dois autores base.

Segundo Heidegger (2013, p. 15), a hermenêutica é "o modo unitário de abordar, concentrar, acessar a ela [facticidade], isto é, de questionar e explicar a facticidade". Facticidade designa "aquele mundo de significados e relações que é inseparável da própria vida" 20 (DAHLSTROM, 2013, p. 72). Para Heidegger "a hermenêutica não se refere à ciência ou às regras da interpretação textual nem a uma metodologia para as Geisteswissenschaften ${ }^{21}$ mas antes à explicação fenomenológica da própria existência humana" (PALMER, [2006], p. 51), "abrangendo assim o todo de sua experiência de mundo" (GADAMER, 2015, p. 16). Assim, a hermenêutica "se preocupa com problemas que surgem quando se lida com ações humanas dotadas de significado e com os produtos dessas ações, principalmente textos" 22 (MANTZAVINOS, 2016, online).

Para Gadamer (2011b, p. 111-112) "hermenêutica significa em primeiro lugar práxis relacionada a uma arte", "a arte, em questão aqui, [sendo] a arte do anúncio, da tradução, da explicação e interpretação, que inclui naturalmente a arte da compreensão que lhe serve de base e que é sempre exigida quando o sentido de algo se acha obscuro e duvidoso".

A etimologia da palavra hermenêutica é obscura, "está relacionad[a] com E $E \mu \tilde{\eta} \varsigma$ [Hermes], o nome do deus mensageiro dos deuses" (HEIDEGGER, 2013, p. 15):

\footnotetext{
A palavra 'hermenêutico' vem do verbo grego غ̇ $\rho \eta v \varepsilon u ́ \varepsilon ı v$. Refere-se ao substantivo

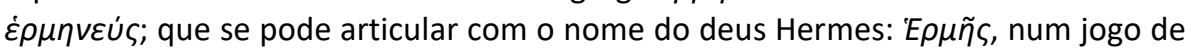
pensamento mais rigoroso do que a exatidão filológica. Hermes é o mensageiro dos deuses. Traz a mensagem do destino; $\dot{\rho} \mu \eta \eta v \varepsilon u ́ \varepsilon \iota v$ é a exposição que dá notícia, à medida que consegue escutar uma mensagem (HEIDEGGER, 2003, p. 96).
}

\footnotetext{
19 [...] the decisive figure in the development of twentieth century hermeneutics [...].

$20[\ldots]$ that world of meanings and relations, which is undetachable from life itself [...].

${ }^{21}$ Ciências do espírito, em tradução literal do alemão para o português. Refere-se àquilo que no Brasil chamamos de humanidades.

$22[\ldots]$ is concerned with problems that arise when dealing with meaningful human actions and the products of such actions, most importantly texts.
} 
Heidegger (2003, p. 97) conclui então que "hermenêutico não diz interpretar, mas trazer mensagem e dar notícia", mensagem esta que precisa ser preservada, conservada, guardada para ser transmitida (HEIDEGGER, 1971, 1985).

Segundo Mueller-Vollmer (1989, p. 1), "a etimologia do termo hermenêutica contém uma óbvia relação com Hermes, o deus mensageiro dos gregos, e sugere uma multiplicidade de significados"23. Para o autor, "analisar a tarefa de Hermes pode nos dar uma clara advertência sobre as complexidades subjacentes ao termo hermenêutica e ao empreendimento hermenêutico em si"24 (MUELLER-VOLLMER, 1989, p. 1):

De modo a entregar as mensagens dos deuses, Hermes tinha de ser proficiente no idioma deles assim como no idioma dos mortais a quem a mensagem era destinada. Ele tinha de entender e interpretar por si mesmo o que os deuses queriam transmitir antes que pudesse proceder a traduzir, articular e explicar a intenção deles aos mortais. Para descrever as diferentes facetas da tarefa de Hermes, mortais modernos têm à sua disposição todo um conjunto de termos, como competência linguística, comunicação, discurso, compreensão, interpretação ${ }^{25}$ (MUELLERVOLLMER, 1989, p. 1).

Observar a tarefa de Hermes nos permite entender as complexidades que subjazem ao empreendimento hermenêutico e nos leva a concordar com Gadamer, para quem "a contribuição que a hermenêutica pode fazer é sempre essa transferência de um mundo para

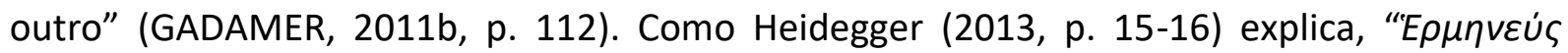
[intérprete] é aquele que comunica, aquele que informa alguém a respeito do que o outro 'pensa', isto é, aquele que transmite, aquele que reproduz a comunicação, a notícia".

O núcleo de interesse da Ciência da Informação são "as propriedades, os comportamentos, os fluxos, o processamento e a acessibilidade da informação registrada através de qualquer linguagem e em qualquer tipo de suporte" (GOMES, 2001, online). Segundo Tálamo e Smit (2007, p. 41), a disciplina objetiva "a formulação de sistemas significantes dos conteúdos registrados para fins de recuperação da informação", ou seja, a

\footnotetext{
${ }^{23}$ The etymology of the term hermeneutics carries an obvious relation to Hermes, the messenger god of the Greeks, and suggests a multiplicity of meanings.

${ }^{24}$ Looking at Hermes' task may give us a clear warning as to the complexities underlying the term hermeneutics and the hermeneutic enterprise itself.

${ }^{25}$ In order to deliver the messages of the gods, Hermes had to be conversant in their idiom as well as in that of the mortals for whom the message was destined. He had to understand and interpret for himself what the gods wanted to convey before he could proceed to translate, articulate, and explicate their intention to mortals. To describe the different facets of Hermes' task, modern mortals have at their disposal a whole set of terms such as linguistic competence, communication, discourse, understanding, interpretation.
} 
Ciência da Informação objetiva a criação de sistemas de coleção, armazenamento e organização de informação registrada que sejam dotados de significado e permitam a recuperação da informação para que esta sirva de auxílio na resolução de diferentes problemas individuais e coletivos.

Esses sistemas, os sistemas de informação, têm uma tarefa semelhante à do próprio Hermes, tendo de ser proficiente nos "idiomas" tanto dos registros de informação como dos usuários do sistema. Profissionais da informação que trabalham em um sistema de informação devem entender e interpretar por si próprios qual mensagem a informação armazenada transmite antes de proceder à tradução e apresentação dessa mensagem aos usuários. Nisto, sistemas de informação levam algo de um mundo para outro, isto é, levam informação do mundo que a produziu para o mundo dos usuários. Assim, sistemas de informação podem ser vistos como tendo uma natureza hermenêutica.

Esta conclusão levou a que formulássemos a hipótese de que ao articularmos Ciência da Informação e hermenêutica, esta serviria de base para a sistematização do corpo teóricoconceitual específico do paradigma social, ou hermenêutico, como o chamaremos, da Ciência da Informação. Ou seja, a aplicação da hermenêutica na articulação, isto é, na combinação, coordenação, no estabelecimento de relações entre os conceitos basilares da Ciência da Informação permitiria a sistematização do corpo teórico-conceitual de seu paradigma hermenêutico.

Ainda em nossa busca pela resposta à nossa pergunta de pesquisa, nos deparamos com um conceito pertinente ao como da sistematização do corpo teórico-conceitual da Ciência da Informação, o conceito de metateoria.

Segundo Vickery (1997, p. 457), “a metateoria de uma área do conhecimento pode muito bem ser equiparada à análise de seus pressupostos" ${ }^{26}$. Já Hjørland (1998, p. 607) afirma que "suposições metateóricas são [...] mais amplas e menos específicas do que teorias" 27 , sendo "suposições mais ou menos conscientes ou inconscientes por trás do trabalho teórico, empírico e prático" ${ }^{28}$, estando "conectadas a pontos de vista filosóficos e [sendo] frequentemente parte constitutiva de tendências interdisciplinares, que [...] podem estar

\footnotetext{
${ }^{26}[. .$.$] the metatheory of an area of knowledge may well be equated with the analysis of its presuppositions.$

27 Metatheoretic assumptions are [...] broader and less specific than theories.

28 [...] more or less conscious or unconscious assumptions behind theoretical, empirical, and practical work.
} 
conectadas ao Zeitgeist ${ }^{29 \prime \prime 30}$. A concepção de Bates $(2005$, p. 2) assemelha-se à de Hjørland quando a autora afirma que a "metateoria pode ser entendida como a filosofia por trás da teoria, o conjunto fundamental de ideias sobre como se deve pensar e pesquisar os fenômenos de interesse a uma área particular"31.

Para Wagner e Berger (1985, p. 700, grifo dos autores) metateoria “é discussão sobre teoria" 32 , ou seja, "sobre quais conceitos ela deve incluir, sobre como esses conceitos devem ser vinculados e sobre como a teoria deve ser estudada"33. Esta definição pode ser complementada com o entendimento de Dow (1977, p. 323) de que a "metateoria é necessária para aprofundar a compreensão da teoria" ${ }^{34}$, pois ela fornece a "perspectiva de um todo sistêmico" 35 e permite e encoraja a "comparação significativa das partes dentro do todo"36.

Fundamentando-se em Wagner e Berger ${ }^{37}$, Vakkari (1997) entende que metateorias são estratégias de orientação, ou perspectivas teóricas, cuja função cognitiva é oferecer diretrizes e diretivas para a construção de teorias. Vakkari (1997, p. 452) afirma que, "consistindo em pressupostos de natureza geral"38, metateorias podem incluir "o desenvolvimento de argumentos ontológicos e epistemológicos acerca do assunto da disciplina em questão, da natureza da realidade estudada pela disciplina e de seus valores e objetivos de pesquisa" ${ }^{39}$, podendo "também envolver a articulação do alicerce conceitual empregado na descrição e análise dos fenômenos estudados"40 e provavelmente culminando

\footnotetext{
${ }^{29}$ Espírito do tempo, em tradução literal do alemão para o português. São as características gerais de uma época determinada.

${ }^{30}[\ldots]$ connected to philosophical views, and [being] often parts of interdisciplinary trends, which [...] can be connected to the Zeitgeist.

${ }^{31}$ Metatheory can be seen as the philosophy behind the theory, the fundamental set of ideas about how phenomena of interest in a particular field should be thought about and researched.

32 [...] is discussion about theory [...].

33 [...] about what concepts it should include, about how those concepts should be linked, and about how theory should be studied.

${ }^{34}[\ldots]$ metatheory is required to deepen the understanding of theory [...].

35 [...] perspective from a systemic whole [...].

${ }^{36}[\ldots]$ meaningful comparison of parts within the whole.

${ }^{37}$ WAGNER, David G.; BERGER, Joseph. (1985). Do sociological theories grow? American Journal of Sociology, [Chicago], v. 90, n. 4, p. 697-728. e WAGNER, David G.; BERGER, Joseph. (1989). Theory growth, social processes, and metatheory. In: TURNER, Jonathan $\mathrm{H}$. (ed.). Theory building in Sociology. [Newbury Park]: Sage. p. 19-42.

${ }^{38}[\ldots]$ consisting of [...] presuppositions of a very general nature [...].

39 [...] the development of ontological and epistemological arguments concerning the subject matter of the discipline in question, the nature of the reality studied by the discipline, and the values and goals of inquiry.

${ }^{40}[. .$.$] also involve the articulation of the conceptual foundation employed in the description and analysis of$ studied phenomena.
} 
na "formulação de diretivas para a seleção de problemas teóricos de investigação e para a construção e avaliação das propostas de solução de problemas"41. Ainda com base nos mesmos autores, Vakkari (1997, p. 453) afirma que "dentro de um quadro metateórico é possível construir um grande número de teorias substantivas diferentes para um dado domínio"42.

Considerando que é através da identificação das bases teóricas subjacentes à Ciência da Informação que seria possível sistematizar seu corpo teórico-conceitual e considerando que metateorias são análises dos pressupostos de uma área, indicando quais conceitos uma área deve incluir e como esses conceitos devem ser vinculados - ou seja, considerando que metateorias são o conjunto fundamental de ideias que guiam uma área e fornecem a perspectiva de um todo sistêmico -, formulamos também a hipótese de que seria possível sistematizar o corpo teórico-conceitual do paradigma hermenêutico da Ciência da Informação através da sistematização de sua metateoria.

Para Rioux (2010, p. 9) “as teorias da Ciência da Informação frequentemente carregam consigo metateorias implícitas, mas com frequência elas são expressas vagamente, diminuindo sua utilidade" ${ }^{43}$. Levando esta análise em consideração, bem como nossas hipóteses de pesquisa, formulamos o objetivo geral de nossa pesquisa como levantar elementos teórico-conceituais de cunho geral que permitam a sistematização futura de uma metateoria hermenêutica da Ciência da Informação. Ainda que a sistematização de uma metateoria completa esteja além do escopo de uma única pesquisa de doutorado, buscamos contribuir para essa sistematização com o levantamento de elementos teórico-conceituais de cunho geral que sirvam de base para a sistematização de uma metatoria hermenêutica da Ciência da Informação.

Para nos aprofundarmos no conceito de metateoria, fizemos uso de Ritzer (1991), já utilizado na Ciência da Informação por Tennis (2005, 2008), Araújo, Guimarães e Tennis (2017) e Araújo e Tennis (2018). Ritzer discute o conceito de metateoria dentro da esfera da sociologia, mas afirma que ele é extensível a outras áreas: "a metateoria pode ser utilizada

\footnotetext{
${ }^{41}[. .$.$] formulation of directives for the selection of theoretical problems of investigation and for the construction$ and evaluation of proposed problem solutions.

42 [...] within a metatheoretical framework one can construct a large number of different substantive theories for a given domain.

${ }^{43}$ LIS theories frequently carry within them implicit metatheories, but they are often vaguely expressed, diminishing their usefulness [...].
} 
para analisar teorias dentro da filosofia (assim como outros campos; veja, por exemplo, o ensaio de Lamont [1987] ${ }^{44}$ sobre Derrida e linguística), assim como pode ser utilizada para estudar teorias dentro da sociologia" 45 (RITZER, 1991, p. 33).

Para Ritzer (1991, p. 2) a diferença entre um metateórico e um teórico, de forma bastante simplificada, é que "um metateórico é alguém que estuda teorias sociológicas do mundo social, enquanto um teórico é alguém que estuda o mundo social mais diretamente de modo a criar (ou empregar) teoria sociológica" ${ }^{46}$. Ele deixa claro, no entanto, que "apesar desta aparente acurada distinção entre metateórico e teórico (e eles são tipos ideais), as categorias se sobrepõem grandemente" ${ }^{47}$ (RITZER, 1991, p. 2-3). Ritzer exemplifica dizendo que

a maioria daqueles que consideramos metateóricos também estuda o mundo social e a maioria daqueles classificados como teóricos também estudam trabalhos teóricos. Além disso, ambos teóricos e metateóricos estudam documentos. O teórico frequentemente examina documentos derivados do mundo social enquanto o metateórico geralmente analisa documentos produzidos por teóricos. Finalmente, e talvez o mais importante, a metateorização substancial frequentemente precede e ajuda a levar a avanços na teoria social ${ }^{48}$ (RITZER, 1991, p. 3).

Ritzer explica que a "metateorização é um processo que ocorre depois que a teoria foi criada e toma aquela própria teoria como objeto de estudo" 49 (RITZER, 1991, p. 3) e que "um estudo cuidadoso das teorias sociológicas existentes pode ser um grande auxílio no ganho de maior entendimento da teoria, na criação de perspectivas transcendentes e na criação e desenvolvimento de teorias"50 (RITZER, 1991, p. 4).

\footnotetext{
${ }^{44}$ LAMONT, Michele. (1987). How to become a dominant French philosopher: the case of Jacques Derrida. American Journal of Sociology, [Chicago], v. 93, n. 3, p. 584-622.

45 Metatheory can be used to analyze theories within philosophy (as well as other fields; see, for example, Lamont's [1987] essay on Derrida and linguistics) just as it can be used to study theories within sociology.

${ }^{46}[. .$.$] a metatheorist is one who studies sociological theories of the social world, while a theorist is one who$ studies the social world more directly in order to create (or employ) sociological theory.

47 [...] despite this seemingly neat distinction between metatheorist and theorist (and they are ideal types), the categories overlap to a great extent.

${ }^{48}[\ldots]$ most of those we consider metatheorists also study the social world and most of those classified as theorists also study theoretical works. Furthermore, both theorists and metatheorists study documents. The theorist often examines documents derived from the social world while the metatheorist usually analyzes documents produced by theorists. Finally, and perhaps most importantly, substantial metatheorizing often precedes, and helps lead to, advances in social theory.

${ }^{49}[. .$.$] metatheorizing is a process that occurs after theory has been created and takes that theory itself as the$ object of study.

50 [...] a careful study of extant sociological theories can be a great aid in gaining a greater understanding of theory, creating transcendent perspectives, and creating and developing theories.
} 
Ritzer (1991, p. 6) entende que existem três tipos de metateorização: 1) "metateorização como um meio de obter um entendimento mais profundo da teoria" 51 , ou seja, "envolve o estudo da teoria de modo a produzir um entendimento melhor e mais profundo da teoria existente" 52 ; 2) "metateorização como um prelúdio ao desenvolvimento de teoria"53, ou seja, "implica o estudo da teoria existente para produzir nova teoria sociológica"54; e 3) “metateorização como uma fonte de perspectivas teóricas abrangentes" 55 , ou seja, metateorização que tem como objetivo "produzir uma perspectiva, pode-se dizer uma metateoria, que abrange alguma parte da ou toda a teoria sociológica"56. Este terceiro tipo de metateorização "é derivado da teoria em vez de se impor sobre a teoria"57 (RITZER, 1991, p. 6), produzindo "uma perspectiva que se sobrepõe à teoria sociológica"58 (RITZER, 1991, p. 7).

Nosso objetivo de pesquisa se encontra no terceiro tipo de metateorização descrito por Ritzer (1991), uma vez que objetivamos levantar elementos teórico-conceituais de cunho geral que sirvam de base para a sistematização de uma perspectiva, ou metateoria, que abrange toda a teoria do paradigma hermenêutico da Ciência da Informação. Ritzer (1991, p. 60) afirma que "essas perspectivas gerais permitem aos sociólogos especializados ver o contexto maior no qual seu trabalho está embutido" ${ }^{\prime 59}$. Nosso objetivo é justamente que os elementos teórico-conceituais por nós levantados levem à sistematização de uma metateoria que permita a orientação tanto dos pesquisadores como dos profissionais praticantes da Ciência da Informação.

Para Ritzer (1991) o terceiro tipo de metateorização apresenta alguns problemas e como nosso objetivo de pesquisa se encontra justamente nesse tipo de metateorização, gostaríamos de debatê-los brevemente. O primeiro problema indicado é que este tipo de metateorização

\footnotetext{
51 [...] metatheorizing as a means of attaining a deeper understanding of theory [...].

52 [...] involves the study of theory in order to produce a better, a more profound understanding of extant theory $[\ldots]$.

$53[\ldots]$ metatheorizing as a prelude to theory development $[. .$.$] .$

$54[\ldots]$ entails the study of extant theory in order to produce new sociological theory [...].

55 [...] metatheorizing as a source of overarching theoretical perspectives [...].

${ }^{56}[\ldots]$ producing a perspective, one could say a metatheory, that overarches some part or all of sociological theory.

$57[\ldots]$ is derived from theory rather than imposing itself on theory.

58 [...] a perspective that stands above sociological theory.

59 These general perspectives allow specialized sociologists to see the broader context in which their work is embedded.
} 
assume, por definição, que toda teoria sociológica, ou ao menos parte substancial dela, pode ser subsumida sob uma única perspectiva abrangente. Ademais, metateóricos que fazem este tipo de trabalho têm a tendência de argumentar que estão oferecendo a perspectiva transcendente 'correta' e que todas as outras abordagens [...] estão 'erradas'. Portanto, trabalho deste tipo sistemática e gravemente subestima a quantidade de diversidade dentro da sociologia em geral e dentro da teoria sociológica em particular. Por causa dessa diversidade profunda e universal, existe uma pequena ou nenhuma possibilidade imediata de se criar uma única, 'correta' perspectiva transcendente ${ }^{60}$ (RITZER, 1991, p. 53).

Podemos dizer que com nosso objetivo de pesquisa buscamos sim levantar elementos teórico-conceituais que sirvam de base para a sistematização de uma perspectiva que abrange toda a Ciência da Informação, contudo, não temos a pretensão de que os elementos levantados sejam utilizados para a sistematização da única metateoria "correta" da disciplina e que todas as outras estariam "erradas". Já chamamos a atenção anteriormente para o fato de que não existe uma única possibilidade global e totalitária de sistematização do corpo teórico-conceitual da Ciência da Informação, sendo necessário definir um ponto de vista a partir do qual buscar essa sistematização. Temos consciência da impossibilidade de levantarmos elementos para a sistematização da metateoria definitiva da Ciência da Informação, já que somos conscientes da diversidade existente dentro da área, razão pela qual buscamos deixar claro qual é nosso ponto de vista, qual seja, o paradigma hermenêutico da Ciência da Informação.

Um segundo problema indicado por Ritzer (1991) é o de que perspectivas abrangentes seriam imprecisas, ou seja, não definiriam claramente seus conceitos e suas inter-relações. Podemos apenas dizer que, em nosso levantamento de elementos teórico-conceituais de cunho geral que sirvam de base para a sistematização de uma metateoria do paradigma hermenêutico da Ciência da Informação, a busca por precisão e clareza dos conceitos levantados e de suas inter-relações é primordial, já que nosso problema de pesquisa é justamente a falta de estruturação do corpo teórico-conceitual da Ciência da Informação.

O terceiro problema ao qual Ritzer (1991) se refere é o de que metateorias não auxiliam o trabalho teórico e tampouco o trabalho empírico dos sociólogos. O problema seria

\footnotetext{
60 [...] assumes, by definition, that sociological theory, or at least a substantial portion of it, can be subsumed under a single overarching perspective. Moreover, metatheorists who do this kind of work have a tendency to argue that they are offering the "right" transcendent perspective and that all other approaches [...] are "wrong." Work of this type thus systematically and gravely underestimates the amount of diversity within sociology in general, and within sociological theory in particular. Because of this deep and pervasive diversity, there is little or no immediate possibility of coming up with a single, "right" transcendent perspective.
} 
que "metateorias abrangentes existem em um nível tão alto de generalidade que elas ignoram ou são difíceis de traduzir para os problemas diários dos sociólogos praticantes"61 (RITZER, 1991, p. 59).

A sistematização de uma metateoria do paradigma hermenêutico da Ciência da Informação a ser realizada a partir de nosso levantamento de elementos teórico-conceituas deverá visar obter um nível de generalidade que auxilie tanto o trabalho teórico como o trabalho empírico dentro da disciplina. A detecção de nosso problema de pesquisa indicou que a falta de um corpo teórico-conceitual sistematizado traz problemas tanto aos desenvolvimentos teóricos como aos desenvolvimentos empíricos da Ciência da Informação, portanto, buscamos justamente levantar elementos que sirvam de base para a sistematização de uma metateoria o suficientemente abrangente, que auxilie o desenvolvimento da disciplina.

É importante sabermos a quais problemas o terceiro tipo de metateorização está sujeito, de modo a que trabalhemos para os evitar. Assim, estamos cientes dos problemas identificados por Ritzer (1991) e em nosso levantamento de elementos que sirvam de base para a sistematização de uma metateoria da Ciência a Informação os teremos sempre em conta, não buscando que esses elementos visem à sistematização de uma metateoria que consideramos ser a única correta, mas buscando apresentar definições claras dos conceitos que levantamos e de suas inter-relações e visando auxiliar o desenvolvimento tanto teórico como empírico da disciplina.

Para o levantamento de elementos teórico-conceituais de cunho geral que sirvam de base para a sistematização de uma metateoria hermenêutica da Ciência da Informação, partimos de uma concepção da disciplina que pode ser entendida como uma concepção de seu paradigma hermenêutico, onde a Ciência da Informação "se preocupa diretamente com o conhecimento e a aprendizagem" 62 , sendo que "permitir às pessoas que se tornem melhor informadas (aprendendo, tornando-se mais conhecedoras) é, ou deveria ser, a preocupação central da Ciência da Informação"63 (BUCKLAND, 2012b, p. 5).

\footnotetext{
${ }^{61}[. .$.$] overarching metatheories exist at such a high level of generality that they ignore, or are difficult to translate$ into, the day-to-day concerns of practicing sociologists.

$62[\ldots]$ is directly concerned with knowing and learning.

${ }^{63}$ Enabling people to become better informed (learning, becoming more knowledgeable) is, or should be, the central concern of information studies [...].
} 
Realizamos primeiramente a identificação dos conceitos basilares da área mediante levantamento, revisão e análise bibliográficos da literatura da disciplina, mais uma vez mediante a hermenêutica crítica. De acordo com nossa análise da literatura da Ciência da Informação (GOMES, 2001; HJØRLAND, 1998; JAEGER, 2010; WERSIG, 1993; WERSIG; WINDEL, 1985), a identificação e subsequente análise desses conceitos e suas inter-relações constitui o primeiro passo para a proposição de modelos e teorias que permitiriam a sistematização do corpo teórico-conceitual da disciplina.

Assim, da pesquisa e seleção de textos realizadas, procedemos à leitura e análise dos mesmos, cotejando entre si as ideias expostas por diferentes autores. Deste processo, foram sintetizados três grandes conceitos que podem ser entendidos como os conceitos fundamentais da Ciência da Informação: a) função atribuída à informação; b) organização e representação da informação; e c) recuperação e acesso à informação para sua apropriação. Estes conceitos com os quais trabalhamos podem ser entendidos como conceitos coligativos.

Segundo a revisão de literatura de Shaw (2013), quando se identifica que a um conjunto de fatos, eventos e ideias subjaz um mesmo pensamento ou prática, ou seja, quando é possível traçar um conjunto de relações intrínsecas dentro de um conjunto de fatos, eventos e ideias, estabelece-se um conceito coligativo. A coligação que origina um conceito é um ato interpretativo no qual se deixa de ver que uma série de fatos, eventos e ideias aconteceu para se ver que essa série de fatos, eventos e ideias é um todo sintético; ou seja, conceitos coligativos refletem como um conjunto de fatos, eventos e ideias é entendido e explicado por alguém.

Ressalvamos que a nomenclatura que adotamos desses conceitos coligativos, bem como suas definições, não são unânimes na Ciência da Informação e que todos os autores analisados não utilizam necessariamente a terminologia que adotamos. A seguir explicaremos aquilo que entendemos por cada um dos conceitos coligativos identificados.

A função atribuída à informação, como o próprio nome do conceito indica, é a utilidade potencial pela qual informação registrada é armazenada em um sistema de armazenamento, organização e recuperação da informação. Informação registrada é intencionalmente incorporada a e mantida em um sistema para que ela cumpra um objetivo, uma função, quando tiver sido apropriada por um indivíduo. Nossa formulação deste conceito se fundamenta nas discussões de Meyriat (2016) e Smit $(2003,2012)$ sobre o mesmo. 
Este conceito, ainda que não seja assim nomeado, é sempre presente na literatura da Ciência da Informação e das disciplinas onde ela tem suas raízes. Por exemplo, os expoentes da perspectiva das ciências naturais do Movimento Bibliográfico atribuíam à informação a função de transformação das condições humanas, pois os indivíduos seriam transformados pela informação que apropriassem e, por conseguinte, interfeririam em suas esferas de vivência e auxiliariam na resolução de problemas (MENDES, 2014).

O mesmo é o caso de Renée-Marie-Hélène-Suzanne Briet (1894-1989), bibliotecária e historiadora expoente da segunda fase do movimento documentalista, que vê na informação uma capacidade de transformação da condição humana, transformação esta cujo objetivo último é a unificação da civilização (BRIET, 2016). Para ela, através da informação apropriada, o ser humano desenvolveria as diversas áreas do conhecimento, levando à evolução destas e ao desenvolvimento da humanidade.

No contexto da Epistemologia Social, proposta por Margaret Elizabeth Egan (19051959) e Jesse Hauk Shera (1903-1982), docentes da Escola de Pós-Graduação em Biblioteconomia da Universidade de Chicago e da Escola de Biblioteconomia da Universidade Western Reserve, atribui-se à informação a função de modificar o comportamento humano de modo a que este afete o comportamento social. Através da informação que apropriada, o indivíduo seria capaz de participar dinamicamente da vida social e política, o que permitiria o desenvolvimento social. Assim, a informação apropriada se tornaria efetiva na ação dos indivíduos na sociedade (EGAN, 1951, 1953, 1955; EGAN; SHERA, 1952; SHERA, 1971, 1973, 1974, 1977).

Já no contexto da Informática - disciplina desenvolvida primordialmente na União Soviética, mas também em outros países comunistas, com o objetivo de pesquisar os processos de produção, circulação e consumo da informação - à informação é atribuída a função de afetar o comportamento do homem e seu controle sobre a tomada de decisão, o que levaria ao desenvolvimento da sociedade e à construção ou crescimento do comunismo (MIJAILOV; CHERNII; GUILIAREVSKII, 1973; MIKHAILOV; CHERNYI; GILYAREVSKYI, 1980; MIKHAILOV; GILAREVSKIJ, 1971).

Na literatura de autores que já se inserem na própria Ciência da Informação também encontramos esse conceito. Por exemplo, o alemão Gernot Wersig (1942-2006), sociólogo, jornalista e documentalista, considerado um dos fundadores da Ciência da Informação alemã, atribui à informação a função de auxiliar o homem nas ações específicas que ele precisa 
realizar em situações específicas (WERSIG, 1993; WERSIG; HENNINGS, 1984; WERSIG; NEVELING, 1975; WERSIG; WINDEL, 1985). O filósofo, bibliotecário e professor do Departamento de Biblioteconomia e Ciência da Informação da Universidade de Indiana, Ronald E. Day, atribui à informação a função de suprir momentaneamente necessidades psicológicas baseadas social e culturalmente (DAY, 2001, 2011, 2014, 2016). Já Bernd Frohmann, filósofo, bibliotecário e professor emérito da Universidade de Western Ontario, atribui à informação e seu registro, entendidos como fenômenos sociais e culturais, poderes de formação e constituição do indivíduo e da sociedade (FROHMANN, 1995, 2001, 2004, 2008).

O segundo conceito coligativo que sintetizamos é o conceito de organização $e$ representação da informação, também chamado comumente de organização e representação do conhecimento.

Segundo Hjørland $(2008,2016)$, o termo organização do conhecimento apresenta dois sentidos: um sentido geral e um sentido específico. Em seu sentido geral, ele se refere tanto à forma como o conhecimento é organizado socialmente, como à organização da realidade. A organização social do conhecimento preocupa-se com a organização de universidades e outras instituições de pesquisa e ensino superior, com a estruturação de disciplinas e profissões e etc. Já a organização intelectual ou cognitiva do conhecimento busca explicar como a realidade é estruturada, sendo comumente da alçada de disciplinas específicas.

Em seu sentido específico, $\mathrm{Hjørland}(2008,2016)$ afirma que o termo se refere às atividades de descrição, indexação e classificação de informação registrada realizadas por instituições de memória, tais como bibliotecas, arquivos e bases de dados. Nesse sentido, a organização do conhecimento se preocupa com os sistemas de organização do conhecimento e com os processos de organização do conhecimento dentro desses sistemas, processos que objetivam organizar e representar registros de informação. É com o sentido específico do termo, ao qual comumente se adiciona a palavra representação, devido à centralidade da representação para a organização do conhecimento, que se preocupa a Ciência da Informação.

Hjørland (2012), em análise sobre os termos organização da informação, arquitetura da informação e organização do conhecimento e as áreas que eles designam, concluiu que todos se preocupam com assuntos, conceitos e relações semânticas entre conceitos, de modo que sua base teórica é a mesma, a arquitetura da informação tendo o diferencial de focar a 
organização de assuntos e conceitos na web. Para o autor (2012, p. 12), contudo, "da perspectiva da pesquisa acadêmica, essas diferenças são superficiais, não essenciais" ${ }^{64}$.

Para Bräscher e Café (2010) os termos organização e representação do conhecimento e organização e representação da informação são empregados sem uma delimitação adequada do conceito a que se referem. Em sua análise do uso dos termos na literatura da Ciência da Informação e sua subsequente proposta conceitual, as autoras afirmam que se referem à organização e representação do conhecimento quando "estamos no mundo dos conceitos e não naquele dos registros de informação" (BRÄSCHER; CAFÉ, 2010, p. 92). Para as autoras, a organização do conhecimento "visa à construção de modelos de mundo que se constituem em abstrações da realidade" e produzem uma "representação do conhecimento, que se constitui numa estrutura conceitual que representa modelos de mundo" (BRÄSCHER; CAFÉ, 2010, p. 93).

Organização e representação da informação têm "como objeto os registros de informação. Estamos, portanto, no mundo dos objetos físicos, distinto do mundo da cognição, ou das ideias, cuja unidade elementar é o conceito" (BRÄSCHER; CAFÉ, 2010, p. 92). Bräscher e Café (2010, p. 92) definem a organização da informação como "um processo que envolve a descrição física e de conteúdo dos objetos informacionais", "o produto desse processo descritivo" se tratando da "representação da informação, entendida como um conjunto de elementos descritivos que representam os atributos de um objeto informacional específico".

Próximo aos conceitos de organização e representação do conhecimento e organização e representação da informação está o conceito de análise e representação documentária.

O termo análise documentária foi cunhado pelo arqueólogo francês Jean-Claude Gardin (1925-2013), conceito este utilizado e desenvolvido na França e no Brasil, onde o termo se refere ao "tratamento da informação para a constituição de sistemas informacionais" (LARA, 2009, p. 24). No Brasil, na Escola de Comunicações e Artes da Universidade de São Paulo, surgiu na década de 1980 um grupo de pesquisas sobre análise documentária, chamado grupo TEMMA, que desenvolveu pesquisas nessa área através de uma perspectiva conceitual e da recuperação da história da Ciência da Informação. É nos pesquisadores deste grupo, que posteriormente foi expandido também para a Universidade Estadual Paulista "Júlio de

\footnotetext{
${ }^{64}[. .$.$] from the perspective of academic research, such differences are superficial, not essential.$
} 
Mesquita Filho" (UNESP), que fundamentamos o conceito de análise e representação documentária.

Com base na literatura (CUNHA, 1987; KOBASHI, 1994, 1996; LARA, 1993, 2009; SMIT, 1987), podemos dizer que a análise documentária é um conjunto de procedimentos de análise de informação registrada, neste contexto chamada documento, que objetiva sua representação para que ela possa ser recuperada. Os procedimentos de análise documentária são a seleção e condensação de unidades de significação pertinentes ao objetivo de um sistema de armazenamento, organização e recuperação da informação. Esses procedimentos levam em consideração não apenas a informação registrada, mas também suas condições de produção e consumo.

O produto do processo de análise documentária é a representação documentária. A representação documentária "é uma construção resultante do processo de Análise Documentária [...], que tem em vista objetivos pragmáticos de facilitar a organização e a recuperação da informação" (LARA, 2009, p. 37). Segundo Lara (2009) essa representação apresenta de modo condensado os registros de informação que integram um sistema de informação, funcionando como um substituto ou indicador desse registro no sistema.

A princípio fazemos equivalência entre os conceitos de organização e representação do conhecimento, organização e representação da informação, e análise e representação documentária, adotando o termo organização e representação da informação pela concordância com o argumento de Bräscher e Café (2010) e pelo termo informação ser mais utilizado na área do que o termo documento.

Em uma perspectiva hermenêutica, a Ciência da Informação objetiva que informação registrada seja recuperada e acessada; contudo, seu objetivo último é a apropriação dessa informação. A recuperação da informação é o processo que identifica quais documentos armazenados em um sistema de armazenamento, organização e recuperação da informação contêm a informação buscada pelo usuário desse sistema (FERNEDA, 2003). Ou seja, é um processo onde o usuário recupera a representação da informação registrada armazenada em um sistema que é pertinente àquilo que ele busca. Assim como no processo de organização e representação da informação, a recuperação da informação é um processo interpretativo que está sujeito a condicionamentos culturais, materiais e sociais.

O acesso à informação se trata de "uma operação físico-espacial" (SMIT, 2009, p. 58), ou seja, é a obtenção de um registro de informação, seja este físico, analógico ou digital. Já a 
apropriação da informação, segundo nossa interpretação da literatura (BARRETO, 1994, 1998; BROOKES, 1980; BUCKLAND, 2012b, 2013; CAPURRO, 2007; KOBASHI; TÁLAMO, 2003; LARA, 2009; SMIT, 2009, 2012; SMIT; BARRETO, 2002; SMIT; TÁLAMO; KOBASHI, 2004), é uma operação subjetiva e pessoal realizada por um agente cognitivo que se encontra inserido em um contexto cultural e social que lhe forneceu as competências necessárias para a realização dessa operação.

A análise desses três grandes conceitos coligativos - a) função atribuída à informação; b) organização e representação da informação; e c) recuperação e acesso à informação para sua apropriação - nos levou a concluir que os pontos centrais ao redor dos quais se estrutura a Ciência da Informação sob uma perspectiva hermenêutica são dois: o indivíduo que busca informação e dela faz uso e o registro de informação capaz de informar. O indivíduo é aquele para quem a informação é organizada de modo a que, quando ele a recupere e a acesse, possa apropriá-la. Por sua vez, o registro de informação é aquilo que é capaz de informar e que é armazenado, organizado e recuperado em um sistema de informação.

Essa conclusão levou a que formulássemos os objetivos específicos desta pesquisa, quais sejam:

a) levantar elementos teórico-conceituais de cunho geral referentes à relação entre indivíduo e informação, isto é, referentes ao comportamento informacional sob a ótica hermenêutica;

b) levantar elementos teórico-conceituais de cunho geral referentes aos modos como os registros de informação, ou documentos, são tratados para que possam ser recuperados e utilizados pelos indivíduos, ou seja, referentes ao armazenamento, organização e recuperação de documentos sob a ótica hermenêutica.

Partimos então para o levantamento, revisão e análise da literatura da Ciência da Informação e da hermenêutica de modo a procedermos à identificação de elementos teóricoconceituais de cunho geral que sirvam de base para a sistematização de uma metateoria da disciplina. Ou seja, realizamos a pesquisa e seleção de textos na bibliografia da área que respondessem a nosso objetivo de pesquisa e procedemos à leitura e análise dos mesmos, apropriando-nos dessa bibliografia em consonância com as ideias expostas pelos autores e cotejando-as entre si mais uma vez mediante a hermenêutica crítica. 
A literatura da Ciência da Informação analisada foi aquela que pode ser entendida como de autores pertencentes ao paradigma hermenêutico da disciplina e, assim como em nossa busca pela explicitação do conceito de hermenêutica, a literatura analisada sobre hermenêutica concentrou-se nas obras de Heidegger e Gadamer, assim como nas obras que discutem a filosofia desses dois autores base.

A seguir passamos para o resultado desse processo. 


\section{Comportamento informacional sob a ótica hermenêutica}

A primeira parte desta tese trata do indivíduo que busca informação e dela faz uso. Aqui visamos definir sob a ótica da hermenêutica o que leva o indivíduo a buscar informação para a utilizar. Queremos saber, em uma perspectiva hermenêutica, "como as pessoas lidam com um mundo incerto ao se instruírem ou se informarem"65 (DERVIN, 1976, p. 327), queremos saber "o que indivíduos fazem para fazer sentido de seus mundos conforme eles se movem de um evento a outro"66 (DERVIN, 1976, p. 333). Queremos saber qual é o comportamento informacional do indivíduo sob a ótica hermenêutica.

Segundo Bates (2017, p. 2074), comportamento informacional é o "termo preferido usado para descrever os diversos modos nos quais seres humanos interagem com informação, em particular, os modos nos quais pessoas buscam e utilizam informação" ${ }^{\prime 67}$. Comportamento informacional também designa uma subdisciplina da Ciência da Informação "que se envolve em uma ampla variedade de tipos de pesquisa conduzida com o fim de compreender a relação humana com a informação" 68 (BATES, 2017, p. 2074). Nesta pesquisa utilizamos o termo em sua primeira acepção. O conceito por nós adotado é detalhado por Wilson da seguinte maneira:

Comportamento Informacional é a totalidade do comportamento humano em relação às fontes e canais de informação, incluindo tanto a busca e uso ativos da informação como a busca e uso passivos da informação. Portanto, ele inclui a comunicação face a face com outros, assim como a recepção passiva de informação como, por exemplo, ao assistir comerciais na TV, sem qualquer intenção de agir sobre a informação recebida ${ }^{69}$ (WILSON, 2000, p. 49, grifo do autor).

Se o comportamento informacional é a totalidade do comportamento do ser humano em relação às fontes e canais de informação, sob uma perspectiva hermenêutica esse comportamento é necessariamente hermenêutico, portanto, o próprio ser humano deve ser

\footnotetext{
65 [...] how people cope with an uncertain world by instructing or informing themselves.

66 [...] what individuals do to make sense out of their worlds as they move from one event to another.

67 [...] preferred term used to describe the many ways in which human beings interact with information, in particular, the ways in which people seek and utilize information.

68 [...] that engages in a wide range of types of research conducted in order to understand the human relationship to information.

${ }^{69}$ Information Behavior is the totality of human behaviour in relation to sources and channels of information, including both active and passive information seeking, and information use. Thus, it includes face-to-face communication with others, as well as the passive reception of information as in, for example, watching TV advertisements, without any intention to act on the information given.
} 
compreendido sob essa ótica. Desse modo, iniciaremos este capítulo com uma discussão sobre o que é o ser humano no contexto da hermenêutica, conceito este desenvolvido por Heidegger em sua fenomenologia hermenêutica, e refletiremos sobre o modo como esse ser humano se encontra no mundo.

Em seguida, de forma a que possamos compreender o que leva o ser humano a buscar e utilizar informação em uma perspectiva hermenêutica, discutiremos os conceitos de informação e documento a partir dessa perspectiva.

\subsection{A presença}

Para Heidegger, existe um "modo peculiarmente humano de existir"70 (DREYFUS; WRATHALL, 2005, p. 3-4), chamado por ele de Dasein. O termo é comumente traduzido do alemão para o português, literalmente, como ser-aí, ou como presença. Neste trabalho, utilizamos o termo presença para designar o modo particularmente humano de existir, pois fazemos uso da tradução de Márcia Sá Cavalcante Schuback da obra fundamental de Heidegger Ser e Tempo (2015) ${ }^{71}$. Toda a terminologia de Heidegger que utilizamos nesta tese segue esta tradução, de modo que, quando fizermos uso de um texto que traduza os termos de modo diferente, colocaremos entre colchetes o termo que adotamos.

Heidegger afirma que "a essência do modo humano de existência é encontrada em nós já sempre existirmos em um mundo"72 (DREYFUS; WRATHALL, 2005, p. 3), sendo que para ele "a tradição filosófica negligenciou o caráter do mundo e a natureza da nossa existência humana em um mundo"73 (DREYFUS; WRATHALL, 2005, p. 4). Por esta razão a presença não é considerada por Heidegger como um sujeito, uma vez que, no sentido tradicional, o sujeito "tem estados mentais e experiências que podem ser o que são independentemente do estado do mundo circundante"74 (DREYFUS; WRATHALL, 2005, p. 4). Segundo Dreyfus e Wrathall

\footnotetext{
70 [...] peculiarly human way of existing [...].

${ }^{71}$ Em edições anteriores de Ser e Tempo, Schuback traduzia Dasein como pre-sença, razão pela qual alguns autores que seguiram essas edições utilizam o termo pre-sença em suas obras. Por este motivo algumas citações presentes nesta tese podem apresentar o termo pre-sença. Detalhes sobre a tradução de Schuback do termo Dasein podem ser encontrados em sua introdução de Ser e Tempo (SCHUBACK, 2015) e nas notas explicativas da obra (NOTAS..., 2015).

72 [...] the essence of the human mode of existence is found in our always already existing in a world.

73 [...] that the philosophical tradition has overlooked the character of the world, and the nature of our human existence in a world.

74 [...] has mental states and experiences which can be what they are independently of the state of the surrounding world.
} 
(2005, p. 4), "para Heidegger nosso modo de ser é fundado não na nossa natureza pensante, mas no nosso existir em um mundo"75, "nosso ser é intimamente e inextricavelmente ligado ao mundo no qual nos encontramos"76. Heidegger rejeita assim a ideia de Descartes do "sujeito pensante como categoria fundamental"77 (MUELLER-VOLLMER, 1989, p. 33). Esta rejeição se dá porque o ser humano "sempre se depara com algo que não pode mais ser descoberto por meio da representação e da antecipação pelo pensamento", o chamado “impassível de ser previamente descoberto pelo pensamento" (GADAMER, 2012a, p. 74), e ela requer que se busque compreender a experiência humana do modo como esta nos é dada, antes de qualquer objetivação científica (LAFONT, 2005).

Heidegger entende também que a tradição filosófica falhou no entendimento da natureza do mundo, já que "ela tendeu a focar exclusivamente em entes dentro do mundo e compreendeu o mundo como sendo uma mera coleção de entes inerentemente sem significado"78 (DREYFUS; WRATHALL, 2005, p. 4). Na realidade, ao atentarmos "para o modo como os entes realmente se mostram para nós em nossos negócios cotidianos"79, aprendemos que as "coisas mundanas não podem ser reduzidas a meros entes físicos com propriedades causais" 80 , pois elas "têm um modo diferente de ser do que os entes delineados causalmente que constituem o universo e que são a preocupação das ciências naturais" 81 (DREYFUS; WRATHALL, 2005, p. 4, grifo dos autores). Para Heidegger o mundo no qual seres humanos vivem é "uma rede holisticamente estruturada de significância"82 (LAFONT, 2005, p. 266).

Heidegger entende que "compreender os entes mundanos - entes, em outras palavras, que são constituídos inerentemente com significado - requer uma abordagem hermenêutica"83 (DREYFUS; WRATHALL, 2005, p. 4). Isto se dá porque Heidegger entende que

\footnotetext{
${ }^{75}$ For Heidegger, our way of being is found not in our thinking nature, but in our existing in a world.

${ }^{76}[. .$.$] our being is intimately and inextricably bound up with the world that we find ourselves in.$

77 [...] thinking subject as a foundational category.

78 [...] it tended to focus exclusively on entities within the world, and understood the world as merely being a collection of inherently meaningless entities.

79 [...] to the way entities actually show up for us in our everyday dealings [...].

80 [...] that worldly things cannot be reduced to merely physical entities with causal properties.

81 [...] have a different mode of being than the causally delineated entities that make up the universe and which are the concern of the natural sciences.

82 [...] a holistically structured web of significance [...].

83 To understand worldly entities - entities, in other words, that are inherently meaningfully constituted requires a hermeneutic approach [...].
} 
“filosofia é hermenêutica"84 (LAFONT, 2005, p. 265), de modo que ele muda o caráter da hermenêutica tradicional, distanciando-a de preocupações tradicionalmente metodológicas (MUELLER-VOLLMER, 1989). Segundo Lafont, trata-se de uma mudança de paradigma dentro da filosofia e que para tanto

Heidegger amplia a hermenêutica de um método tradicional para a interpretação de textos autoritários (principalmente textos sagrados ou legais) a um modo de entender os próprios seres humanos. Consequentemente, o paradigma hermenêutico oferece uma compreensão radicalmente nova do que é característico dos seres humanos: ser humano não é ser primeiramente um animal racional, mas ser em primeiro lugar um animal auto-interpretativo. É precisamente porque seres humanos não são nada além de interpretação que a atividade de interpretar um texto significativo oferece o modelo mais apropriado para compreender qualquer que seja a experiência humana. Esta mudança de perspectiva equivale à maior quebra com a filosofia tradicional, pois esta foi principalmente guiada por uma tentativa diametralmente oposta, isto é, modelar toda a experiência humana na base de nossa percepção de objetos físicos ${ }^{85}$ (LAFONT, 2005, p. 265, grifos da autora).

Assim, "Heidegger oferece um relato hermenêutico alternativo da nossa experiência que torna possível compreender seres humanos como habitando um mundo simbolicamente estruturado no qual tudo que eles encontram já é compreendido como uma coisa ou outra" 86 (LAFONT, 2005, p. 266). Para Heidegger o mundo é mais do que "uma mera coleção de entes"87, "o mundo, propriamente compreendido, é aquilo com base no qual entes podem ser envolvidos uns com os outros" ${ }^{88}$, sendo "nossa familiaridade com o mundo entendido como tal que torna possível para nós agir sobre, pensar sobre, experimentar, etc. as coisas no mundo"89 (DREYFUS; WRATHALL, 2005, p. 4). Segundo Gadamer (2012a, p. 74) "uma tal hermenêutica não segue manifestamente a curiosidade ávida por ordem, a curiosidade com

\footnotetext{
${ }^{84}[\ldots]$ philosophy is hermeneutics.

85 [...] Heidegger generalizes hermeneutics from a traditional method for interpreting authoritative texts (mainly sacred or legal texts) to a way of understanding human beings themselves. As a consequence, the hermeneutic paradigm offers a radically new understanding of what is distinctive about human beings: to be human is not primarily to be a rational animal, but first and foremost to be a self-interpreting animal. It is precisely because human beings are nothing but interpretation all the way down that the activity of interpreting a meaningful text offers the most appropriate model for understanding any human experience whatsoever. This change of perspective amounts to a major break with traditional philosophy. For the latter has been mainly guided by a diametrically opposed attempt, namely to model all human experience on the basis of our perception of physical objects.

${ }^{86}$ [...] Heidegger offers an alternative, hermeneutic account of our experience that makes it possible to understand human beings as inhabiting a symbolically structured world, in which everything they encounter is already understood as something or other.

87 [...] a mere collection of entities.

${ }^{88}$ The world, properly understood, is that on the basis of which entities can be involved with one another.

89 [...] our familiarity with the world so understood which makes it possible for us to act on, think about, experience, etc. things in the world.
} 
a qual o sistema da filosofia é ensinado nas cátedras. Trata-se à sua maneira de uma outra compreensão - trata-se daquilo que a própria vida dá a entender".

Para Lafont (2005, p. 270) a chave do paradigma hermenêutico é "a introdução de uma nova noção de mundo"90. Segundo a autora (2005, p. 270), "depois da virada hermenêutica, o mundo não é mais a totalidade dos entes, mas uma totalidade de significância, uma rede de significados que estrutura a compreensão que a presença tem de si mesma e de tudo que pode se manifestar dentro do mundo"91.

Desse modo, para Lafont (2005, p. 271), se nos preocupamos com entes significantes e como compreendê-los, em vez de nos preocuparmos com entes naturais e com o modo de lidar com eles, "parece plausível pensar em entes tais como culturas como totalidades de significância (que permitem a seres humanos compreenderem a si mesmos e a tudo em volta deles como uma coisa ou outra)"92. Segundo a autora $(2005$, p. 271), é por essa razão que “podemos nos referir a culturas como 'mundos' em expressões tais como 'o mundo do homem renascentista' ou 'o mundo medieval'"193. Lafont $(2005$, p. 271) conclui assim que este uso do termo mundo dá plausibilidade à noção de mundo de Heidegger, onde "culturas são o tipo de coisa 'nas' quais se pode dizer que humanos estão (ou se desenvolveram 'em') em um sentido não-espacial do termo"94, e onde culturas "também são o tipo de coisa que pode ser compreendida ou interpretada em vez de percebida ou manipulada, etc." 95 .

Feitas as considerações sobre o entendimento de Heidegger sobre o mundo, podemos tratar da inserção da presença no mundo.

Para Heidegger,

o ser-aí [presença] não apenas tem, de certo modo, uma relação com o mundo também articulada consigo mesmo; ao contrário, a ligação com o mundo é um traço essencial do ser-aí [presença] mesmo e, porque não dizer, é a sua constituição essencial marcante. Ser-aí [presença] não significa nada senão ser-no-mundo (HEIDEGGER, 2008, p. 324).

\footnotetext{
90 [...] the introduction of a new notion of world.

${ }^{91}$ After the hermeneutic turn, the world is no longer the totality of entities, but a totality of significance, a web of meanings that structures Dasein's understanding of itself and of everything that can show up within the world [...].

92 [...] it does seem plausible to think of entities such as cultures as totalities of significance (which enable human beings to understand themselves and everything around them as something or other).

93 [...] we can refer to cultures as "worlds" in expressions such as "the world of the Renaissance man" or "the medieval world."

94 [...] cultures are the kind of things that humans can be said to be "in" (or grow up "into") in a non-spatial sense of the term [...].

${ }^{95}$ are also the kind of things that can be understood or interpreted rather than perceived or manipulated, etc.
} 
Desse modo, ser-'no'-mundo não corresponde à noção tradicional de inclusão física; ser-'no'-mundo tem "o sentido de envolvimento"96, "é a habilidade de compreender e ser envolvido com tudo que se mostra dentro do mundo e, portanto, ter uma relação simbólica e não meramente causal com ele"97 (LAFONT, 2005, p. 271). Com isto, a presença, enquanto ser-no-mundo "tem a habilidade de ter a perspectiva interna do participante em uma cultura em vez da perspectiva externa de um observador do mundo físico"98 (LAFONT, 2005, p. 271).

Enquanto seres-no-mundo, "somos (a um grau significativo) constituídos como os seres que somos pelo fato de que sempre habitamos um mundo compartilhado, e o modo como existimos nesse mundo é essencialmente sempre estruturado por outros"99 (DREYFUS; WRATHALL, 2005, p. 7).

Segundo Dreyfus e Wrathall (2005, p. 6), a concepção do mundo de Heidegger confere um papel constitutivo a outrem para determinar que possibilidades estão disponíveis para um indivíduo, ou seja, as relações sociais têm um papel na constituição de quem somos: "é uma característica constitutiva de nosso modo de ser que assumimos a responsabilidade sobre nossa compreensão de nós mesmos e do mundo ao nosso redor a partir daqueles com quem existimos" ${ }^{\prime 100}$ :

Isto significa que quem eu sou não pode ser compreendido em termos de um sujeito que poderia ser constituído como ele é independentemente de qualquer relacionamento com outros seres humanos. Mesmo exemplos aparentemente contrários - seres humanos que são solitários ou indiferentes a seus pares ou pessoas desajustadas e párias - confirmam isto, já que eles são seres humanos que são solitários ou indiferentes ou rejeitados pela sociedade ${ }^{101}$ (DREYFUS; WRATHALL, 2005 , p. 6, grifo dos autores).

Para Heidegger "nunca se dá um ser ou modo de ser isolado. Todo ser é sempre sercom; mesmo na solidão e isolamento, a presença é sempre copresença (Mitdasein), o mundo

\footnotetext{
${ }^{96}[\ldots]$ the sense of involvement.

97 [...] is the ability to understand and be involved with everything that shows up within the world, and thus to have a symbolic and not merely a causal relationship to it.

98 [...] has the ability to take the internal perspective of a participant in a culture rather than the external perspective of an observer of the physical world.

${ }^{99}[. .$.$] we are (to a significant degree) constituted as the beings that we are by the fact that we always inhabit a$ shared world, and the way we exist in this world is always essentially structured by others.

${ }^{100}$ It is a constitutive feature of our way of being that we take over our understanding of ourselves and the world around us from those others with whom we exist.

101 This means that who I am cannot be understood in terms of a subject who could be constituted as he is, independently of any relationship to other human beings. Even seemingly contrary examples - human beings who are alone, or indifferent to their fellows, or misfits and outcasts - confirm this since they are human beings who are alone or indifferent or rejected by society.
} 
é sempre mundo compartilhado (Mitwelt), o viver é sempre convivência (Miteinandersein)" (NOTAS..., 2015, p. 571). Segundo Heidegger, "o ser-com constitui existencialmente o ser-nomundo" (HEIDEGGER, 2015, p. 177), de modo que, "enquanto ser-com, a presença 'é', essencialmente, em virtude dos outros" (HEIDEGGER, 2015, p. 180).

Heidegger (2015, p. 174, grifo do autor) entende que “os 'outros' não significam todo o resto dos demais além de mim, do qual o eu se isolaria. Os outros, ao contrário, são aqueles dos quais, na maior parte das vezes, não se consegue propriamente diferenciar, são aqueles entre os quais também se está". Assim, "o ser-com determina existencialmente a presença, mesmo quando um outro não é, de fato, dado ou percebido. Mesmo o estar-só da presença é ser-com no mundo" (HEIDEGGER, 2015, p. 177).

Segundo Heidegger (2015, p. 176), “numa primeira aproximação e na maior parte das vezes, a presença se entende a partir de seu mundo e a copresença dos outros vem ao encontro nas mais diversas formas, a partir do que está à mão dentro do mundo". Os outros "se mostram em seu ser-no-mundo, empenhado nas ocupações do mundo circundante, a partir do ser que, no mundo, está à mão" (HEIDEGGER, 2015, p. 180). "Nas ocupações com o mundo circundante, os outros nos vêm ao encontro naquilo que são. Eles são o que empreendem" (HEIDEGGER, 2015, p. 183).

A presença encontra o outro no ser-no-mundo dele:

\footnotetext{
a presença, enquanto ser-com, permite o encontro de muitos em seu mundo. Sercom é sempre uma determinação da própria presença; ser copresente caracteriza a presença de outros na medida em que, pelo mundo da presença, libera-se a possibilidade para um ser-com. A própria presença só é possuindo a estrutura essencial do ser-com, enquanto copresença que vem ao encontro de outros (HEIDEGGER, 2015, p. 177).
}

Desse modo, "na compreensão do ser da presença já subsiste uma compreensão dos outros, porque seu ser é ser-com" (HEIDEGGER, 2015, p. 180), assim "no ser-com e para os outros, subsiste, portanto, uma relação ontológica entre presenças", relação esta que se torna "projeção do próprio ser para si mesmo 'num outro", ou seja, "o outro é um duplo de si mesmo" (HEIDEGGER, 2015, p. 181). Por esta razão, a convivência "não pode ser concebida como o resultado da soma de vários 'sujeitos'” (HEIDEGGER, 2015, p. 182). 
Para Heidegger "a totalidade de significações que compõem o mundo no qual a presença fática se desenvolve é essencialmente compartilhada intersubjetivamente"102 (LAFONT, 2005, p. 271, grifo da autora). É somente quando a presença "aprende a adotar a perspectiva intersubjetiva de um participante em seu mundo cultural" ${ }^{103}$ que ela pode aprender a adotar uma perspectiva própria individual e autêntica (LAFONT, 2005, p. 272).

Para se desenvolver dentro de uma cultura, "para se tornar familiar com o conjunto de significações disponíveis dentro dela"104, a presença precisa primeiramente "aprender os padrões normativos de interpretação e conduta que essa cultura prescreve"105, ou seja, tradições culturais precedem sujeitos individuais (LAFONT, 2005, p. 272). Segundo Dreyfus e Wrathall (2005, p. 7), "as normas que governam as coisas são as normas disponíveis para todos - portanto, existe um caráter público inescapável à inteligibilidade do mundo"106. Assim, "dentro do modelo hermenêutico, o mundo não é constituído pelo sujeito, mas pelo 'impessoal'”'107 (LAFONT, 2005, p. 272).

Segundo Heidegger (2015, p. 186, grifo do autor) "o impessoal é um existencial ${ }^{108}$ e, enquanto fenômeno originário, pertence à constituição positiva da presença". Nesse sentido, "cada presença se acha dispersa no impessoal, precisando ainda encontrar a si mesma" (HEIDEGGER, 2015, p. 186, grifo do autor). O impessoal estabelece a primeira interpretação do mundo e do ser-no-mundo, de modo que a presença que está dispersa no impessoal “articula o contexto referencial da significância" (HEIDEGGER, 2015, p. 187):

Numa primeira aproximação, 'eu' não 'sou' no sentido do propriamente si mesmo e sim os outros nos moldes do impessoal. É a partir deste e como este que, numa primeira aproximação, eu 'sou dado' a mim mesmo. Numa primeira aproximação, a presença é impessoal, assim permanecendo na maior parte das vezes. Quando a presença descobre o mundo e o aproxima de si, quando abre para si mesma seu próprio ser, este descobrimento de 'mundo' e esta abertura da presença se cumprem e realizam como uma eliminação das obstruções, encobrimentos, obscurecimentos, como um romper das distorções em que a presença se tranca contra si mesma (HEIDEGGER, 2015, p. 187, grifo do autor).

\footnotetext{
$102[\ldots]$ the totality of significations that make up the world in which a factical Dasein grows up into is essentially intersubjectively shared [...].

103 [...] learns to adopt the intersubjective perspective of a participant in its cultural world [...].

104 [...] to become familiar with the whole of significations available within it [...].

$105[\ldots]$ to learn the normative patterns of interpretation and conduct that such a culture prescribes.

${ }^{106}$ The norms that govern things are the norms available to anyone - thus there is an inescapable public character to the intelligibility of the world.

107 Within the hermeneutic model, the world is not constituted by the subject, but by "the one."

108 "Existencial remete às estruturas que compõem o ser do homem a partir da existência em seus desdobramentos advindos da presença" (NOTAS..., 2015, p. 563).
} 
Segundo Heidegger (2015, p. 184), na convivência "cada um é como o outro", pois “este conviver dissolve inteiramente a própria presença no modo de ser dos 'outros', e isso de tal maneira que os outros desaparecem ainda mais em sua possibilidade de diferença e expressão". Este é "o impessoal, que não é nada determinado, mas que todos são, embora não como soma, prescreve o modo de ser da cotidianidade" (HEIDEGGER, 2015, p. 184).

Apesar de a presença precisar adotar a perspectiva intersubjetiva de um participante em seu mundo cultural, ela precisa aprender os padrões normativos de interpretação e conduta que sua cultura prescreve para que ela possa se desenvolver, o impessoal pode se constituir em um problema, porque, como "prescreve todo julgamento e decisão, o impessoal retira a responsabilidade de cada presença" (HEIDEGGER, 2015, p. 185). O impessoal "pode assumir tudo com a maior facilidade e responder por tudo, já que não há ninguém que precise responsabilizar-se por alguma coisa" (HEIDEGGER, 2015, p. 185):

O impessoal tira o encargo de cada presença em sua cotidianidade. E não apenas isso; com esse desencargo, o impessoal vem ao encontro da presença na tendência de superficialidade e facilitação. Uma vez que sempre vem ao encontro de cada presença, dispensando-a de ser, o impessoal conserva e solidifica seu domínio teimoso (HEIDEGGER, 2015, p. 185, grifo do autor).

Ou seja, a presença não pode se desenvolver no sentido do propriamente si mesmo enquanto ela for impessoal. Butler torna esta questão bastante inteligível:

\begin{abstract}
Heidegger (1976) ${ }^{109}$ argumenta que é a autoridade silenciosa de das Man (grosseiramente traduzido como 'o eles' ou 'o qualquer um') [o impessoal] que fornece reafirmação na face da turbulência existencial. O estado de 'estar situado' ou 'afinado' sob a influência de das Man [o impessoal], (por exemplo, como operacionalizado através da opinião pública ou normas de grupo), fornece entornos familiares e reconfortantes; auto-reflexão precipitada pela turbulência existencial (um 'colapso') despedaça esta tranquilidade e acarreta uma 'estranheza' (Unheimlichkeit) da existência. Apesar de nunca garantido, Heidegger considera a transição da irreflexão de 'estar situado' para o estado reflexivo da compreensão o único estado autêntico de existência - como sendo atingível por todos; uma realização na qual a autoridade de das Man [o impessoal] e a influência da Tradição são criticamente escrutinadas para verificar sua autenticidade e para superar essa influência se necessário ${ }^{110}$ (BUTLER, 1998, p. 288).
\end{abstract}

\footnotetext{
109 HEIDEGGER, Martin. (1976). Being and time. New York: Harper and Row.

110 Heidegger (1976) argues that it is the quiet authority of das Man (roughly translated as 'the they' or 'the anyone') which provides reassurance in the face of existential turbulence. The state of 'being situated' or 'tuned' under the sway of das Man, (e.g. as operationalized through public opinion or group norms), provides one with familiar and comforting surroundings; self-reflection precipitated by existential turbulence (a 'breakdown') shatters this tranquillity and brings about an 'unhomliness' [sic] (Unheimlichkeit) of existence. Although never guaranteed, Heidegger considers the transition from the unreflectiveness of 'being situated' to
} 
Ser-no-mundo "significa que sempre nos encontramos no mundo de um modo particular - temos [...] uma situação estruturada significativamente na qual agir e existir - e somos sempre dispostos a coisas de um modo particular, elas sempre importam para nós de um modo ou de outro"111 (DREYFUS; WRATHALL, 2005, p. 5). Por esta razão, Heidegger afirma que é característico da presença aquilo que chamou de o estar-lançado da existência humana:

Nenhum de nós é o fundamento de sua própria existência. Em vez disso, somos lançados no mundo e esse estar-lançado é algo que não pode ser desfeito. Somos lançados na posição de ter que nos responsabilizar por nós mesmos, de fundamentar nosso respectivo ser-no-mundo, no entanto, não somos responsáveis por estar nesta posição ${ }^{112}$ (DAHLSTROM, 2013, p. 212).

Segundo Heidegger (2015), seres humanos estão sempre nessa condição lançada, o que quer dizer que estão perdidos dentro do mundo no qual foram lançados, necessitando encarar quaisquer circunstâncias nas quais se encontrem e que possam aparecer em seus caminhos.

Para Gadamer (2012a, p. 73) “é constitutivo do ser-aí [presença] humano o fato de virmos ao mundo sem sermos questionados e de sermos chamados sem sermos questionados. Em todo o nosso 'ter-sido-jogado' [estar-lançado], vivemos em vista de nosso futuro, de um futuro para o qual nos projetamos".

Segundo Dahlstrom (2013, p. 213, grifo do autor), esse "estar-lançado está atado à 'facticidade de ser entregue' a si mesmo para ser"113 e enquanto há presença, "ela permanece envolvida no estar-lançado e no mundo específico no qual foi lançada"114, "sempre no processo de projetar algumas possibilidades factuais, isto é, algumas possibilidades na qual ela está lançada"115. Para Gadamer (2012a, p. 74) a "hermenêutica da facticidade encontra-se diante do enigma de o ser-aí jogado [presença lançada] no aí interpretar a si mesmo, de ele

the reflective state of understanding - the only authentic state of existence - as being achievable by all; an achievement in which the authority of das Man and the influence of Tradition are critically scrutinized to verify their authenticity and to overcome such influence if necessary.

111 [...] means that we always find ourselves in the world in a particular way - we have [...] a meaningfully structured situation in which to act and exist - and we are always disposed to things in a particular way, they always matter to us somehow or other.

112 None of us is the ground of her own existence. Instead we are thrown into the world and this thrownness is something that cannot be undone. We are thrown into the position of having to take responsibility for ourselves, to ground our respective being-in-the-world, yet we are not responsible for being in this position.

113 [...] thrownness is tied to "the facticity of being handed over" to itself to be.

$114[\ldots]$ it remains caught up in the throw and the specific world into which it is thrown [...].

$115[\ldots]$ always in the process of projecting some factical possibilities, i.e. some of the possibilities into which it is thrown $[. .$.$] .$ 
projetar a si mesmo em vista de possibilidades, em vista do que advém e do que vem ao seu encontro". Assim, "a presença é a possibilidade de ser que está entregue à sua responsabilidade, é a possibilidade que Ihe foi inteiramente lançada" (HEIDEGGER, 2015, p. 204 , grifo do autor).

Segundo Heidegger (2015, p. 246-247, grifo do autor), "o estar-lançado é o modo de ser de um ente que sempre é ele mesmo as suas possibilidades e isso de tal maneira que ele se compreende nessas possibilidades e a partir delas (projeta-se para elas)".

Compreender é o modo de ser das pessoas lançadas no mundo, abarcando o todo de sua experiência no mundo (GADAMER, 2011b, 2015). De modo a fundamentar seus respectivos ser-no-mundo, seres humanos precisam compreender o mundo no qual se encontram, já que "compreender de existência como tal é sempre compreender mundo" (HEIDEGGER, 2015, p. 207). A presença é "ser em um mundo", de modo que "a compreensão de ser, própria da presença, inclui, de maneira igualmente originária, a compreensão de 'mundo' e a compreensão do ser dos entes que se tornam acessíveis dentro do mundo" (HEIDEGGER, 2015, p. 49).

Gadamer (2015, p. 16) afirma que Heidegger "mostrou de maneira convincente que a compreensão não é um dentre outros modos de comportamento do sujeito, mas o modo de ser da própria pré-sença". Para Gadamer (2015, p. 16), "o fato de o movimento da compreensão ser abrangente e universal não é arbitrariedade nem extrapolação construtiva de um aspecto unilateral; reside na natureza da própria coisa".

Heidegger (2015, p. 202, grifo do autor) interpreta "o compreender como um existencial fundamental", o que para ele mostra "que esse fenômeno é concebido como modo fundamental de ser da presença". Segundo Heidegger (2015) a presença, em sua essência, é compreender, e a compreensão e a interpretação são os "modos fundantes da existência humana" (PALMER, [2006], p. 51).

Dentro deste contexto, voltamo-nos agora para os modos fundantes da existência humana.

\subsection{Compreensão, interpretação e círculo hermenêutico}

Compreensão para Heidegger, segundo Dahlstrom (2013, p. 231), é a capacidade de projetar várias possibilidades nas situações apropriadas, o ser-no-mundo "deve[ndo] tanto 
sua capacidade de projetar como as possibilidades elas mesmas a estar lançado no mundo"116. Isto significa que a compreensão acontece enquanto um ser humano existe, ou seja, uma pessoa "está sempre projetando possibilidades e, no projetar, descobrindo o que significa ser para si mesma e para os outros"117 (DAHLSTROM, 2013, p. 231). Compreender é como alguém sabe “'o que está acontecendo' ou 'do que se trata' [...] em termos de sua própria capacidade de ser"118 (DAHLSTROM, 2013, p. 231). Segundo Gadamer (2015, p. 25), “o caráter de projeto da compreensão" mostra "o caráter de futuro da pré-sença".

Enquanto elemento constitutivo do ser-no-mundo, a compreensão é intrinsecamente ligada à temporalidade, uma vez que, "segundo Heidegger, o ser do homem é essencialmente temporal: seu horizonte vivido inclui passado, presente e futuro"119, o ser-no-mundo "se projetando essencialmente para o futuro"120 (MUELLER-VOLLMER, 1989, p. 34).

Contudo, compreender não é "algum tipo de experiência interna, cognitiva pertencente a um sujeito"121 (DAHLSTROM, 2013, p. 231). Não é "uma auto-percepção imanente"122, mas "uma projeção dinâmica, auto-reveladora do ser-no-mundo"123 (DAHLSTROM, 2013, p. 231). Segundo Dahlstrom (2013, p. 231), “em outras palavras, mesmo que não compreenda sempre seu ser, estar aqui é compreender seu ser como uma projeção lançada de possibilidades" ${ }^{124}$. Para Dahlstrom (2013, p. 232) "compreender assegura a inteligibilidade ontológica [...] de entes dentro do mundo"125, o que permite que as pessoas respondam a esses entes.

Segundo Dreyfus e Wrathall (2005), para Heidegger a compreensão do mundo é um tipo de projeção em possibilidades em vez da compreensão cognitiva e conceitual que comumente se considera compreensão:

Para ver o que Heidegger tem em mente com o termo 'compreensão', é necessário focar primeiramente nos contextos práticos e envolvimentos práticos com coisas em

\footnotetext{
$116[\ldots]$ it owes both its capacity to project and the possibilities themselves to having been thrown into the world.

117 [...] is always projecting possibilities and, in the projecting, disclosing what it means to be for itself and others.

118 [...] 'what's going on' or 'what it's about' [...] in terms of its own capability of being.

119 According to Heidegger, man's being is essentially temporal: his lived horizon includes past, present, and future $[\ldots]$.

$120[\ldots]$ projects himself primarily toward the future.

121 [...] some sort of internal, cognitive experience belonging to a subject.

$122[\ldots]$ an immanent self-perception [...].

123 [...] a dynamic, self-disclosing projection of being-in-the-world.

124 In other words, even if it does not always comprehend its being, to be here is to understand its being as a thrown projection of possibilities.

125 [...] understanding secures the ontological intelligibility [...] of entities within the world [...].
} 
um mundo organizado e significativo. Eu estou no mundo compreensivamente quando estou fazendo algo propositadamente, por exemplo, fazendo uma omelete na minha cozinha. Ao fazê-lo, eu 'deixo' as coisas na minha cozinha se 'envolverem' umas com as outras - os ovos são envolvidos com a tigela, que é envolvida com o batedor e a frigideira e a espátula. Conforme eu aqueço a frigideira para derreter a manteiga para fritar a omelete para alimentar meus filhos, eu estou agindo em última análise pelo bem de um modo de ser um ser humano - pelo bem de ser um pai, por exemplo. Todas essas conexões entre atividades e entes e modos de ser são constitutivos da compreensão do mundo que eu possuo. No processo de agir com base nessa compreensão, por sua vez, eu permito que coisas e atividades se mostrem como as coisas e atividades que elas são (frigideiras como frigideiras, espátulas como espátulas, etc.) ${ }^{126}$ (DREYFUS; WRATHALL, 2005, p. 5).

Isso quer dizer que "ao agir no mundo, então, eu compreendo como as coisas se relacionam umas com as outras - quer dizer, eu compreendo no sentido de 'saber como' tudo no mundo faz sentido"127 (DREYFUS; WRATHALL, 2005, p. 5).

Heidegger afirma que essa compreensão não é um domínio cognitivo de papéis e conceitos, pois isto reduziria o que é projetado como possibilidade aos conteúdos dados que temos na mente (DREYFUS; WRATHALL, 2005). Assim, "ao compreender o comportamento humano no mundo, Heidegger argumenta que precisamos primeiramente focar no enfrentamento habilidoso e prático"128 (DREYFUS; WRATHALL, 2005, p. 6).

Nesse sentido, "o modo mais imediato de lidar [no mundo] não é o conhecer meramente perceptivo e sim a ocupação no manuseio e uso, a qual possui um 'conhecimento próprio'” (HEIDEGGER, 2015, p. 114-115). As coisas do mundo, os entes, não são objeto de um conhecimento teórico do mundo - mundo aqui entendido como uma multiplicidade de entes -, mas sim coisas que são usadas, produzidas e etc. (HEIDEGGER, 2015). Ou seja, esse "não é, pois, um conhecimento de propriedades entitativas dos entes, mas uma determinação da

\footnotetext{
${ }^{126}$ To see what Heidegger has in mind with the term "understanding," one needs to focus primarily on practical contexts and practical involvements with things in an organized and meaningful world. I am in the world understandingly when I am doing something purposively, for example, making an omelet in my kitchen. In doing so, I "let" the things in my kitchen be "involved with" each other - the eggs are involved with the mixing bowl, which is involved with the wire whisk and the frying pan and the spatula. As I heat the frying pan in order to melt the butter in order to fry up the omelet in order to feed my children, I am ultimately acting for the sake of some way of being a human being - for the sake of being a father, for example. All of these connections between activities and entities and ways of being are constitutive of the understanding of the world I possess. In the process of acting on the basis of that understanding, in turn, I allow things and activities to show up as the things and activities that they are (frying pans as frying pans, spatulas as spatulas, etc.) [...].

127 In acting in the world, then, I understand how things relate to each other - that is to say, I understand in the sense of "knowing how" everything in the world hangs together.

128 In understanding human comportment in the world, Heidegger argues that we need to focus first on skillful, practical coping.
} 
estrutura de seu ser" (HEIDEGGER, 2015, p. 115). Desse modo, a coisa usada, produzida ou etc. se torna acessível quando são transferidas para ocupações (HEIDEGGER, 2015).

A ocupação é o modo de relação da presença com os entes que não são dotados do modo de ser da presença, ou seja, ela enfatiza o significado prático de uso e produção de um ente em vez de se concentrar no ente em si (BUNNIN; YU, 2004; NOTAS..., 2015). Ou seja, "a aplicação" que ocorre com a ocupação "é um momento do próprio compreender" (GADAMER, 2015, p. 19).

Assim, quando Heidegger (2015, p. 107) afirma que "conhecer é um modo de ser da presença enquanto ser-no-mundo" ele entende que conhecer o mundo é compreender o mundo, sendo que para que o conhecer perceptivo, o conhecer da tradição filosófica, ocorra

\begin{abstract}
É necessário que ocorra previamente uma deficiência do afazer que se ocupa do mundo para que o conhecimento, no sentido de determinação observadora de algo simplesmente dado, se torne possível. Abstendo-se de todo produzir, manusear etc., a ocupação se concentra no único modo ainda restante de ser-em, ou seja, no simples demorar-se junto a... Com base nesse modo de ser para o mundo, que só

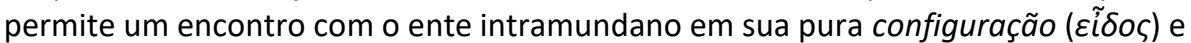
como modo dessa maneira de ser, é que se torna possível uma visualização explícita do que assim vem ao encontro. Essa visualização é sempre um direcionamento para..., um encarar o ente simplesmente dado. Retira antecipadamente do ente que vem ao encontro um 'ponto de vista'. Essa visualização se dá em si mesma, demorando-se, de modo autônomo, junto ao ente intramundano. Nessa "demora" - enquanto abstenção de todo manuseio e utilização - cumpre-se a percepção de um ente simplesmente dado. Esse perceber se realiza no modo de dizer e discutir algo como algo. A percepção torna-se determinação com base neste interpretar, entendido em sentido amplo. $O$ que se percebe e determina pode ser pronunciado em proposições e manter-se e preservar-se nessa qualidade de enunciado (HEIDEGGER, 2015, p. 108, grifos do autor).
\end{abstract}

Desse modo, em Heidegger conhecer é mais do que o conhecer perceptivo da tradição filosófica. E o conhecimento é o mesmo conhecimento com o qual Berger e Luckmann lidam na sociologia do conhecimento ${ }^{129}$, ou seja, "tudo aquilo que é considerado 'conhecimento' na sociedade" (BERGER; LUCKMANN, 2004, p. 29, grifo dos autores), "conhecimento que dirige a conduta na vida diária" (BERGER; LUCKMANN, 2004, p. 35). Com isto eles querem dizer que conhecimento é muito mais do que conhecimento teórico:

\footnotetext{
${ }^{129}$ Trouxemos essa discussão da sociologia do conhecimento porque Hekman (1986, p. 3), com base em Simonds, afirma que a sociologia do conhecimento é um método hermenêutico. O artigo no qual Hekman se baseia é SIMONDS, A. P. (1975). Mannheim's sociology of knowledge as a hermeneutic method. Cultural Hermeneutics, Dordrecht, v. 3, n. 1, p. 81-105.
} 
O pensamento teórico, as 'ideias', Weltanschauungen ${ }^{130}$ não são tão importantes assim na sociedade. Embora todas as sociedades contenham estes fenômenos, são apenas parte da soma total daquilo que é considerado "conhecimento". Em qualquer sociedade somente um grupo muito limitado de pessoas se empenha em produzir teorias, em ocupar-se de 'ideias' e construir Weltanschauungen, mas todos os homens na sociedade participam, de uma maneira ou de outra, do "conhecimento" por ela possuído. Dito de outra maneira, só muito poucas pessoas preocupam-se com a interpretação teórica do mundo, mas todos vivem em um mundo de algum tipo. Não somente a focalização sobre o pensamento teórico é indevidamente restritiva da sociologia do conhecimento, mas também insatisfatória, porque mesmo esta parte do 'conhecimento' socialmente existente não pode ser plenamente compreendida se não for colocada na estrutura de uma análise mais geral do 'conhecimento'.

Exagerar a importância do pensamento teórico na sociedade e na história é um natural engano dos teorizadores. Isto torna por conseguinte ainda mais necessário corrigir esta incompreensão intelectualista. As formulações teóricas da realidade, quer sejam científicas ou filosóficas quer sejam até mitológicas, não esgotam o que é 'real' para os membros de uma sociedade. Sendo assim, a sociologia do conhecimento deve acima de tudo ocupar-se com o que os homens 'conhecem' como 'realidade' em sua vida cotidiana, vida não teórica ou pré-teórica. Em outras palavras, o 'conhecimento' do senso comum, e não as 'ideias', deve ser o foco central da sociologia do conhecimento. É precisamente este 'conhecimento' que constitui o tecido de significados sem o qual nenhuma sociedade poderia existir (BERGER; LUCKMANN, 2004, p. 29-30, grifo dos autores).

Berger e Luckmann não estão menosprezando o conhecimento teórico, estão indicando que ele é apenas um dos tipos de conhecimento que existe no mundo.

Quando Heidegger descreve a compreensão como aquilo que nos mostra o que é possível, ele quer dizer que "ela nos mostra a gama disponível de modos de ser, ela nos mostra nosso poder-ser ou habilidade-de-ser"131, mostrando as possibilidades que nos estão disponíveis e dando a elas um modo de serem significantes para nós (DREYFUS; WRATHALL, 2005, p. 6).

Para Heidegger (2015, p. 203) "o que se pode no compreender, assumido como existencial, não é uma coisa, mas o ser como existir. Pois no compreender subsiste, existencialmente, o modo de ser da presença enquanto poder-ser". Assim:

A presença não é algo simplesmente dado que ainda possui de quebra a possibilidade de poder alguma coisa. Primariamente, ela é possibilidade de ser. Toda presença é o que ela pode ser e o modo em que é a sua possibilidade. A possibilidade essencial da presença diz respeito aos modos caracterizados de ocupação com o 'mundo', de preocupação com os outros e, nisso tudo, à possibilidade de ser para si

130 Conceito de mundo, concepção de mundo, ideia de mundo, opinião de mundo ou visão de mundo, em tradução literal do alemão para o português. Refere-se ao conceito que em português chamamos de cosmovisão ou mundividência.

${ }^{131}[\ldots]$ it shows us the available range of ways to be, it shows us our can-be or ability-to-be [...]. 
mesma, em virtude de si mesma. A possibilidade de ser, que a presença existencialmente sempre é, distingue-se tanto da possibilidade lógica e vazia como da contingência de algo simplesmente dado em que isso ou aquilo pode 'se passar'. Como categoria modal do ser simplesmente dado, a possibilidade designa o que ainda não é real e que nunca será necessário. Caracteriza o somente possível. [...] Como existencial, a possibilidade é, ao contrário, a determinação ontológica mais originária e mais positiva da presença (HEIDEGGER, 2015, p. 203-204, grifo do autor).

Heidegger entende que a interpretação é "a estrutura holística da compreensão"132 (LAFONT, 2005, p. 269), ou seja, "compreensão é sempre interpretação"133 (LAFONT, 2005, p. 276-277, grifo da autora). Para Heidegger (2015, p. 209) “na interpretação, o compreender vem a ser ele mesmo", ou seja, "interpretar não é tomar conhecimento do que se compreendeu, mas elaborar as possibilidades projetadas no compreender". Desse modo, a "constituição existencial da presença" é "um compreender que interpreta" (HEIDEGGER, 2015, p. 215). Segundo Gadamer (2015, p. 503), "em última instância, compreender e interpretar são uma e a mesma coisa", a forma de compreensão sendo a interpretação.

Com base em Heidegger, Gadamer (2015) afirma que a compreensão tem uma estrutura circular que ficou conhecida como círculo hermenêutico e é enraizada na temporalidade da existência humana, sendo constantemente exercitada e ontologicamente positiva. Nesse sentido, "o tempo não é primeiramente um abismo que se deve ultrapassar porque separa e distancia", pois ele "é na verdade o fundamento sustentador do acontecer, onde se realiza a compreensão atual" (GADAMER, 2011f, p. 79). Por essa razão, "a distância temporal não é algo que deva ser superado" (GADAMER, 2011f, p. 79). Assim, a "interpretação é sempre relativa a um contexto, perspectiva e vocabulários particulares [...] que juntos constituem o que Heidegger chama de 'situação hermenêutica', da qual a interpretação se desenvolve"134 (LAFONT, 2005, p. 277).

Gadamer (2011f, p. 80) afirma que "o primeiro elemento com que se inicia a compreensão é o fato de que algo nos interpela. É a primeira de todas as condições hermenêuticas". As "experiências de compreensão sempre pressupõem dificuldades na compreensão, a perturbação do consenso. Assim, todo esforço de querer compreender começa quando nos deparamos com algo estranho, provocante e desorientador" (GADAMER,

\footnotetext{
$132[\ldots]$ the holistic structure of understanding.

133 [...] understanding is always interpretation [...].

134 [...] interpretation is always relative to a particular context, perspective, and vocabulary [...] that together constitute what Heidegger calls the "hermeneutic situation" out of which interpretation evolves [...].
} 
2011d, p. 217-218). Para Gadamer (2011d, p. 218) "esse desconcerto e admiração, esse não poder mais avançar, visa sempre um avanço, um conhecimento mais profundo".

Segundo Gadamer (2011f, 2015), o processo de compreensão acontece através da realização de projetos. Assim que um primeiro sentido emerge naquilo que se busca compreender, o indivíduo em busca da compreensão "projeta de antemão um sentido do todo" com base em expectativas pré-existentes e "na perspectiva de um determinado sentido" (GADAMER, 2011f, p. 75), ou seja, o projeto é "dirigido por uma expectativa de sentido que provém do contexto anterior" (GADAMER, 2011f, p. 72). A compreensão "consiste na elaboração desse projeto prévio" e na sua constante revisão e correção conforme o indivíduo "aprofunda e amplia o sentido" (GADAMER, 2011f, p. 75). Com isto Gadamer quer dizer que

\begin{abstract}
a expectativa sofre uma outra determinação e que o texto se conjuga na unidade de um pensamento, a partir de uma outra expectativa de sentido. Dessa forma, o movimento da compreensão transcorre sempre do todo para a parte e, desta, de volta para o todo. A tarefa é ampliar, em círculos concêntricos, a unidade do sentido compreendido. $\mathrm{O}$ critério que cada vez se há de empregar para constatar a justeza da compreensão é a concordância de todas as partes singulares com o todo. A falta dessa concordância significa o fracasso da compreensão (GADAMER, 2011f, p. 72).
\end{abstract}

Cada revisão de um projeto prévio pode originar um outro projeto e um outro sentido, pois ao longo do processo de interpretação "conceitos prévios" são "substituídos por conceitos mais adequados", "projetos conflitantes pode[ndo] posicionar-se lado a lado na elaboração, até que se confirme de modo mais unívoco a unidade de sentido" (GADAMER, 2011f, p. 75):

\begin{abstract}
Em suma, esse constante projetar de novo é o que perfaz o movimento semântico de compreender e de interpretar. Quem procura compreender está sujeito a errar por causa das opiniões prévias, que não se confirmam nas coisas elas mesmas. Dessa forma, a constante tarefa do compreender consiste em elaborar projetos corretos, adequados às coisas, isto é, ousar hipóteses que só devem ser confirmadas 'nas coisas elas mesmas'. Aqui não há outra 'objetividade' além da elaboração da opinião prévia a ser confirmada. Faz sentido afirmar que o intérprete não vai diretamente ao 'texto', a partir da opinião prévia pronta e instalada nele. Ao contrário, põe à prova, de maneira expressa, a opinião prévia instalada nele a fim de comprovar sua legitimidade, o que significa, sua origem e sua validade (GADAMER, 2011f, p. 75).
\end{abstract}

Na ótica de Bauman (1978, p. 17) "compreender significa ir em círculos: em vez de um progresso unilinear em direção ao conhecimento melhor e menos vulnerável, ele consiste em 
uma recapitulação e reavaliação infinitas de memórias coletivas - cada vez mais volumosas, mas sempre seletivas" ${ }^{135}$. Assim, "a decantação do sentido verdadeiro de um texto ou de uma obra de arte é um processo infinito" (GADAMER, 2011f, p. 80).

No processo de compreender e interpretar, "quando se ouve alguém ou quando se empreende uma leitura, não é necessário que se esqueçam todas as opiniões prévias sobre seu conteúdo e todas as opiniões próprias. O que se exige é simplesmente a abertura para a opinião do outro ou para a opinião do texto" (GADAMER, 2015, p. 358). No entanto, "essa abertura implica sempre colocar a opinião do outro em alguma relação com o conjunto das opiniões próprias, ou que a gente se ponha em certa relação com elas" (GADAMER, 2015, p. 358). Por essa razão Gadamer (2015, p. 18) afirma que "a compreensão jamais é um comportamento subjetivo frente a um 'objeto' dado, mas pertence à história efeitual, e isto significa, pertence ao ser daquilo que é compreendido".

Ainda que as opiniões representem inúmeras possibilidades mutáveis, "dentro dessa multiplicidade [...] nem tudo é possível, e quem não ouve direito o que o outro realmente está dizendo acabará por não conseguir integrar o mal-entendido em suas próprias e variadas expectativas de sentido" (GADAMER, 2015, p. 358). Assim, o processo de compreensão e interpretação possui critérios: a tarefa hermenêutica é um "questionamento pautado na coisa em questão", pois essa tarefa "já se encontra sempre codeterminada" pela coisa em questão (GADAMER, 2015, p. 358). A compreensão "permanece sempre determinada pelo movimento pré-apreensivo da compreensão prévia" (GADAMER, 2011f, p. 77).

Segundo Gadamer (2015, p. 355) "toda interpretação correta tem que proteger-se da arbitrariedade de intuições repentinas e da estreiteza dos hábitos de pensar imperceptíveis, e voltar seu olhar para 'as coisas elas mesmas'”. Guiar sua própria interpretação pelas "coisas elas mesmas" é "sua primeira, única e última tarefa" (HEIDEGGER, 2015, p. 214). Para Gadamer (2015, p. 355-356) “o que importa é manter a vista atenta à coisa através de todos os desvios a que se vê constantemente submetido o intérprete em virtude das ideias que lhe ocorrem". Desse modo, "uma compreensão efetuada com consciência metodológica não buscará simplesmente confirmar suas antecipações, mas tomar consciência delas, a fim de

\footnotetext{
135 Understanding means going in circles: rather than a unilinear progress towards better and less vulnerable knowledge, it consists of an endless recapitulation and reassessment of collective memories - ever more voluminous, but always selective.
} 
controlá-las e com isso alcançar a compreensão correta a partir das coisas elas mesmas" (GADAMER, 2011f, p. 77). Assim,

\begin{abstract}
o empreendimento hermenêutico ganha um solo firme sob seus pés. Aquele que quer compreender não pode se entregar de antemão ao arbítrio de suas próprias opiniões prévias, ignorando a opinião do texto da maneira mais obstinada e consequente possível - até que este acabe por não poder ser ignorado e derrube a suposta compreensão. Em princípio, quem quer compreender um texto deve estar disposto a deixar que este lhe diga alguma coisa. Por isso, uma consciência formada hermeneuticamente deve, desde o princípio, mostrar-se receptiva à alteridade do texto. Mas essa receptividade não pressupõe nem uma 'neutralidade' com relação à coisa nem tampouco um anulamento de si mesma; implica antes uma destacada apropriação das opiniões prévias e preconceitos pessoais. O que importa é dar-se conta dos próprios pressupostos, a fim de que o próprio texto possa apresentar-se em sua alteridade, podendo assim confrontar sua verdade com as opiniões prévias pessoais (GADAMER, 2015, p. 358).
\end{abstract}

Portanto, "interpretar significa justamente colocar em jogo os próprios conceitos prévios, para com isso trazer realmente à fala a opinião do texto" (GADAMER, 2015, p. 514).

Gadamer (2015, p. 377) esclarece, no entanto, que "é verdade que o nosso interesse se orienta para a coisa, mas esta só pode adquirir vida através do aspecto sob o qual nos é mostrada". Assim, ele (2015, p. 377) admite "que em tempos diversos ou a partir de pontos de vista diferentes também a coisa se apresenta historicamente sob aspectos diversos", aspectos que "não se suprimem pura e simplesmente no curso do progresso investigativo, mas que são como que condições que se excluem entre si, existem cada qual por si e se unem somente em nós".

Por essa razão Gadamer (2015) entende que as ideias de preconceito e tradição são fundamentais no empreendimento hermenêutico. Ele (2015, p. 359) afirma que não se trata de "assegurar-se frente à tradição que faz ouvir sua voz a partir do texto, mas, ao contrário, trata-se de manter afastado tudo o que possa impedir alguém de compreendê-la a partir da própria coisa em questão". Para ele (2015, p. 359) o problema "são os preconceitos não percebidos", "que, com seu domínio, nos tornam surdos para a coisa de que nos fala a tradição".

Segundo Gadamer (2015, p. 360), "é só o reconhecimento do caráter essencialmente preconceituoso de toda compreensão que pode levar o problema hermenêutico à sua real agudeza". Para ele (2011g, p. 261) "mais do que nossos conceitos, são nossos preconceitos que perfazem nosso ser". 
Gadamer (2015, p. 360) explica que a ideia de preconceito como algo negativo é algo surgido com o lluminismo, que tem um "preconceito contra os preconceitos em geral e, com isso, a despotenciação da tradição". Segundo ele (2015, p. 360), é somente com o lluminismo que o conceito de "preconceito recebeu o matiz negativo que agora possui", pois "em si mesmo, preconceito (Vorurteil) quer dizer um juízo (Urteil) que se forma antes do exame definitivo de todos os momentos determinantes segundo a coisa em questão". Assim, "os preconceitos não são necessariamente injustificados e errôneos, de modo a distorcer a verdade” (GADAMER, 2011g, p. 261), “'preconceito' não significa pois, de modo algum, falso juízo, uma vez que seu conceito permite que ele possa ser valorizado positiva ou negativamente" (GADAMER, 2015, p. 360):

\footnotetext{
O termo alemão Vorurteil (preconceito) - assim como o termo francês préjugé mas de modo ainda mais pregnante - parece ter sido restringido, pela Aufklärung ${ }^{136} \mathrm{e}$ sua crítica religiosa, ao significado de 'juízo não fundamentado'. É só a fundamentação, a garantia do método (e não a coisa como tal), que confere ao juízo sua dignidade. Aos olhos do Aufklärung, a falta de fundamentação não deixa espaço a outros modos de validade, pois significa que o juízo não tem um fundamento na coisa em questão, que é um juízo 'sem fundamento'. Essa é uma conclusão típica do espírito do racionalismo. Sobre ele funda-se o descrédito dos preconceitos em geral e a pretensão do conhecimento científico de excluí-los totalmente (GADAMER, 2015, p. 361).
}

Gadamer (2011g, p. 261) entende que os preconceitos constituem “a orientação prévia de toda nossa capacidade de experiência", fato que "é constitutivo da historicidade de nossa existência". Os preconceitos "são antecipações de nossa abertura para o mundo, que se tornam condições para que possamos experimentar qualquer coisa, para que aquilo que nos vem ao encontro possa nos dizer algo" (GADAMER, 2011g, p. 261).

Gadamer (2015) busca então reabilitar a autoridade e a tradição, que não podem ser vistas como estando em oposição à razão e à liberdade. Segundo ele, a autoridade não é fundada na submissão e na abdicação da razão, mas sim num ato de reconhecimento e conhecimento, onde se reconhece a superioridade e visão de outrem sobre a nossa com base numa ação da razão, que se torna consciente de seus próprios limites.

Para Gadamer (2015) a tradição é uma forma de autoridade que se tornou anônima, que nos foi transmitida e que tem validade sem precisar de fundamentação. Ela é um tipo de autoridade que tem poder sobre nossa ação e nosso comportamento e da qual não se pode

\footnotetext{
136 Iluminismo, em tradução literal do alemão para o português.
} 
libertar totalmente em algum momento de amadurecimento, pois ela determina amplamente nossas instituições e comportamentos.

Segundo Gadamer (2015), estamos sempre inseridos na tradição, sendo que esta inserção não é objetiva. A tradição não pode ser pensada como estranha ou alheia a nós, ela é sempre "algo próprio, modelo e intimidação, um reconhecer a si mesmos no qual o nosso juízo histórico posterior não verá tanto um conhecimento, mas uma transformação espontânea e imperceptível da tradição" (GADAMER, 2015, p. 374):

a tradição mais autêntica e a tradição melhor estabelecida não se realizam naturalmente em virtude da capacidade de inércia que permite ao que está aí de persistir, mas necessita ser afirmada, assumida e cultivada. A tradição é essencialmente conservação e como tal sempre está atuante nas mudanças históricas. Mas a conservação é um ato de razão, e se caracteriza por não atrair a atenção sobre si. Essa é a razão por que as inovações, os planejamentos aparecem como as únicas ações e realizações da razão. Mas isso não passa de aparência. Inclusive quando a vida sofre suas transformações mais tumultuadas, como em tempos revolucionários, em meio à suposta mudança de todas as coisas, do antigo conserva-se muito mais do que se poderia crer, integrando-se com o novo numa nova forma de validez. Em todo caso, a conservação representa uma conduta tão livre como a destruição e a inovação (GADAMER, 2015, p. 373-374).

Gadamer explica que "ninguém pode simplesmente escapar do modo de pensamento, no qual foi formado, por meio de uma reflexão" (2012b, p. 166), mas é possível deixar "morrer os preconceitos de natureza particular" (2011f, p. 80) e permitir "o surgimento daqueles que possibilitam uma verdadeira compreensão" (2011f, p. 80). Isto significa que "os nossos preconceitos devem ser sempre colocados em jogo no processo do compreender" (GADAMER, 2011b, p. 140).

Para Gadamer (2011b, p. 132), “o que a reflexão faz é apenas descobrir os condicionamentos que já estão atuando, a cada vez, sobre o compreender", condicionamentos estes "que já sempre estão sendo aplicados quando nos empenhamos em esclarecer um texto, visto que são constitutivos de nossa 'compreensão prévia'”. Desse modo, “'compreender' as articulações e ordenamentos de nosso mundo, compreender-nos mutuamente nesse mundo, pressupõe tanto a crítica e a contestação de que se estagnou e tornou-se estranho quanto o reconhecimento e a defesa das ordens estabelecidas" (GADAMER, 2011d, p. 221).

Assim, "a reflexão hermenêutica teve que elaborar [...] uma teoria dos preconceitos que, sem menosprezar o sentido de crítica de todos os preconceitos que ameaçam o 
conhecimento, faz justiça ao sentido produtivo da compreensão prévia, que é premissa de toda compressão" (GADAMER, 2011a, p. 505).

Desse modo, "uma hermenêutica filosófica haverá de concluir que o compreender só é possível quando aquele que compreende coloca em jogo seus próprios preconceitos. A contribuição produtiva do intérprete é parte inalienável do próprio sentido do compreender" (GADAMER, 2011b, p. 132). Segundo Gadamer (2012b, p. 166), "mesmo que venhamos a entrar cada vez mais em contato com outras línguas culturais e com outros mundos culturais, isso é antes de tudo um ganho para nós. Nós somos nossa proveniência e estamos em casa em nossa língua materna que pensa conosco".

Por essa razão, Berger e Luckmann (2004, p. 20-21), com base em Scheler ${ }^{137}$, afirmam que "o conhecimento humano é dado na sociedade como um a priori à experiência individual, fornecendo a esta sua ordem de significação. Esta ordem, embora relativa a uma particular situação sócio-histórica, aparece ao indivíduo como o modo natural de conceber o mundo", fazendo dela uma "relativa e natural concepção do mundo".

Gadamer deixa claro, contudo, que:

\begin{abstract}
Isso não legitima o caráter privado e arbitrário das pressuposições subjetivas, visto que a coisa que está em questão a cada vez - o texto que se quer compreender - é o único critério dotado de validade. A distância insuperável e necessária entre os tempos, as culturas, as classes, as raças - ou mesmo entre as pessoas - é um momento suprassubjetivo, que confere tensão e vida a todo compreender. Pode-se descrever esse fenômeno também do seguinte modo: O intérprete e o texto possuem cada qual seu próprio 'horizonte' e todo compreender representa uma fusão desses horizontes (GADAMER, 2011b, p. 132).
\end{abstract}

Com base em Husserl, Gadamer (2015, p. 399) afirma que "horizonte é o âmbito de visão que abarca e encerra tudo o que pode ser visto a partir de determinado ponto", horizonte devendo ser entendido aqui como um termo técnico, o horizonte sendo expansível, sendo "aquilo que podemos ver além com um pequeno esforço e aquilo que aponta para algo mais"138 (VESSEY, 2009, p. 533):

Apesar de um horizonte marcar o limite de visão em um dado momento, ele não é um limite intransponível. Simplesmente andar uma curta distância ou ir até o último andar de um edifício pode nos ajudar a ver além do nosso horizonte prévio. Na

\footnotetext{
137 SCHELER, Max. (1960). Die Wissensformen und die Gesellschaft. Bern: Francke.

138 [...] in favour of a horizon as that which expands, that which we can see beyond with a little effort, and that which points toward something more.
} 
verdade, a maior parte de nós sabe muito bem o que está além do horizonte simplesmente por experiência prévia. Horizontes podem funcionar como um limite em um determinado momento, mas eles também são portais de entrada para algo que está além ${ }^{139}$ (VESSEY, 2009, p. 533).

Para Vessey (2009) horizontes demarcam aquilo que pode ser diretamente percebido daquilo que não pode ser diretamente percebido, mas eles não limitam a percepção a somente aquilo que se pode perceber diretamente. Na verdade, segundo o autor, horizontes são aquilo que permite que se perceba mais do que aquilo que é diretamente perceptível, abrindo possibilidades de percepções futuras do ente, dando-Ihe suas características básicas. Mesmo que nossos sentidos somente nos deem informação incompleta sobre um ente, este ente pode ser percebido em sua totalidade. De modo a clarificar a questão, Vessey a exemplifica:

mesmo que quando olhando para uma cadeira nós sejamos apresentados a somente um lado da cadeira, nós percebemos uma cadeira, não o lado de uma cadeira. Não somos surpreendidos quando nos movemos e vemos que a cadeira tem outros lados, que ela é tridimensional e assim por diante. Na verdade, ficaríamos bastante chocados quando nos movêssemos e víssemos que o que pensávamos ser uma cadeira era apenas a fachada de uma cadeira. [...] Portanto, a percepção sempre vai além daquilo que é realmente dado aos sentidos ${ }^{140}$ (VESSEY, 2009, p. 533, grifo do autor).

Assim, Vessey (2009) afirma que os horizontes são as condições que fornecem o significado de algo, condições que precisam ser conscientes para que se compreenda propriamente algo. Para o autor, ao fornecerem a chave para a compreensão de nossas percepções, os horizontes nos impulsionam para a frente, estimulando a investigação e permitindo que nossas expectativas sejam confirmadas ou não. Por essa razão, Gadamer (2015, p. 330) entende que "tudo o que está dado como ente está dado como mundo e leva consigo o horizonte do mundo", de modo que "um horizonte não é uma fronteira rígida, mas algo que se desloca com a pessoa e que convida a que se continue a caminhar". Isso leva a

\footnotetext{
${ }^{139}$ Although a horizon marks the limit of sight at any moment, it is not an insurmountable limit. Simply walking a short distance or going to the top floor of a building can help us see beyond our previous horizon. In fact, most of us know quite well what lies beyond the horizon simply from past experience. Horizons might function as a limit at a particular time, but they are always also gateways to something beyond [...].

${ }^{140}$ So although when looking at a chair we are only presented with one side of the chair, we perceive a chair, not a chair-side. We are not surprised when we move to see that the chair has other sides to it, that it's threedimensional, and so on. In fact we would be quite shocked to find that what we thought was a chair was only a chair-façade. [...] So perception always goes beyond what is actually given to the senses.
} 
que o indivíduo não se limite àquilo que lhe é imediatamente dado, mas que vá em direção do contexto maior que dá o sentido, de modo que "o horizonte mude conforme a percepção muda" (VESSEY, 2009, p. 536).

Na perspectiva de Gadamer, que se funda no texto, o horizonte é "o conjunto de crenças que faz com que seja possível compreender uma frase" (VESSEY, 2009, p. 536), não sendo apenas sobre o assunto da frase, mas também sobre o contexto no qual a frase aparece:

Horizontes proporcionam perspectiva por serem as crenças implícitas e explícitas que fornecem o contexto para a compreender uma frase; eles estabelecem o que é significativo para a compreensão (aqueles em primeiro plano) e o que não é significativo (aqueles em segundo plano). Horizontes marcam os limites de nossa compreensão conforme nossas crenças subjacentes afetam quais frases nós compreendemos e como nós as compreendemos ${ }^{141}$ (VESSEY, 2009, p. 537).

Desse modo, Vessey (2009) afirma que o horizonte da frase mostra que esta pertence a um mundo linguístico, cultural e histórico, tornando possível a compreensão de algo que tem relevância dentro de um mundo. Para o autor, portanto, o horizonte não significa limites, mas sim aquilo que se pode compreender dentro de determinados limites.

Enquanto horizontes de percepção são sempre presentes, horizontes de compreensão podem não o ser, podendo requerer trabalho para que sejam adquiridos: "quando estamos tentando compreender outra pessoa ou um texto, precisamos ter alguma ideia do horizonte no qual o assunto é inteligível para o autor ou falante"142, o que "não significa que precisamos saber as intenções do falante ou do autor (apesar de que as saber pode ser útil), pois horizontes são características objetivas do ambiente conceitual que fazem um assunto inteligível, não características das mentes dos falantes"143 (VESSEY, 2009, p. 539). Ou seja, “o fato de que uma frase é inteligível não é um fato das intenções do falante, mas a natureza da

\footnotetext{
141 Horizons provide perspective by being the implicit and explicit beliefs that furnish the context for understanding a sentence; they establish what is significant for understanding (those in the foreground), and what is insignificant (those in the background). Horizons mark the limits of our understanding as our background beliefs affect what sentences we understand and how we understand them.

142 When we are trying to understand another person or a text, we need to have some idea of the horizon in which the subject matter is intelligible to the author or speaker.

$143[\ldots]$ does not mean that we need to know the intentions of the speaker or the author (though knowing them might help) as horizons are objective features of the conceptual environment that make a subject matter intelligible, not subjective features of the mind of the speakers.
} 
linguagem e do assunto da frase"144, de modo que "a chave para a interpretação adequada jaz na aquisição de horizontes adequados"145 (VESSEY, 2009, p. 539).

Assim, Vessey (2009) afirma que se consideramos o que Gadamer compreende por horizontes, isto é, crenças que tornam possível a compreensão, podemos compreender o que ele quer dizer com fusão de horizontes. Horizontes se fundem quando um indivíduo percebe como o contexto pode ser considerado de modo diferente e levar a uma interpretação também ela diferente da interpretação inicial. Com isto, “a compreensão original é ultrapassada e integrada a uma compreensão mais ampla"146, "nossos horizontes são ampliados"147, "temos uma nova perspectiva sobre nossas visões antigas"148 e talvez, inclusive, novas visões: "este é o significado de 'fusão de horizontes"149 (VESSEY, 2009, p. 540).

Por essa razão Gadamer afirma que:

\begin{abstract}
A mobilidade histórica da existência humana se constitui precisamente no fato de não possuir uma vinculação absoluta a uma determinada posição, e nesse sentido jamais possui um horizonte verdadeiramente fechado. O horizonte é, antes, algo no qual trilhamos nosso caminho e que conosco faz o caminho. Os horizontes se deslocam ao passo de quem se move (GADAMER, 2015, p. 402).
\end{abstract}

Assim, podemos dizer que compreender não é algum tipo de experiência interna, cognitiva pertencente a um sujeito, mas uma projeção dinâmica, auto-reveladora do ser-nomundo, porque é "participação num sentido comum" (GADAMER, 2011f, p. 73), uma vez que "todo ser-aí [presença] compreende-se a partir de seu mundo circundante e de sua vida cotidiana, articulando-se na forma linguística em que se movimenta" (GADAMER, 2012a, p. 75).

Segundo Lafont (2005, p. 273), "essa é outra característica central da noção hermenêutica de mundo: o mundo é sempre compartilhado intersubjetivamente porque é linguisticamente articulado"150, ou seja, "é em virtude do compartilhamento de uma

\footnotetext{
${ }^{144}[\ldots]$ the fact that a sentence is intelligible is not a fact of the intentions of the speaker, but of the nature of language and of the subject matter of the sentence.

145 The key to a proper interpretation lies in acquiring the proper horizons.

146 [...] the original understanding is surpassed and integrated into a broader [...] understanding.

147 Our horizons are broadened [...]

148 [...] we have a new perspective on our old views [...]

149 This is the meaning of 'the fusion of horizons'.

${ }^{150}$ This is another central feature of the hermeneutic notion of world: the world is always intersubjectively shared because it is linguistically articulated.
} 
linguagem natural que a presença pode compartilhar o mesmo mundo com outros"151. Para Gadamer (2011c, p. 175) "no espelho da linguagem podiam se reconhecer as cosmovisões dos povos, conhecer detalhadamente a estrutura de sua cultura".

Segundo Gadamer (2015, p. 497), "a linguagem é o meio em que se realizam o acordo dos interlocutores e o entendimento sobre a coisa em questão". Assim, "o problema hermenêutico não é um problema de domínio correto da língua, mas de correto acordo sobre um assunto, que se dá no medium da linguagem" (GADAMER, 2015, p. 499): "todo compreender é interpretar, e todo interpretar se desenvolve no medium de uma linguagem que pretende deixar falar o objeto, sendo, ao mesmo tempo, a própria linguagem do intérprete" (GADAMER, 2015, p. 503). Com isso, "a linguagem constitui-se no modo fundamental de realização de nosso ser no mundo, a forma de constituição de mundo que tudo envolve" (GADAMER, 2011g, p. 255).

É preciso lembrar que, apesar de Gadamer falar constantemente na interpretação e compreensão de textos, o círculo hermenêutico é extensível a outros entes:

a interpretação não se limita aos textos e à compreensão histórica que neles se deve alcançar. Todas as estruturas de sentido concebidas como textos, desde a natureza (interpretatio naturae, Bacon), passando pela arte (cuja carência de conceitos [Kant] converte-se em exemplo preferencial de interpretação [Dilthey]), até as motivações conscientes ou inconscientes da ação humana, são suscetíveis de interpretação (GADAMER, 2011g, p. 506).

A explicação sobre a origem da palavra texto permite uma melhor compreensão da ideia de que todas as estruturas de sentido podem ser concebidas como textos:

Podemos encontrar nas origens da própria palavra 'texto' sustentáculo para estender seu significado de manuscritos e impressos para outras formas. Ela deriva, naturalmente, do latim texere, 'tecer', e, portanto, se refere não a qualquer material específico como tal, mas a seu estado tecido, ao tramar ou tecer dos materiais. De fato, ela não era restrita à tecelagem de têxteis, mas poderia ser aplicada igualmente bem ao entrelaçamento ou entremear de qualquer tipo de material. O Oxford Latin Dictionary sugere que ela é provavelmente cognato do védico 'tāșți', 'criar através de carpintaria', e consequentemente do grego $\tau \dot{\varepsilon} \kappa \tau \omega \nu$ e $\tau \dot{\varepsilon} \chi v \eta$.

A mudança de criação de um meio material para um sistema conceitual, da tecelagem de tecidos para a rede de palavras, também está implícita no grego ü $\varphi \circ \varsigma$

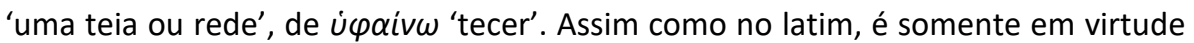
de uma mudança metafórica que ela se aplica à linguagem, que o verbo 'tecer' serve para o verbo 'escrever', que a teia de palavras se torna um texto. Em cada caso, portanto, o sentido primário é um que define um processo de construção material.

\footnotetext{
${ }^{151}$ It is by virtue of sharing a natural language that Dasein can share the same world with others.
} 
Ele cria um objeto, mas ele não é característico de nenhuma substância ou qualquer forma. A ideia de que textos são registros escritos em pergaminho ou papel deriva somente de um sentido secundário e metafórico de que a escrita de palavras é como a tecedura de fios $^{152}$ (McKENZIE, 1999, p. 13-14).

Ressalvamos que, enquanto a compreensão humana e o conhecimento humano surgem dentro de um contexto que inclui um contexto social, eles vão além deste, como pudemos ver nas críticas de Heidegger ao impessoal. Desse modo, associando à hermenêutica as teorias do significado de Jacob von Uexküll (1864-1944), é possível entender que, mesmo que seres humanos vivam em um mundo de significado compartilhado, eles criam mundos de significado individual a partir do mundo como um todo (UEXKÜLL, 2010), do mundo no qual foram originalmente lançados. Segundo Uexküll "um organismo incorpora implicitamente dentro de sua organização informação sobre aqueles aspectos de seu entorno que são especificamente relevantes, isto é, significativos, para sua autopreservação"153 (KOUTROUFINIS, 2016, p. 49), dando então origem a seu Umwelt ${ }^{154}$ :

Umwelt é o mundo semiótico de um organismo. Ele inclui todos os aspectos significativos do mundo para um organismo particular. Assim, Umwelt é um termo unindo todos os processos semióticos de um organismo em um todo. [...] Ao mesmo tempo, os Umwelts de diferentes organismos diferem, o que decorre da individualidade e singularidade da história de cada organismo individual ${ }^{155}$ (KULL, 1998, p. 304).

152 We can find in the origins of the word 'text' itself some support for extending its meaning from manuscripts and print to other forms. It derives, of course, from the Latin texere, 'to weave', and therefore refers, not to any specific material as such, but to its woven state, the web or texture of the materials. Indeed, it was not restricted to the weaving of textiles, but might be applied equally well to the interlacing or entwining of any kind of material. The Oxford Latin Dictionary suggests that it is probably cognate with the Vedic 'tāști', to

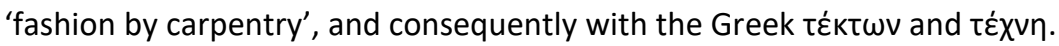

The shift from fashioning a material medium to a conceptual system, from the weaving of fabrics to the web of words, is also implicit in the Greek üфoৎ 'a web or net', from ú申aivw 'to weave'. As with the Latin, it is only by virtue of a metaphoric shift that it applies to language, that the verb 'to weave' serves for the verb 'to write', that the web of words becomes a text. In each case, therefore, the primary sense is one which defines a process of material construction. It creates an object, but it is not peculiar to any one substance or any one form. The idea that texts are written records on parchment or paper derives only from the secondary and metaphoric sense that the writing of words is like the weaving of threads.

153 [...] an organism implicitly incorporates within its organization information about those aspects of its surroundings that are specifically relevant, i.e. meaningful, to its self-preservation.

${ }^{154}$ A palavra Umwelt pode ser traduzida literalmente do alemão para o português como meio, ambiente ou meioambiente. Aqui não traduzimos o termo porque ele possui um significado teórico específico, conforme corpo do texto, sendo utilizado sem tradução na literatura em português quando é utilizado com este significado específico.

155 Umwelt is the semiotic world of [an] organism. It includes all the meaningful aspects of the world for a particular organism. Thus, Umwelt is a term uniting all the semiotic processes of an organism into a whole. [...] At the same time, the Umwelts of different organisms differ, which follows from the individuality and uniqueness of the history of every single organism. 
O Umwelt permite que um organismo guie seus movimentos, sendo composto pelo mundo-como-percebido e pelo mundo de ação do organismo (KOUTROUFINIS, 2016). Para Uexküll ${ }^{156}$ (apud KOUTROUFINIS, 2016, p. 50) "o poder do sujeito [...] que exerce essa atividade aperceptiva está incessantemente criando novas estruturas; em sua própria natureza, é uma força formativa" ${ }^{157}$.

Face ao exposto, entendemos que é o ser humano como presença, como ser-nomundo, como ser-com em seu estar-lançado e em seu Umwelt quem apresenta um comportamento informacional. Concluímos que em sua condição lançada, com a compreensão como seu modo fundante, o ser humano se relaciona com a informação, seja essa relação passiva ou ativa.

Em nossa revisão da literatura de Heidegger e Gadamer, assim como das obras que discutem sua filosofia, o conceito de informação não aparece, contudo, a partir do modo como esse conceito é entendido em uma perspectiva hermenêutica na Ciência da Informação, procuraremos demonstrar de que maneira o estar-lançado pode ser visto como a motivação para que a informação seja buscada e utilizada.

\subsection{Informação e documento}

Informação é um termo polissêmico, que teve significados variados ao longo do tempo e de acordo com a área que dele fez e faz uso, como demonstrado por diversos autores, tais como Adriaans (2018), Bates (2006), Capurro (1978, 2008), Capurro e Hjørland (2003), Duguid (2015), Machlup e Mansfield [1983], Nunberg (1996), Ørom (2007) e Peters (1988).

No contexto deste trabalho, o conceito de informação que melhor se aplica é aquele elaborado por Buckland (1991). O autor procurou refletir sobre o significado de informação de um modo que ele considera pragmático: identificando os principais usos da palavra. Ele concluiu que são três os principais usos da palavra informação: informação entendida como conhecimento, informação entendida como processo e informação entendida como "coisa":

(1) Informação-como-processo: Quando alguém é informado, o que ele conhece é mudado. Neste sentido 'informação' é 'O ato de informar...; comunicação do

\footnotetext{
156 UEXKÜLL, Jacob von. (1926). Theoretical Biology. New York: Harcourt, Brace \& Company, Inc.

157 [...] the power of the subject [...] that exercises this apperceptive activity is forever creating new structures; in its very nature, it is a formative force [...].
} 
conhecimento ou 'notícias' sobre algum fato ou ocorrência; a ação de contar algo ou fato de algo Ihe ter sido contado' (Oxford English Dictionary, 1989, vol. 7, p. 944) ${ }^{158}$.

(2) Informação-como-conhecimento: 'Informação' também é utilizada para denotar aquilo que é percebido em 'informação-como-processo': o 'conhecimento comunicado referente a algum fato, sujeito ou evento particular; aquilo do que alguém é notificado ou aquilo que é contado; fatos, notícias' (Oxford English Dictionary, 1989, vol. 7, p. 944) ${ }^{158}$. A noção de informação como aquilo que reduz incerteza pode ser vista como um caso especial de 'informação-comoconhecimento'. Às vezes informação aumenta a incerteza.

(3) Informação-como-coisa: O termo 'informação' também é utilizado atributivamente para objetos, tais como dados e documentos, que são referidos como 'informação' porque são considerados como sendo informativos, como 'tendo a qualidade de transmitir conhecimento ou comunicar informação; instrutivo' (Oxford English Dictionary, 1989, vol. 7, p. 946) ${ }^{158,159}$ (BUCKLAND, 1991, p. 351, grifos do autor).

Em síntese, informação-como-processo é o processo de se tornar informado, informação-como-conhecimento significa conhecimento comunicado e informação-comocoisa denota "bits, bytes, livros e outras mídias físicas" 160 , incluindo "qualquer coisa material ou ação física percebida como significativa"161 (BUCKLAND, 2017, p. 22).

Buckland compara a informação-como-coisa à evidência no contexto da Ciência da Informação, considerando que:

É razoável considerar a informação-como-coisa como evidência, sem implicar que aquilo que é lido, considerado, ouvido ou de outra maneira percebido ou observado era necessariamente acurado, útil ou até mesmo pertinente aos propósitos do usuário. Tampouco se precisa supor que o usuário acreditou ou deveria acreditar ou concordar com o que foi percebido, 'Evidência' é um termo apropriado porque denota algo relacionado à compreensão, algo que, se encontrado e corretamente

158 OXFORD English Dictionary. (1989). 2. ed. Oxford: Clarendon Press.

159 (1) Information-as-process: When someone is informed, what they know is changed. In this sense "information" is "The act of informing...; communication of the knowledge or 'news' of some fact or occurrence; the action of telling or fact of being told of something" (Oxford English Dictionary, 1989, vol. 7, p. 944).

(2) Information-as-knowledge: "Information" is also used to denote that which is perceived in "informationas-process:" the "knowledge communicated concerning some particular fact, subject, or event; that of which one is apprised or told; intelligence, news" (Oxford English Dictionary, 1989, vol. 7, p. 944). The notion of information as that which reduces uncertainty could be viewed as a special case of "information-asknowledge." Sometimes information increases uncertainty.

(3) Information-as-thing: The term "information" is also used attributively for objects, such as data and documents, that are referred to as "information" because they are regarded as being informative, as "having the quality of imparting knowledge or communicating information; instructive." (Oxford English Dictionary, 1989, vol. 7, p. 946).

160 [...] bits, bytes, books, and other physical media.

$161[\ldots]$ any material thing or physical action perceived as signifying. 
compreendido, poderia mudar o conhecimento, as crenças de alguém sobre alguma questão $^{162}$ (BUCKLAND, 1991, p. 353, grifo do autor).

O conceito de evidência não deve ser entendido em nenhum sentido estritamente teórico, seja ele científico, filosófico ou jurídico. Aqui utilizamos a palavra em sentido amplo deliberadamente. Assim, aqui evidência significa "aquilo que indica a existência de (algo); indicação, indício" e não "qualidade ou caráter do que é evidente, do que não dá margem à dúvida" (HOUAISS; VILLAR, 2009, p. 851). Segundo Kelly (2016, online, grifo do autor), "a noção básica de evidência é aquela de algo que serve como um sinal, sintoma ou marca confiável daquilo que ela é evidência $d e^{\prime 163}$ e é esta que utilizamos.

$\mathrm{Na}$ literatura da Ciência da Informação é possível encontrar discussões sobre o conceito de evidência. Para Anderson (2013, p. 353), "evidência é intimamente ligada a crenças profundas-religião, conhecimento do ser e percepções da realidade. Evidência é consequentemente uma questão metafísica"164. Schum (1994, p. 1) afirma que "usamos o termo evidência com referência a fenômenos observáveis sobre os quais baseamos inferências sobre questões de interesse e importância para nós"165 e Yeo nos diz que

Evidência pode ser empregada para apoiar a ação ou tomada de decisão assim como para provar ou refutar alegações e hipóteses. Ela pode ser usada para se chegar a novas conclusões ou corroborar uma proposição existente. Ela pode ser um meio de verificar se uma proposição é verdadeira, justificar que uma crença é verdadeira, explicar porque ela é verdadeira, persuadir uma audiência de sua verdade ${ }^{166}$ (YEO, 2007, p. 322).

\footnotetext{
$162[\ldots]$ it is reasonable to view information-as-thing as evidence, though without implying that what was read, viewed, listened to, or otherwise perceived or observed was necessarily accurate, useful, or even pertinent to the user's purposes. Nor need it be assumed that the user did (or should) believe or agree with what was perceived, "Evidence" is an appropriate term because it denotes something related to understanding, something which, if found and correctly understood, could change one's knowledge, one's beliefs, concerning some matter.

$163[\ldots]$ the root notion of evidence is that of something which serves as a reliable sign, symptom, or mark of that which it is evidence of.

164 [...] evidence is closely tied to deeply held beliefs - religion, knowledge of being, and perceptions of reality. Evidence is consequently a metaphysical subject.

165 [...] use the term evidence with reference to observable phenomena upon which we base inferences about matters of interest and importance to us.

166 [...] Evidence can be employed to support action or decision making as well as to prove or refute claims and hypotheses. It can be used to draw new conclusions or corroborate an existing proposition. It can be a means of ascertaining whether a proposition is true, justifying a belief that it is true, explaining why it is true, or persuading an audience of its truth.
} 
Em sua análise do conceito de evidência, Kelly (2016, online) afirma que de evidências se obtém informação e que "de modo geral, a dimensão na qual alguém está em posição de ganhar nova informação com base em evidências específicas depende tipicamente de seu conhecimento prévio"167. Aqui nos deparamos com o conceito fundamental da Ciência da Informação: informação.

Entendendo informação-como-coisa como evidência, isto é, "em termos do potencial para o processo de informar"168, Buckland (1991, p. 356) afirma que a informação-como-coisa inclui dados, documentos, objetos e eventos, o que implica a adoção de um conceito de informação-como-coisa mais amplo do que aquele que é comum. Para ele, se a informaçãocomo-coisa é qualquer coisa, qualquer ente com o potencial de informar, não há porque restringir a informação-como-coisa àquilo que comumente é entendido como tal, isto é, dados e documentos, ou seja, aquilo que foi propositalmente criado com o objetivo de informar.

Para Buckland (1991), a ampliação do conceito de informação-como-coisa se faz necessária porque, quando se considera somente dados e documentos como informaçãocomo-coisa, outras coisas potencialmente informativas, tais como fósseis, pegadas e até mesmo gritos de terror, ficam sem um nome. Além disso, fica em aberto a questão de qual nível de processamento ou agregação leva a que dados sejam considerados informação.

Assim como quando analisa o conceito de informação de modo pragmático, Buckland (1991, p. 356) entende que se todas as coisas são iguais, neste caso se todas as coisas são potencialmente informativas, "uma solução mais simples deve ser preferida a uma mais complicada"169. Desse modo, ele considera informação-como-coisa qualquer coisa, qualquer ente informativo.

Em sua exploração do conceito de evidência em relação ao conceito de informação, Buckland chama atenção para o fato de que:

\footnotetext{
O termo 'evidência' sugere passividade. Evidência [...] não faz nada ativamente. Seres humanos fazem algo com ela ou não. Eles a examinam, a descrevem e a categorizam. Eles a compreendem, a compreendem mal, a interpretam, a sumarizam ou a refutam. Eles podem até mesmo tentar falsificá-la, alterá-la, escondê-la ou destruí-la. A essência da evidência é precisamente que a percepção dela pode levar
}

\footnotetext{
167 In general, the extent to which one is in a position to gain new information on the basis of particular pieces of evidence typically depends upon one's background knowledge.

$168[\ldots]$ in terms of the potential for the process of informing [...].

169 [...] a simpler solution is to be preferred to a more complicated one.
} 
a mudanças naquilo que as pessoas acreditam que sabem ${ }^{170}$ (BUCKLAND, 1991, p. 353).

Nesse sentido, a informação-como-coisa, o ente informativo, tem como característica essencial o fato de que alguém Ihe atribuiu o caráter informativo. É preciso esclarecer, no entanto, que essa atribuição não é uma atividade de caráter exclusivamente cognitivo, pois qualquer coisa manifesta no mundo é sempre socialmente mediada, já que existe em um mundo de significação compartilhada.

Entendemos que é a informação-como-coisa aquela com a qual a Ciência da Informação tradicionalmente trabalha, uma vez que seu núcleo de interesse são "as propriedades, os comportamentos, os fluxos, o processamento e a acessibilidade da informação registrada através de qualquer linguagem e em qualquer tipo de suporte" (GOMES, 2001, online, grifo nosso), informação registrada sendo aqui entendida como qualquer coisa considerada informativa, como propõe Smit (2012).

Ressalvamos que a caracterização "registrada" não é a mais adequada se estamos falando de qualquer ente considerado informativo, uma vez que o verbo registrar é usado comumente na contemporaneidade com o significado de "assinalar por escrito, fazer o registro de" (HOUAISS; VILLAR, 2009, p. 1635), ou seja, a expressão "informação registrada" leva a crer que estamos nos limitando àquilo que foi propositalmente criado com o objetivo de informar.

A informação-como-coisa pode ou não ser produzida socialmente. Quando ela foi produzida socialmente, ela é adquirida através de comunicação interpessoal, seja face a face ou indiretamente através de seu registro. A informação-como-coisa que não foi produzida socialmente é qualquer coisa manifesta no mundo que seja identificada por alguém como apresentando um significado. Animais, matéria inorgânica, fenômenos naturais, entre outros, podem ser vistos como este tipo de informação-como-coisa, pois, mesmo que em si não sejam uma produção social, eles adquirem significados dentro de contextos sociais de significação compartilhada.

\footnotetext{
170 [...] the term 'evidence' implies passiveness. Evidence [...] does not do anything actively. Human beings do things with it or to it. They examine it, describe it, and categorize it. They understand, misunderstand, interpret, summarize, or rebut it. They may even try to fake it, alter it, hide it, or destroy it. The essence of evidence is precisely that perception of it can lead to changes in what people believe that they know.
} 
A informação-como-coisa também pode ser tanto materialmente efêmera como materialmente duradoura. Ou seja, a informação-como-coisa obtida através de interações face a face é material, já que o som é "uma vibração em um meio elástico a uma frequência e intensidade que é capaz de ser ouvida pela orelha humana"171 (SOUND, 2015, online), mas sua permanência é efêmera. Entretanto, uma vez que uma interação face a face, por exemplo, seja gravada em áudio, ela se torna materialmente duradoura. O mesmo ocorre com a informação-como-coisa que não foi produzida socialmente. Por exemplo, o trovão pode ser informação-como-coisa em determinadas situações e é material, já que é um som, mas sua permanência é efêmera. Por outro lado, uma pedra é um exemplo de algo que tem o potencial de ser informação-como-coisa não produzida socialmente e que é materialmente duradoura.

Enquanto a informação-como-coisa que não é produzida socialmente pode ser compreendida por alguém por conta própria, ainda que essa compreensão seja socialmente mediada, pois esse alguém se encontra inserido em um mundo de significação compartilhada, a informação-como-coisa produzida socialmente é necessariamente obtida através de comunicação interpessoal:

Desde os primórdios da raça humana, a comunicação interpessoal foi uma ocorrência entre membros de uma família em uma mesma habitação ou quando duas ou mais pessoas se encontravam em alguma área pública - ou, conforme a sociedade evoluiu, em reuniões municipais ou em um comitê ou em um parlamento ou onde quer que fosse ${ }^{172}$ (HAVELOCK, 1986, p. 63).

Segundo Smit (2012, p. 85), "a informação não registrada em algum tipo de suporte, tecnologia ou código, por mais importante que seja, não é passível de uma socialização mais ampla, uma vez que seu acesso é condicionado pelas variáveis espaciais e temporais". Assim, a informação-como-coisa produzida socialmente e que é registrada ampliaria a comunicação interpessoal, permitindo que ela fosse independente de seu enunciador.

Como discutido anteriormente, o verbo registrar é usado comumente na contemporaneidade com o significado de "assinalar por escrito, fazer o registro de"; no entanto, ele apresenta outro significado menos comum, qual seja, "colocar na memória, na

\footnotetext{
171 [...] a vibration in an elastic medium at a frequency and intensity that is capable of being heard by the human ear.

172 From the beginnings of the human race, interpersonal communication was an occurrence between members of a family in the same dwelling, or as two or more people met each other in some public area - or, as society evolved, in town meetings or in a committee or in parliament or whatever.
} 
lembrança; memorizar" (HOUAISS; VILLAR, 2009, p. 1635). Isto traz consequências para como vemos e entendemos a informação, sua disseminação e sua permanência.

Segundo Havelock,

O que se percebe em seguida é que as terminologias de 'informação' e 'armazenamento'-e também 'reuso' [...]-insensivelmente sugerem que aquilo que é armazenado e reutilizado é algo material: sua linguagem deve então também ser de algum modo material. Isto pode acontecer quando algo é escrito, quando algo se torna documentado. A mesma suposição está por trás das palavras 'código', 'codificação' e impressão usadas para descrever o tipo de informação que a cultura segue (isto é, usos e reusos), como por exemplo uma 'codificação jurídica'173 (HAVELOCK, 1986, p. 56).

Apesar de o uso que Havelock faz da palavra material diferir do nosso próprio uso da palavra - entendemos que ele utiliza a palavra com o significado de algo permanente que é fisicamente externo ao corpo humano -, sua crítica é, no entanto, relevante para nossa discussão. A análise de Havelock é importante para nosso entendimento do conceito de informação produzida socialmente, já que essa análise amplia o que se entende por registro e armazenamento.

Havelock é um dentre um grupo de acadêmicos que dedicou sua pesquisa a questões relacionadas à produção, circulação e uso da informação antes da invenção da escrita. Goody, outro acadêmico dedicado a essa área, afirma que "como todas as culturas, culturas orais dependem de conhecimento armazenado"174 (GOODY, 2000, p. 43). Havelock concorda com Goody:

\begin{abstract}
Uma vez que a necessidade de preservar a identidade cultural através de armazenamento linguístico, por um lado, e a natureza oral das primeiras culturas por outro, são trazidas em conjunção e vistas juntamente, surge a questão: Como então pode a oralidade armazenar sua informação para reuso? Como ela pode preservar sua identidade? Já que ela pode sustentar a cultura sem o benefício da escrita, quais são os mecanismos que fornecem a função material que a escrita fornece mais tarde, nomeadamente a provisão de informação linguística que pode sobreviver [?] ${ }^{175}$ (HAVELOCK, 1986, p. 56).
\end{abstract}

\footnotetext{
${ }^{173}$ What one next realizes is that the terminologies of "information" and "storage" -and also "re-use" [...]insensibly imply that what is stored and re-used is something material: its language must then somehow be material also. This can come about when it is written, when it becomes documented. The same presumption lies behind the words "code" and "codification" and "encoding" and imprinting used to describe the kind of information that a culture follows (i.e. uses and re-uses), as for example a "law code."

174 Like all cultures, oral ones depend on stored knowledge [...].

175 Once the necessity to preserve cultural identity through linguistic storage, on the one hand, and the oral character of early cultures on the other, are brought into conjunction and viewed together, the question arises: How then, can orality store its information for re-use? How can it preserve its identity? Since it can support a
} 
Goody explica que:

A comunicação em culturas orais ocorre esmagadoramente em situações face a face. Basicamente a informação é armazenada na memória, na mente. Sem a escrita não há virtualmente armazenamento da informação fora do cérebro humano e consequentemente não há comunicação através de grandes distâncias e longos períodos de tempo ${ }^{176}$ (GOODY, 2000, p. 27).

Para Goody (2000, p. 27) "essas sociedades são grandemente dependentes da memória interna para a transmissão da cultura, para a passagem de conhecimento e costumes de uma geração para a próxima"177. Havelock segue a mesma ideia declarando que antes da invenção da escrita "o que primeiramente falavam era provavelmente uma linguagem formada acusticamente para o armazenamento, uma linguagem de comunicação preservada, um corpo de informação oral "útil'"178 (HAVELOCK, 1986, p. 61). Se a "alfabetização nos forneceu uma memória artificial no documento preservado"179, "originalmente tínhamos de moldar nossa memória nós mesmos a partir da língua falada" ${ }^{180}$ (HAVELOCK, 1986, p. 71). 0 que acontece é que "a informação armazenada em sistemas mnemônicos é raramente literal, palavra por palavra; em vez disso esses sistemas apresentam aos indivíduos um objeto ou grafema para que eles se lembrem de um evento ou declamação, que esses indivíduos então elaboram"181 (GOODY, 2000, p. 30).

Os modos como as culturas orais registram, armazenam, organizam e recuperam a informação-como-coisa produzida socialmente é fundamentalmente diferente dos modos como as culturas escritas o fazem. Quando afirmamos na contemporaneidade que a informação-como-coisa produzida socialmente e que está registrada em um objeto físico externo ao corpo humano permite a ampliação da comunicação interpessoal, estamos pensando fundamentalmente na comunicação autoral, isto é, na comunicação da informação-

culture without benefit of writing, what are the mechanisms that supply the material function that writing later supplies, namely the provision of linguistic information which can survive [?].

${ }^{176}$ Communication in oral cultures takes place overwhelmingly in face-to-face situations. Basically information is stored in the memory, in the mind. Without writing there is virtually no storage of information outside the human brain and hence no communication over great distances and long periods of time.

177 [...] such societies are largely dependent on internal memory for transmitting culture, for the handing down of knowledge and customs from one generation to the next.

178 What they first speak is likely to be a language shaped acoustically for storage, a language of preserved communication, a body of "useful" oral information.

179 Literacy has supplied us with an artificial memory in the preserved document.

${ }^{180}$ We originally had to fashion our memory for ourselves out of the spoken tongue.

${ }^{181}$ The information stored in mnemonic systems is rarely verbatim, word for word; instead such systems present you with an object or a grapheme to remind you of an event or a recitation, which you then elaborate. 
como-coisa produzida socialmente por um indivíduo específico que é considerado o autor ou criador dessa informação. A ideia de que alguém específico é o autor ou criador de uma mensagem, de que uma mensagem pertence a alguém, é uma ideia originada com o desenvolvimento da escrita e, principalmente, da imprensa, assim como das alterações subsequentes que elas trouxeram à sociedade, como pode ser verificado em Ong (2002). Isto é, a informação-como-coisa produzida socialmente e que não está registrada em um objeto físico externo ao corpo humano é passível de comunicação através do espaço e do tempo, contudo, essa informação não é comunicada literalmente, exatamente como na primeira vez em que foi comunicada. Existe a possibilidade de registro, armazenamento, organização e recuperação da informação-como-coisa produzida socialmente e que não está registrada em um objeto físico externo ao corpo humano, ou seja, é possível registrar, armazenar, organizar e recuperar algo socialmente produzido que é dotado de significação e que tem potencial enquanto evidência. O que não existe é a possibilidade de que algo socialmente produzido que é dotado de significação e que tem potencial enquanto evidência seja registrado, armazenado, organizado e recuperado em sua forma primeira. A relevância da permanência de uma mensagem na sua literalidade é resultante da valoração do conceito de autor.

O registro, armazenamento, organização e recuperação da informação-como-coisa produzida socialmente são questões relacionadas à memória e à lembrança e podem tomar diferentes formas. É somente com o passar do tempo que registrar passou a significar fixar algo em alguma forma permanente, e é do mesmo modo que a informação-como-coisa produzida socialmente fixada em alguma forma permanente ganhou um status superior ao da informação-como-coisa produzida socialmente de permanência efêmera. $O$ arquétipo da informação-como-coisa produzida socialmente e que está registrada é o registro escrito, e sua mera aparição não Ihe garantiu status superior como informação. Segundo Clanchy (2013, p. 2), a "confiança no registro escrito não foi nem imediata nem automática. Confiança na escrita e a compreensão do que ela poderia - e não poderia - alcançar se desenvolveram da crescente familiaridade com documentos"182. A ideia é extensível a qualquer outro tipo de registro de informação-como-coisa produzida socialmente.

Chamamos a atenção para o fato de que as formas de registro e armazenamento da informação-como-coisa produzida socialmente mudaram ao longo do tempo, e para o fato de

\footnotetext{
182 [...] confidence in written record was neither immediate nor automatic. Trust in writing and understanding of what it could - and could not - achieve developed from growing familiarity with documents.
} 
que formas de registro que hoje não têm sua validade questionada um dia não foram consideradas de confiança, porque esses fatos mostram que aquilo que consideramos informativo e aquilo que consideramos válido em seu poder informativo têm como referência um contexto. Desse modo, não é apenas aquilo que foi propositalmente criado com o objetivo de informar que é informação-como-coisa, que é um ente informativo. Portanto, se considerarmos informação registrada como aquela que diz respeito à Ciência da Informação, é preciso entender que a informação registrada é mais do que apenas a informação-comocoisa produzida socialmente e que é permanente, pois não é só aquilo que foi propositalmente criado com o objetivo de informar que tem esse potencial. Assim, no contexto da Ciência da Informação, informação registrada, mais do que ser algo considerado digno de ser assinalado por escrito - escrito sendo aqui entendido de forma ampla, como inscrever ou gravar - é algo considerado digno de ser colocado na memória, de ser lembrado, ou seja, de ser preservado.

Buckland (2017, p. 22, grifo do autor) afirma que a informação-como-coisa é "sinônimo de uma visão ampla de documento" ${ }^{183}$. Esta comparação pode ser entendida no contexto da Neo-Documentação, um movimento iniciado na década de 1990 e que busca a retomada das ideias da Documentação, disciplina que se encontra nas raízes da Ciência da Informação.

O documento é o objeto da Documentação. Em sua acepção comum, documento é uma "declaração escrita que se reconhece oficialmente como prova de um estado, condição, habilitação, fato ou acontecimento"; é um "texto ou qualquer objeto que se colige como prova de autenticidade de um fato e que constitui elemento de informação" (HOUAISS; VILLAR, 2009, p. 705).

O termo documento, assim como o termo informação, teve significados variados ao longo do tempo e de acordo com a área que dele fez ou faz uso, como pode ser verificado, por exemplo, nos trabalhos de Gorichanaz (2016), Grenersen, Kemi e Nilsen (2016), López Yepes (1997), Lund (2009, 2010), Lund e Skare (2017), Mijailov, Chernii e Guiliarevskii (1973) e Rabello (2009, 2011). No âmbito da Ciência da Informação e das disciplinas onde ela tem suas raízes, tais como a Documentação e a Informática ${ }^{184}$, são também encontradas diversas definições do conceito de documento. A seguir, apresentamos algumas dessas definições.

\footnotetext{
183 [...] synonym for a broad view of document.

${ }^{184}$ Disciplina desenvolvida primordialmente na União Soviética, mas também em outros países comunistas, com o objetivo de pesquisar os processos de produção, circulação e consumo da informação.
} 
Em seu Tratado de documentação, Paul Otlet (1868-1944) define o documento da seguinte maneira:

1. Livro (bíblion, documento ou grama) é o termo convencional aqui empregado para designar toda espécie de documento. Abrange não apenas o livro propriamente dito, manuscrito ou impresso, mas também revistas, jornais, textos escritos e reproduções gráficas de qualquer espécie, desenhos, gravuras, mapas, esquemas, diagramas, fotografias, etc. A documentação no sentido lato do termo abrange o livro, isto é, meios que servem para representar ou reproduzir determinado pensamento, independentemente da forma como se apresente.

2. O livro assim entendido apresenta um duplo aspecto: a) é, primordialmente, uma obra feita pelo homem, o resultado de seu trabalho intelectual; b) mas, multiplicado em inúmeros exemplares, apresenta-se também como um dos inúmeros objetos criados pela civilização e capazes de sobre ela produzir efeito; isso é próprio de todo objeto que possua caráter corporal e que se organiza tecnicamente (OTLET, $2018^{185}$, p. 11).

Robert Pagès ${ }^{186}$ (1919-2007) assim define o documento:

UM DOCUMENTO É UM SÍMBOLO OU GRUPO DE SÍMBOLOS QUE É NATURAL OU ARTIFICIALMENTE CAPAZ DE DURAR ALÉM DO MOMENTO DE SUA EMISSÃO (OS graus dessa duração são muito variáveis: de alguns minutos a milênios) e, portanto, serve como um instrumento para a acumulação de atividade simbólica ${ }^{187}$ (PAGÈS, 1948 , p. 55, grifo do autor).

Briet $\left(2016^{188}\right.$, p. 1) define o documento como "todo indício, concreto ou simbólico, conservado ou registrado, com a finalidade de representar, reconstituir ou provar um fenômeno físico ou intelectual".

No contexto da Informática, o documento era definido como "o principal instrumento para sua [a informação científica] transmissão no espaço e no tempo"189 (MIJAILOV; CHERNII; GUILIAREVSKII, $1973^{190}$, p. 79), sendo que

\footnotetext{
185 Originalmente publicado em 1934.

${ }^{186}$ Cientista e psicólogo social que estudou no programa de educação professional em Documentação criado por Suzanne Briet e outros no Conservatório Nacional de Artes e Ofícios na França.

187 UN DOCUMENT, C'EST UN SYMBOLE OU UN GROUPEMENT DE SYMBOLES NATURELLEMENT OU ARTIFICIELLEMENT CAPABLE DE DURER AU DELA DU MOMENT DE SON EMISSION (les degrés de cette durée sont très variables: de quelques minutes à des millénaires) et servant ainsi d'instrument d'accumulation pour l'activité symbolique.

188 Originalmente publicado em 1951.

189 [...] el principal instrumento para su transmisión en el espacio y en el tiempo.

190 Originalmente publicado em 1968.
} 
Em sua acepção mais ampla, este termo convém não só às inscrições, manuscritos e edições impressas, mas também às obras de arte, moedas antigas e peças de museu de carácter antropológico, zoológico, botânico ou mineral. Se reconhece como documento qualquer objeto material que registre ou fixe algum conhecimento e possa ser incluído em uma recopilação ${ }^{191}$ (MIJAILOV; CHERNII; GUILIAREVSKII, 1973, p. 79).

Para Meyriat (2016 192 , p. 241) "o documento pode ser definido como um objeto que suporta a informação, que serve para comunicar e que é durável (a comunicação pode, assim, ser repetida)".

Lund (2010, p. 743) define documento como "quaisquer resultados dos esforços humanos de contar, instruir, demonstrar, ensinar ou produzir uma peça, em resumo, documentar pelo uso de alguns meios de alguns modos"193.

Para López Yepes:

O documento é a mensagem documentária que se transmite transformada a partir de uma mensagem produzida com anterioridade para o domínio do usuário para satisfazer uma necessidade de informação. A mensagem no documento se transmite no espaço e no tempo convertida em fonte de informação para obter outra informação. Ou, de outro modo, o documento é a objetivação de uma mensagem em um suporte físico potencialmente transmissível no espaço e no tempo e atualizado como fonte para a obtenção de uma nova mensagem 194 (LÓPEZ YEPES, 2015, p. 164).

Os conceitos expostos fazem parte de concepções de caráter prático e teórico amplas, as quais não são aqui detalhadas; contudo, dessas definições é possível verificar que há fundamentação para o entendimento de Buckland (2017) de que a informação-como-coisa é sinônimo de documento. Todos de alguma maneira consideram que documento é algo que permite que sejam feitas inferências. Eles não são necessariamente algo que foi propositalmente criado com o objetivo de informar; a muitos lhes foi atribuído o potencial de comunicar algo. Esta ideia é sintetizada por Meyriat da seguinte maneira:

191 En su acepción más amplia, este término conviene no sólo a las inscripciones, manuscritos y ediciones impresas, sino también a las obras de arte, monedas antiguas y piezas de museo de carácter antropológico, zoológico, botánico o mineral. Se reconoce como documento cualquier objeto material que registre o fije algún conocimiento y pueda ser incluido en una recopilación.

192 Originalmente publicado em 1981.

193 [...] any results of human efforts to tell, instruct, demonstrate, teach or produce a play, in short to document, by using some means in some ways.

194 El documento es el mensaje documentario que se transmite transformado a partir de un mensaje producido con anterioridad hacia el dominio del usuario para colmar una necesidad de información. O, de otro modo, el documento es la objetivación de un mensaje en un soporte físico potencialmente transmisible en el espacio y en el tiempo y actualizado como fuente para la obtención de un nuevo mensaje. 
os escritos estão longe de serem os únicos objetos cuja função é transmitir uma informação. É o caso, por exemplo, daqueles que são reunidos em um museu. Os esqueletos do Museu de História Natural conservam e dão informações sobre a fauna do Quaternário; os trajes camponeses do Museu de Artes e Tradições Populares, sobre os modos de vida e costumes da França rural do século XVII, mas também sobre as técnicas de tecelagem, sobre o clima de várias regiões naquela época... Não é sequer necessário que os objetos tenham sido reunidos com o fim de informar: o arqueólogo utiliza como documento os objetos que ele descobre em seu lugar de pesquisa, porque estes lhe fornecem informações sobre os grupos humanos que os fabricaram ou utilizaram (MEYRIAT, 2016, p. 241).

Para Buckland (2018) documento é um termo genérico utilizado não apenas para livros, artigos e cartas, publicados ou não, mas também para música, imagens e registros sonoros, ou seja, documento não designa apenas textos, podendo incluir objetos de museu, animais em um zoológico e até mesmo paisagens. Segundo ele, documentos têm

enorme e crescente significado social porque influenciam o que sabemos e como sentimos. Documentos são utilizados para nos persuadir do que comprar e de como viver. Professores os utilizam para nos educar. Religiões e políticos usam documentos para nos persuadir. Artistas e profissionais do entretenimento usam documentos para nos provocar e nos divertir. Governos os utilizam para nos controlar. A economia moderna depende da documentação de suas transações. Nossa habilidade de usar documentos efetivamente dá forma ao nosso mundo ${ }^{195}$ (BUCKLAND, 2011, p. 19).

Nesse sentido, Buckland (2018) afirma que houve um aumento dramático tanto no número de documentos existentes como na dependência deles por parte da humanidade. Por esta razão ele entende que é incorreto falar de uma "sociedade da informação" - se a estivermos considerando como informação-como-conhecimento -, uma vez que todas as sociedades, mesmo os caçadores e coletores pré-históricos, dependem do compartilhamento de informação. Assim, "é o papel e o número sempre crescentes de documentos que é novo e significante"196 (BUCKLAND, 2018, p. 426). Esta constatação permite que se entenda porque houve um movimento de retomada das ideias da Documentação no contexto da Ciência da Informação. A isto se agrega a emergência do paradigma hermenêutico da disciplina, que é crítico das visões física e cognitiva e que, segundo Capurro (2007), já existia nos primórdios da

\footnotetext{
195 [...] enormous and increasing social significance because they influence what we know and how we feel. Documents are used to persuade us what to buy and how to live. Teachers use them to educate us. Religions and politicians use documents to persuade us. Artists and entertainers use documents to provoke and to amuse us. Governments use them to control us. The modern economy depends on documenting transactions. Our ability to use documents effectively shapes our world.

${ }^{196}$ It is the ever-increasing role and number of documents that is new and significant.
} 
Ciência da Informação, não como paradigma dela própria, mas de suas predecessoras, a Biblioteconomia e a Documentação.

Buckland (2018, p. 432) afirma que "a teoria do documento difere da teorização da informação porque o uso da palavra 'informação' foi ampliado por alguns teóricos para incluir formas físicas, formação e padrões que não têm relação direta com a atividade cognitiva, com seres humanos se tornarem informados" ${ }^{\prime 197}$. Buckland não está com isto assumindo uma posição cognitivista, pois para ele a teoria do documento se preocupa com contextos materiais, históricos e culturais. Buckland está chamando atenção para o papel do indivíduo, que é por ele entendido contextualmente, em relação aos documentos:

O significado de um documento-o que é percebido como significante-torna um documento importante, mas o que ele significa é influenciado e ampliado por relações com outros documentos e com pessoas. Qualquer interação ou qualquer atributo compartilhado pode ser usado para indicar uma relação, portanto, o escopo para o estabelecimento de relações é, na realidade, ilimitado ${ }^{198}$ (BUCKLAND, 2018, p. 429).

Assim como o fez com o conceito de informação-como-coisa, Buckland compara o conceito de documento ao conceito de evidência:

\begin{abstract}
Um objeto é considerado um documento quando há uma afirmação ou uma percepção de evidência para alguma crença. O efeito de um documento, portanto, depende de uma crença a respeito de algum aspecto da realidade. Certamente, qualquer afirmação ou crença pode ser considerada por outros (ou pela mesma pessoa em outro momento) como errada, desatualizada, incompleta e/ou uma deturpação. Contudo, para funcionar como um documento, requer-se um ato de percepção (leitura, visualização ou qualquer outro tipo de deteç̧ão), de modo que um apreensor é necessariamente um criador $^{199}$ (BUCKLAND, 2018, p. 427).
\end{abstract}

Segundo Buckland, hoje se apresentam três visões sobre o conceito de documento:

197 [...] document theory differs from theorizing information in that use of the word "information" has been extended by some theorists to include physical forms, forming, and patterns that have no direct relationship with cognitive activity, with humans becoming informed.

198 The meaning of a document-what it is perceived as signifying-makes a document important, but what it signifies is influenced and extended by relationships with other documents and with people. Any interaction or any shared attribute can be used to indicate a relationship, so the scope for establishing relationships is, in effect, unlimited [...].

${ }^{199}$ An object is considered to be a document when there is an assertion or a perception of evidence for some belief. The effect of a document, then, depends on belief concerning some aspect of reality. Of course, any assertion or belief may be deemed by others (or by the same person at another time) to be erroneous, out-ofdate, incomplete, and/or a misrepresentation. However, to function as a document requires an act of perception (reading, viewing, or otherwise sensing), so a perceiver is as necessary as a creator. 
1. uma visão convencional, material. A visão cotidiana, convencional dos documentos é de registros gráficos, geralmente texto, escrito em uma superfície plana (papel, tábua de argila, microfilme, arquivos de processador de texto, etc.) que são materiais, locais e, geralmente, transportáveis. Esses objetos são criados como documentos. Os limites de inclusão não são claros.

2. uma visão instrumental. Quase qualquer coisa pode ser feita para servir como um documento, para significar algo, para ser considerada como constituindo evidência de algum tipo. Coleções de história natural e traços arqueológicos podem ser incluídos nesta visão. Antes da adoção de uniformes militares, era difícil para um soldado em batalha saber quem era um amigo e quem era um inimigo. Em uma batalha no século VI entre galeses e saxões, travada em um campo de alho-poró, São David instruiu os galeses a indicarem sua identidade uns aos outros adornando-se com um alho-poró. $\mathrm{O}$ alho-poró documentou a identidade galesa àqueles que entendiam o código e permanece até hoje o símbolo nacional do País de Gales. Em seu manifesto $O$ que é Documentação? a discussão de Suzanne Briet sobre documentos examina documentos feitos de objetos ou a partir deles. Ela notoriamente afirmou que uma espécie recém descoberta de antílope, quando posicionada em uma taxonomia e colocada em uma gaiola, passa a servir como um documento. Esta visão é baseada em sua afirmação de que a Bibliografia é apropriadamente considerada preocupada com o acesso à evidência, não somente com o acesso a textos.

3. uma visão semiótica. As duas visões anteriores enfatizam a criação de documentos e sugerem criação intencional. Portanto, elas são incompletas do ponto de vista da visão semiótica, na qual qualquer coisa poderia ser considerada um documento se ela é considerada como evidência de algo, independentemente do que o criador (se algum) do objeto pretendia (se algo) ${ }^{200}$ (BUCKLAND, 2017, p. 23-24).

A visão de Buckland e aquela dos outros neo-documentalistas pode ser entendida como a visão semiótica. Essa visão mais ampla de documento, que é visto como qualquer coisa capaz de informar e não apenas como aquilo que foi propositalmente criado com o objetivo de informar, tem se ampliado, surgindo inclusive a conceptualização do documento oral (TURNER, 2007, 2009, 2010, 2012a, 2012b; TURNER; ALLEN, 2011), isto é, "um artefato que

\footnotetext{
${ }^{200} 1$. a conventional, material view. The everyday, conventional view of documents is of graphic records, usually text, written on a flat surface (paper, clay tablet, microfilm, word processor files, etc.) that are material, local, and, generally, transportable. These objects are made as documents. The limits of inclusion are unclear.

2. an instrumental view. Almost anything can be made to serve as a document, to signify something, to be held up as constituting evidence of some sort. Natural history collections and archeological traces can be included in this view. Before the adoption of military uniforms, it was hard for a soldier in battle to know who was a friend and who was an enemy. In a sixth-century battle between Welsh and Saxons, fought in a field of leeks, Saint David instructed the Welsh to indicate their identity to each other by wearing a leek. The leek documented Welsh identity to those who understood the code and remains today a national symbol of Wales. In her manifesto What Is Documentation? Suzanne Briet's discussion of documents examined documents made of or from objects. She famously asserted that a newly discovered species of antelope, when positioned in a taxonomy and placed in a cage, was made to serve as a document. This view follows from her assertion that bibliography is properly considered to be concerned with access to evidence, not just to texts.

3. a semiotic view. The two previous views emphasize the creation of documents and imply intentional creation. So they are incomplete from a semiotic view, in which anything could be considered a document if it is regarded as evidence of something, regardless of what the creator (if any) of that object intended (if anything).
} 
transmite evidência ou informação que é sobre um conteúdo específico e é integrado na ação de fornecer aquele conteúdo através da oralidade"201 (TURNER, 2012a, p. 856).

Com base em Lara e Ortega (2012), podemos dizer que aquilo que Buckland (2017) chama de visão semiótica se desenvolveu a partir das ideias dos documentalistas de primeira e segunda geração, tais como Otlet e Briet, ideias posteriormente continuadas por pesquisadores franceses e espanhóis que ressaltam os elementos semióticos do documento. As próprias autoras (2012, p. 381) contribuem para esta visão ao adotarem uma abordagem linguístico-semiótica, propondo "o documento como signo, um objeto que tem forma e conteúdo (Hjelmslev, 1975) ${ }^{202}$, que representa algo para alguém, sob algum aspecto ou capacidade (Peirce, 1977) ${ }^{203 "}$ e que é sempre institucional, pois depende de convenção. As autoras continuam sua discussão afirmando que:

\begin{abstract}
As características do signo permitem confirmar que o documento é uma construção, uma leitura do 'real' sob determinada perspectiva. Por meio da atividade nuclear da Ciência da Informação, o documento é tornado pertinente a partir da seleção, da descrição formal e da atribuição de descritores ou outras unidades de classificação e indexação. A 'leitura' do objeto que o transforma em documento para o sistema documentário segue uma política de informação que privilegia perspectivas institucionais e comunidades discursivas potenciais: o objeto é, assim, transformado em documento cuja 'representação' caracteriza uma abordagem que é integrada ao sistema ao lado de outras representações igualmente perspectivadas pela política institucional (LARA, ORTEGA, 2012, p. 382).
\end{abstract}

Frohmann (2001, p. 17), autor que pode ser visto como pertencente ao movimento da Neo-Documentação, afirma que “'documento' é um termo tão bom quanto 'informação' para se referir a uma ampla gama de fenômenos que a Biblioteconomia e a Ciência da Informação atualmente coletam sob sua rubrica"204 e o termo "Documentação" não é apenas tão bom quando o termo "Ciência da Informação" "para o estudo dos documentos na vida social, mas pode até ser melhor, já que evita os vieses epistemológicos da última [Ciência da Informação]"205, vieses estes que entendemos serem as ideias dos paradigmas físico e cognitivo da disciplina.

\footnotetext{
201 [...] an artifact conveying evidence or information that is about specific content, and is embedded in the action(s) of furnishing that content through orality.

202 HJELMSLEV, Louis T. (1975). Prolegômenos a uma teoria da linguagem. São Paulo: Perspectiva.

203 PEIRCE, Charles S. (1977). Semiótica. São Paulo: Perspectiva. (Estudos, n. 46).

204 "Document" is as good a term as "information" to refer to the wide range of phenomena that LIS currently collects under the latter rubric.

205 [...] for the study of documents in social life, but perhaps even better, since it avoids the latter's epistemological biases.
} 
Segundo Frohmann (1995), a informação navega por sistemas relativamente estáveis, com formas e estruturas específicas, de produtores específicos, através de estruturas organizacionais específicas até consumidores específicos, naquilo que denomina regime de informação. Um regime de informação é "construído por práticas nas quais natureza e sociedade estão entrelaçadas" 206 (FROHMANN, 1995, p. 25), assim, adotar a perspectiva de um regime de informação pressupõe que se compreenda a informação e seu fluxo através da sociedade em relação intrínseca com práticas sociais complexas onde existem tensões entre grupos, interesses, discursos e artefatos científicos e tecnológicos. Ou seja, esta perspectiva se recusa a limitar o entendimento da informação, de seus fluxos e usos a apenas uma explicação: ou natural ou social ou discursiva.

Frohmann (2001, p. 12) considera essa "uma concepção material de informação" 207. Para ele (2008), o conceito de materialidade permite conciliar o conceito de informação ao estudo das práticas públicas e sociais. Segundo o autor,

se 'documento' nomeia a materialidade da informação, e se a materialidade é importante para o entendimento dos aspectos públicos e sociais da informação, então os estudos da documentação tornam-se importantes para os estudos da informação. A documentação se torna o meio de materialização da informação. Estudar a documentação é estudar as consequências e os efeitos da materialidade da informação (FROHMANN, 2008, online).

Para Frohmann (2007, p. 27) a Documentação muda o conceito central da Biblioteconomia e Ciência da Informação da informação para o documento, que "é visto como muito mais do que um veículo acidental para a comunicação de informação" ${ }^{208}$, informação esta que "é tão frequentemente concebida como uma substância abstrata, imaterial e mentalista"209, uma concepção que desconsidera os mundos social, político, científico e cultural. Entendemos que Frohmann critica aqui o conceito de informação dos paradigmas físico e cognitivo da Ciência da Informação. Vemos sua proposta de que o conceito de documento tome o lugar do conceito de informação como uma ação que visa deixar claro que a informação não é uma substância abstrata, imaterial e mentalista, que ela deve levar em consideração os mundos social, político, científico e cultural.

\footnotetext{
$206[\ldots]$ is built by practices in which nature and society are intertwined.

207 [...] a material conception of information [...].

208 [...] is seen as much more than an accidental vehicle for the communication of information [...].

$209[. .$.$] is so often conceived as an abstract, immaterial, and mentalistic substance [...].$
} 
Uma concepção material de informação vê a informação como "algo pertencente a uma categoria ontológica diferente dos entes representacionais imateriais e abstratos" $210 \mathrm{e}$ compreendê-la no contexto de práticas socialmente institucionalizadas "é muito diferente de assumir que a coisa mais importante que acontece com documentos é seu papel em trazer a 'informação' - ou 'conhecimento' - para a mente"211 (FROHMANN, 2001, p. 16). Segundo Frohmann (2001, p. 21), "a ênfase no conteúdo como um ente existente independentemente" 212 , ou seja, a ênfase na informação como entendida pelos paradigmas físico e cognitivo, diminui as possibilidades de relações e efeitos culturais devido à atenção dada aos significados que se acredita haver "dentro" dos objetos culturais.

Para Frohmann (2004) a informação não é o pensamento puro, uma abstração pura que passa de uma mente para a outra e é indiferente a influências materiais, institucionais e sociais, o mesmo sendo válido para os documentos. Analisando a informação e o documento sob essa ótica, Frohmann (2004, p. 397) afirma que "um documento se torna informativo somente dados certos tipos de práticas documentárias"213. Estas práticas, ou seja, as ações realizadas com documentos, são dependentes de sua materialidade, contexto de produção e uso, institucionalização e historicidade, não se podendo esquecer que as práticas documentárias dependem de treinamento, ensino e correção. Esse conjunto de fatores é o que determina a "informatividade" ${ }^{214}$ de um documento, ou seja, aquilo que o torna informativo:

A atenção às práticas documentárias revela como documentos específicos, em tempos e lugares específicos e em áreas específicas do terreno social e cultural se tornam informativos. [...] a informatividade dos documentos, quando reconhecida como dependente de práticas, também depende do que os forma e configura ${ }^{215}$ (FROHMANN, 2004, p. 405).

\footnotetext{
${ }^{210}[\ldots]$ something belonging to a different ontological category than immaterial and abstract representational entities [...].

${ }^{211}[\ldots]$ is very different from assuming that the most important thing that happens to documents is their role in bringing "information" - or "knowledge" - to mind.

${ }^{212}$ The emphasis on content as an independently existing entity [...].

${ }^{213}[\ldots]$ a document becomes informing only given certain kinds of documentary practices.

${ }^{214}$ Informativeness no original em inglês.

${ }^{215}$ Attention to practices with documents reveals how it is that particular documents, at particular times and places and in particular areas of the social and cultural terrain, become informative. [...] the informativeness of documents, when recognized as dependent on practices, is also dependent on what shapes and configures them.
} 
Desse modo, Frohmann (2007) acredita que, enquanto o termo informação é carregado de conotações de abstração, descontextualização, imaterialidade, imutabilidade, mentalismo e uniformidade, o termo documento apresenta conotações opostas. Para ele (2007, p. 33) documentos são necessariamente múltiplos e materiais, sua materialidade tendo efeitos específicos e podendo apresentar agência autônoma, isto é, existindo como mais do que instrumentos de registro, representação e transmissão de substâncias imateriais, tendo "efeitos documentários significativos que não podem ser atribuídos à consciência de seres humanos individuais"216.

Na mesma linha, Day (2014, p. 5), outro autor que pode ser visto como pertencente ao movimento da Neo-Documentação, entende o documento como "qualquer tipo de substância ontológica que aja como evidência" ${ }^{217}$, o que leva a que ele se pergunte de que os documentos são evidência. O autor (2014, p. 5, grifo do autor) entende que "toda evidência é evidência de algo, e este algo pertence a ordens de evidência possível para uma necessidade (das quais a necessidade é formada)"218. Assim, ele entende que quando documentos são vistos como evidência, eles são entes ontológicos cuja condição evidencial jaz no fato de que eles pertencem a regimes taxonômicos ou indiciais ou, de forma mais ampla, a regimes discursivos ou conversacionais.

Para Day (2016) isso quer dizer que documentos podem ser entendidos como evidência em função de sistemas sociais de nomenclatura e de discursos, o que permite que qualquer coisa tenha a potencialidade de se tornar um documento. Ele (2016, p. 59, grifo do autor) conclui então que "documentos não são mais sobre coisas, mas são coisas que são 'sobre'"219 e que coisas se tornam 'sobre' algo, coisas se tornam evidência de algo, por meio de um processo de criação de significado em sistemas sociais e culturais.

Segundo Day (2014), documentos são signos que significam algo em sua relação com outros signos, ganhando sua identidade e sua qualidade referencial em sua diferenciação desses outros signos e em sua relação com coisas e eventos. Desse modo, evidências não são autorreferentes, elas somente são evidência dentro de contextos específicos. Assim, "o lugar dos documentos em taxonomias e discursos, como formas dotadas de significado que são

\footnotetext{
216 [...] significant documentary effects which cannot be traced to the consciousness of individual humans.

217 [...] any type of ontological substance that acts as evidence.

${ }^{218}$ All evidence is evidence of something, and that something belongs to orders of possible evidence for a need (from which the need is formed).

${ }^{219}$ Documents are no longer about things, but are things that are 'about.'
} 
sobre algo, quer dizer que documentos são signos que têm relações referenciais com outros signos e com formas de vida"220 (DAY, 2014, p. 7, grifo do autor). Desse modo,

\begin{abstract}
documentos fazem coisas dotadas de significado porque são dotados de significado dentro de redes e usos de outros signos dotados de significado (que podem ser linguísticos, físicos, visuais ou de outro tipo). Em sua circulação nessas redes e usos, eles tanto apontam para outros signos, tanto dentro como fora de suas redes de circulação, como traçam suas redes sociais e práticas como um todo. Eles são, deste modo, o que anteriormente chamei de [...] 'objetos informacionais'; eles informam ou referenciam algo, mas vistos criticamente, eles também nos informam sobre como eles referenciam, nomeadamente ao traçar as redes vivas e economias de signos no interior das quais eles circulam ${ }^{221}$ (DAY, 2014, p. 6-7).
\end{abstract}

Day (2016) afirma que, em uma visão tradicional, documentos são entendidos como materiais que fixam ou armazenam informação considerada como conteúdo, ou seja, documentos são entendidos como resultantes de ações de registro permanente de algum conteúdo. Contudo, usando o exemplo do documento fotográfico, o autor (2016, p. 16) diz que o que se observa não é a fixação, armazenamento ou permanência do que algo é, o que se observa é "a indicação daquilo que não é mostrado por aquilo que é mostrado" ${ }^{222}$. Por esta razão ele entende que um documento não é apenas sobre algo ou sobre alguém, mas também é sobre uma comunidade documentária compartilhada à qual o documento pertence. Ele conclui assim que é a vida dos signos que estão "no" documento e a vida dos signos que estão fora do documento que Ihe dão seu significado ou seu caráter de referência.

Segundo Day (2016), documentos não fixam o significado de um conteúdo representacional, eles evocam significados por indicarem ordens de significado sociocultural em situações específicas. Desse modo, um documento evoca algo em uma comunidade não porque necessariamente mostre algo, mas porque, sendo dotado de significado, ele está envolvido em seus próprios signos culturais e na circulação social deles. Com isto o autor quer dizer que a condição do documento enquanto algo que indica não pertence ou não se encontra no seu conteúdo, essa condição se encontra na função que os documentos exercem

\footnotetext{
220 The place of documents in taxonomies and discourses, as signifying forms that are about something, means that documents are signs that have referential relations to other signs and to forms of life.

221 [...] documents do meaningful things because they are meaningful within networks and uses of other meaningful signs (which may be linguistic, physical, visual, or otherwise). In their circulation in such networks and uses they both point to other signs, both in and outside of their networks of circulation, and they trace their social and practical networks as a whole. They are, in this way, what I earlier called [...] "informational objects"; they inform or reference something, but viewed critically, they also inform us about how they reference, namely by tracing the living networks and economies of signs that they circulate within [...].

$222[\ldots]$ the indexing of what is not shown by what is shown.
} 
na vida das pessoas, uma função que dá vida a algo que está ausente e que para poder significar depende da vida social, de formas culturais e de normas sociais.

Na ótica de Day (2016), documentos armazenam poderes potenciais em suas estruturas, poderes estes que são compostos por utilidades culturais, sociais e físicas que permitem que alguém se expresse. Para o autor seres humanos não fazem apenas uso do conteúdo dos documentos, seres humanos constroem um senso de vida através de documentos e de seus signos, incluindo a disponibilidade desses documentos em prateleiras, bases de dados e etc. Documentos não contém algo, eles são parte de modos de vida e são considerados documentos por causa daquilo que se pode fazer através deles. Assim, "somos informados não pelo suposto conteúdo do [documento], mas por nossas relações com aquilo que supomos ser o conteúdo"223 (DAY, 2016, p. 63).

Para Day (2016, p. 59) a proposição de Briet de que documentos sejam vistos como índices, em vez de como representações diretas ou essenciais de algo, "é um passo importante para nos ajudar a entender documentos não como sendo sobre fatos, mas como sendo sobre a possibilidade de fatos, mesmo em sua ausência" ${ }^{224}$. Ele considera isto como um passo em direção à remoção da ideia de que a informação significa a verdade em vez de significar possibilidades de conhecimento, crença e confiança. Segundo Day, isto significa assumir uma responsabilidade maior pela facticidade - que ele considera ser a condição de algo ser um fato - e pela "evidencialidade"225 - que ele considera ser a condição de algo ser evidência - do documento do que quando ele é entendido em um contexto empirista e positivista ingênuo. Nesta ótica, "fatos são construídos tanto por signos dotados de significado como por atividades com emoções e efeitos"226 (DAY, 2016, p. 59).

Desse modo, Day (2016) afirma que pensar sobre evidência como sentido, considerando-se o sentido como a raiz do significado, é um passo importante em direção à percepção dos seres, mesmo quando eles estão ausentes. Day (2016, p. 59) entende assim que, sem essa apreciação, não temos como considerar todos aqueles que ele chama de "fatos

\footnotetext{
${ }^{223}$ We are informed not by the supposed content of the [document], but by our relations to what we suppose is the content $[\ldots]$.

${ }^{224}[\ldots]$ is an important step in helping us understand documents as not being about facts, but being about the possibility of facts, even in their absence.

${ }^{225}$ Evidentarity no original em inglês.

${ }^{226}$ Facts are constructed by both meaningful signs and by activities with affects and effects.
} 
não factuais" 227 , tais como estados místicos, a ficção e todo tipo de expressão sensível que pode ser verdadeira em um contexto que não seja aquele do realismo empírico.

Os conceitos de informação e documento como discutidos nesta seção são conceitos que podem ser entendidos como parte do paradigma hermenêutico da Ciência da Informação. Pensar a informação em sua materialidade, seja esta chamada de informação-como-coisa ou como documento, é abri-la para ser discutida sob uma perspectiva hermenêutica. Dados os desenvolvimentos do movimento da Neo-Documentação, como expostos aqui, optamos pelo uso do termo documento nesta tese.

Pensar sobre práticas com documentos e nos usos do documento em contextos de significação cultural e social é um processo de interpretação e compreensão dos entes informativos não apenas em um domínio cognitivo teórico-conceitual, mas também no domínio da ocupação no manuseio e uso do qual nos fala a hermenêutica. A ocupação enfatiza o significado prático de uso e produção de um ente, portanto, pensar o documento em termos de ocupação é enfatizar seu significado prático de uso e produção. Assim, pode-se ver como Day (2016, p. 59, grifo do autor) que "documentos não são mais sobre coisas, mas são coisas que são 'sobre'"228. Essa concepção não ignora o domínio cognitivo teórico-conceitual, pois como afirma Buckland (2018, p. 431), "discussões sobre documentos incluem aspectos físicos (materiais), aspectos cognitivos e aspectos sociais (culturais)"229, que segundo Lund, estão sempre presentes ao mesmo tempo (LUND, 2004, 2010; OLSEN et al., 2012).

Pensar sobre práticas e usos do documento em contextos de significação social e cultural é um processo de interpretação e compreensão do ente informativo que é circular e acontece através da realização de projetos que inicialmente têm como base os preconceitos, no sentido hermenêutico, de um horizonte de compreensão específico. No entanto, quando o intérprete busca se concentrar nas "coisas elas mesmas" e permite que elas falem, ele amplia a compreensão dessas práticas e desses usos do documento.

É levando em consideração os conceitos de informação e documento aqui apresentados que podemos discutir o comportamento informacional sob a ótica da hermenêutica.

\footnotetext{
227 [...] non-factual facts [...].

228 Documents are no longer about things, but are things that are 'about.'

229 [...] discussions of documents include physical (material) aspects, cognitive, and social (cultural) aspects [...].
} 


\subsection{Presença e comportamento informacional}

Como afirmamos após nossa exposição do que é um ser humano no contexto da hermenêutica e de como ele se encontra no mundo, entendemos que é o ser humano como presença, como ser-no-mundo, como ser-com em seu estar-lançado e em seu Umwelt que interage com a informação. É a compreensão como modo fundante de sua existência que leva o ser humano a se relacionar com a informação, seja esta relação passiva ou ativa.

Uma vez que em nossa revisão da literatura de Heidegger e Gadamer o conceito de informação não aparece, partimos para a discussão do modo como esse conceito é entendido na perspectiva do paradigma hermenêutico da Ciência da Informação para que pudéssemos demonstrar como o estar-lançado pode ser visto como a motivação para que a informação seja buscada e utilizada.

É de suas relações com outros entes, sejam eles dotados ou não do modo de ser da presença, que o ser-no-mundo lida com seu estar-lançado. Essas relações, que abarcam o todo de sua experiência, se dão através do processo de compreensão, que é o modo de ser da própria presença. Este compreender é conhecer em sentido amplo, ou seja, é mais do que perceber algo em sua pura configuração e em seu modo de ser, é mostrar aquilo que é possível para nós e como isso é significante para nós.

Wilson (2000, p. 49, grifo do autor) nos fala do comportamento informacional passivo, mencionando como exemplo "a recepção passiva de informação [...] ao assistir comerciais na $T V$, sem qualquer intenção de agir sobre a informação recebida"230. Tendo o compreender como o modo fundamental de ser, ainda que não tenha ativamente obtido um ente informativo, um documento, o ser humano irá interpretar o ente informativo que o interpelar. No exemplo dado por Wilson, ainda que não tenha intenção de agir sobre aquilo que compreenderá ao assistir um comercial, o ser humano o interpretará ainda que minimamente.

Quando o ser humano se relaciona ativamente com o documento, é sua condição lançada, a necessidade de encarar quaisquer circunstâncias nas quais se encontre e que possam aparecer em seu caminho, que o leva a buscar e utilizar um documento. É a necessidade de compreender o mundo, de "fazer sentido de seus mundos conforme eles se

\footnotetext{
${ }^{230}[. .$.$] the passive reception of information [...] watching TV advertisements, without any intention to act on the$ information given.
} 
movem de um evento a outro"231 (DERVIN, 1976, p. 333), que impele os seres humanos a interagir com um documento.

No contexto do paradigma hermenêutico da Ciência da Informação - ou seja, em um paradigma onde a Ciência da Informação "se preocupa diretamente com o conhecimento e a aprendizagem"232, sendo sua preocupação central "permitir às pessoas que se tornem melhor informadas (aprendendo, tornando-se mais conhecedoras)"233 (BUCKLAND, 2012b, p. 5) -, o processo que permite que as pessoas se informem e, por conseguinte, que o conhecimento de alguém seja mudado, é um processo que tem início quando uma pessoa entra em contato com uma evidência, com um documento, que, com base no contexto de um indivíduo, pode ser considerado informativo, levando a que esse indivíduo seja informado e tenha seu conhecimento mudado. Lembramos que no paradigma hermenêutico conhecimento não significa unicamente conhecimento teórico ou factual, mas sim todo o "conhecimento que dirige a vida diária" (BERGER; LUCKMANN, 2004, p. 25).

Segundo Gadamer, "o primeiro elemento com que se inicia a compreensão é o fato de que algo nos interpela" (2011f, p. 80), é "quando nos deparamos com algo estranho, provocante e desorientador" (2011d, p. 218). Quando algo nos interpela, nos é estranho, provocante ou desorientador, para que o possamos compreender fazemos uso daquilo que Lafont (2005, p. 271) chama de "totalidade de significações que compõem o mundo", ou seja, um conjunto de significações que é compartilhado intersubjetivamente. Contudo, sabemos que essas significações compartilhadas não são suficientes para que possamos compreender todas as circunstâncias nas quais nos encontremos ou aquelas que possam aparecer em nossos caminhos. Às vezes precisamos adquirir horizontes de compreensão para interpretar algo com o qual nos deparamos. É preciso criar um conjunto de significações próprio que vai além daquele no qual se foi lançado, é preciso criar um Umwelt.

Face ao exposto, inferimos que, ao se informar, a presença está ampliando seu horizonte de compreensão ou realizando uma fusão de horizontes, ela está ampliando suas estruturas de significação, ela está criando seu Umwelt. Isto é o resultado da interpretação que a presença faz de um ente informativo, interpretação que se dá através do círculo hermenêutico. Na medida em que a presença se abre para o documento "ele mesmo", ou

\footnotetext{
231 [...] make sense out of their worlds as they move from one event to another.

$232[\ldots]$ is directly concerned with knowing and learning.

${ }^{233}$ Enabling people to become better informed (learning, becoming more knowledgeable) [...].
} 
seja, que efetue a compreensão sendo consciente de seus preconceitos e que esteja aberta para o que o documento pode lhe informar, seus horizontes são ampliados, ela tem uma nova perspectiva sobre suas visões antigas ou até mesmo novas perspectivas. Isto se dá porque "o sujeito conhecente está indissoluvelmente unido ao que se lhe abre e se mostra como dotado de sentido" (GADAMER, 2011a, p. 507).

Entender o ser humano sob a ótica da hermenêutica nos levou a concluir que o comportamento humano em relação às fontes e canais de informação é resultante da compreensão enquanto modo fundante da existência humana. Concluímos também que no caso do comportamento informacional ativo, ou seja, quando o indivíduo busca o documento que necessita, a motivação de busca é a condição lançada do indivíduo, que faz com que ele tenha de encarar quaisquer circunstâncias nas quais ele se encontre ou que possam aparecer em seu caminho.

Quando seu comportamento informacional é ativo, a presença pode se voltar para instituições que armazenam, organizam e recuperam documentos. É para a compreensão destas instituições e de suas atividades sob uma ótica hermenêutica que nos voltamos no próximo capítulo. 


\section{Armazenamento, organização e recuperação de documentos sob a ótica hermenêutica}

A discussão sobre o comportamento informacional sob a ótica hermenêutica realizada no capítulo anterior mostrou quem é o indivíduo que se relaciona com a informação, a presença, e o que é a informação na perspectiva específica que adotamos. Dessa análise pudemos concluir que a presença que objetiva se responsabilizar por si mesma e se fundamentar no mundo em seu estar-lançado precisa se informar. Ela buscará informaçãocomo-coisa conforme sua situação hermenêutica em um momento específico do tempo, podendo buscar informação-como-coisa produzida socialmente ou não, materialmente duradoura ou não. A informação-como-coisa pode ser vista como sinônimo de uma visão ampla de informação registrada ou de documento. Este último termo é aquele que adotamos nesta tese.

Esses conceitos e suas inter-relações foram levantados de modo a cumprir um dos objetivos específicos de nossa pesquisa, qual seja, levantar elementos teórico-conceituais de cunho geral referentes à relação entre indivíduo e informação, isto é, referentes ao comportamento informacional sob a ótica hermenêutica. No presente capítulo, visamos cumprir nosso segundo objetivo especifico de pesquisa: levantar elementos teóricoconceituais de cunho geral referentes aos modos como os documentos são tratados para que possam ser recuperados e utilizados pelos indivíduos, ou seja, referentes ao armazenamento, organização e recuperação de documentos sob a ótica hermenêutica.

As atividades de armazenamento, organização e recuperação de documentos são realizadas em sistemas de documentação. Na Ciência da Informação estes sistemas são comumente conhecidos como sistemas de informação, contudo, considerando nossa discussão sobre os conceitos de informação e documento no capítulo anterior, optamos por chamar estes sistemas de sistemas de documentação.

Se, como propõe Heidegger, a hermenêutica é o modo de vida inerente da presença e sistemas de documentação são parte do mundo no qual a presença está lançada, sistemas de documentação e os processos neles desenvolvidos podem ser pensados sob a perspectiva da hermenêutica. Assim, neste capítulo serão analisados sob a ótica da hermenêutica conceitos fundamentais às atividades de armazenamento, organização e recuperação de documentos, quais sejam: 
a) análise de comunidade e avaliação de necessidades;

b) desenvolvimento de coleções;

c) análise e representação documentária;

d) busca e recuperação de documentos, serviço de referência e relevância;

e) infraestrutura.

Os processos realizados dentro de um sistema de documentação ficam a cargo do profissional documentalista, portanto, ele é considerado como um elemento fundamental desses processos e do sistema. $O$ documentalista é também ele presença, ser-no-mundo, sercom que se encontra em uma condição lançada, caracterizações estas já discutidas no capítulo anterior. Desse modo, as atividades que ele desempenha em um serviço de documentação são atividades que têm como base os modos fundantes da existência humana, isto é, compreensão e interpretação.

Na medida em que nosso objetivo é levantar elementos teórico-conceituais de cunho geral que sirvam de base para a sistematização de uma metateoria hermenêutica da Ciência da Informação, metateoria em nosso contexto sendo entendida como uma perspectiva abrangente da disciplina, nos limitaremos a analisar os processos acima elencados teoricamente, ou seja, não analisaremos as diversas metodologias específicas envolvidas nas atividades de armazenamento, organização e recuperação de documentos.

Iniciaremos nossa discussão pelo processo de análise de comunidade e avaliação de necessidades.

\subsection{Análise de comunidade e avaliação de necessidades}

McCleer define o processo de análise de comunidade ou, como ela o chama, avaliação de comunidade, da seguinte maneira:

Avaliação de comunidade é o processo sistemático de análise e compreensão das características de uma comunidade; das práticas de uma comunidade; e, especificamente no caso de bibliotecas e centros de informação, quais as 
percepções, os comportamentos, as necessidades e os interesses informacionais são em uma comunidade ${ }^{234}$ (McCLEER, 2013, p. 263)

A análise de comunidade deve ser o primeiro estágio na instituição de um sistema de documentação, pois é fundamental para o seu planejamento e desenvolvimento. A criação e gestão de coleções, serviços e programas eficazes para os usuários, o estabelecimento das metas, objetivos e políticas de desenvolvimento do sistema de documentação, bem como a obtenção de recursos e financiamento, dependem da compreensão que se tem da comunidade que se deseja atender.

Atender às necessidades informacionais de uma comunidade é a razão pela qual sistemas de documentação são criados, portanto, é necessário saber quais são elas por meio da compreensão das características dessa comunidade, assim como de seu comportamento informacional. Segundo Barron e Curran (1981, p. 29), através da análise de comunidade os documentalistas "podem descobrir como integrar a biblioteca [ou outros sistemas de documentação] à vida de uma comunidade"235.

Comunidades não são estáticas, de modo que sua compreensão e a compreensão das mudanças que nela possam ocorrer impactam o funcionamento do sistema de documentação como um todo, afetando o atendimento das necessidades informacionais. Por esta razão, a análise de comunidade deve ser uma atividade constante, permitindo que o sistema de documentação esteja sempre a par da caracterização da comunidade.

Analisar e entender as características e práticas de uma comunidade, assim como suas percepções, comportamentos, e necessidades informacionais, são processos de interpretação e compreensão, o que faz deles processos hermenêuticos. Em nossa visão, uma comunidade pode ser entendida como um mundo no sentido hermenêutico, ou seja, como, segundo Lafont (2005), uma totalidade de significância, uma rede de significados compartilhada intersubjetivamente que possui uma tradição própria e que estrutura a compreensão dos seres humanos.

A comunidade pode ser entendida como o mundo-da-vida de um serviço de informação, mundo-da-vida sendo entendido aqui na perspectiva de Heidegger, ou seja, como

\footnotetext{
${ }^{234}$ Community assessment is the systematic process of analyzing and understanding the characteristics of a community; the practices of a community; and, specific to libraries and information centers, what the information perceptions, behaviors, needs, and interests are in a community [...].

$235[\ldots]$ can discover how to integrate the library into the life of a community [...].
} 
"a fundação última, e o único habitat, dos significados e da atividade de compreensão"236 (BAUMAN, 1978, p. 21). Ao entendermos a comunidade dessa maneira, vemos a sua análise como a análise de uma totalidade de significância específica, de uma rede de significados específica e de uma tradição específica. Como Bauman (1978, p. 21) afirma, "a comunidade de membros interagentes é mostrada como um universo poderoso o suficiente e o único universo possível de estabelecer, sustentar em vida e garantir a intepretação de significados" 237 .

Os resultados dessa análise permitem que sistemas de documentação sejam estruturados a partir da mesma estrutura de interpretação e compreensão da comunidade, ou seja, que compartilhem o mesmo horizonte de compreensão. É somente compreendendo uma comunidade que um sistema de documentação pode comunicar o potencial informativo dos documentos a seus usuários e suprir suas necessidades informacionais, pois assim como a presença precisa se tornar familiar com o conjunto de significações de sua cultura, aprendendo os padrões normativos de interpretação e conduta dessa cultura, os documentalistas precisam se familiarizar com a totalidade de significância da comunidade e necessitam aprender os padrões normativos de interpretação e conduta dessa comunidade.

Se, como afirmam Dreyfus e Wrathall (2005), é nossa familiaridade com o mundo que torna possível que ajamos sobre, pensemos sobre e experimentemos as coisas do mundo, a familiaridade dos documentalistas com a estrutura de interpretação e compreensão da comunidade permite que esta consiga fazer uso do serviço, que ela consiga buscar, recuperar e utilizar documentos capazes de responder às suas necessidades informacionais. Sem conhecimento do mundo compartilhado, o sistema de documentação não consegue atender às necessidades da comunidade, ou não as consegue atender eficazmente.

Aqui não entendemos necessidades em um sentido puramente cognitivo, onde a informação-como-conhecimento necessária visa o aumento do conhecimento como entendido pela filosofia tradicional e onde esse aumento de conhecimento é visto como resultante de uma relação causal. Aqui, necessidades devem ser entendidas em sentido amplo, onde a informação-como-conhecimento necessária visa a que a presença enquanto ser-no-mundo possa lidar com seu estar-lançado, ou seja, possa encarar quaisquer

\footnotetext{
${ }^{236}[\ldots]$ the ultimate foundation, and the only habitat, of meanings and of the activity of understanding.

237 [...] the community of interacting members is shown as a universe powerful enough, and the only universe able, to establish, to sustain in life, and to warrant interpretation of meanings.
} 
circunstâncias nas quais se encontre ou que possam aparecer em seu caminho. Aqui, necessidades atendidas permitem que a presença viva projetada para seu futuro, assumindo responsabilidade por si mesma e fundamentando seu ser-no-mundo.

Concordamos assim com Wilson (1981), para quem a motivação do indivíduo para buscar informação-como-coisa é toda a gama de necessidades humanas que emergem dos diversos papéis que um indivíduo desempenha em sua vida. Na visão ampla e holística que Wilson tem do indivíduo, este não deve ser compreendido apenas como alguém impelido a buscar informação-como-coisa para fins puramente cognitivos, mas sim como um ente que vive e trabalha em configurações sociais que criam diversas motivações para que a informação-como-coisa seja buscada ${ }^{238}$.

Desse modo, podemos dizer que sistemas de documentação sempre objetivam que um ser-no-mundo assuma responsabilidade por si mesmo e que se fundamente na esfera de vida específica a que o sistema atende, esfera que podemos considerar como um mundo específico. Por exemplo, uma biblioteca pública visa a que o ser-no-mundo assuma responsabilidade por si mesmo e que fundamente sua existência de um modo geral; já uma uma biblioteca universitária visa a que o ser-no-mundo assuma responsabilidade por si mesmo e se fundamente enquanto estudante, docente ou pesquisador.

A interpretação e a compreensão bem-sucedidos de uma comunidade e a avaliação de suas necessidades informacionais para o planejamento de um sistema de documentação deve ser guiada pela comunidade "ela mesma" a partir de uma situação hermenêutica específica. O primeiro significado que emerge em uma análise de comunidade e as primeiras necessidades informacionais projetadas se originam de expectativas pré-existentes e com um significado projetado em vista, como em qualquer processo de compreensão. As projeções iniciais sobre como é uma comunidade, de quais são suas práticas, comportamentos informacionais e de quais são suas necessidades informacionais devem ser revisadas e corrigidas conforme se aprofunda e amplia a compreensão da comunidade e de suas necessidades.

Segundo Gadamer (2012a, p. 80), “precisamente quando buscamos compreender o outro, fazemos a experiência hermenêutica de que precisamos romper uma resistência em

\footnotetext{
${ }^{238}$ Wilson não utiliza a tipologia de informação proposta por Buckland $(1991,2017)$, utilizando somente a palavra informação para se referir às diferentes acepções do termo; contudo, consideramos essa tipologia útil e a adotamos.
} 
nós, se quisermos ouvir o outro enquanto outro". Nesse sentido, a análise de comunidade pressupõe que a comunidade seja compreendida por "ela mesma", ou seja, ainda que a interpretação parta da situação hermenêutica e do horizonte de compreensão específico de um documentalista ou de um grupo deles, estes devem estar abertos à compreensão da comunidade em si e de suas necessidades em si, sendo conscientes de onde parte seu processo interpretativo, de modo a que este possa ser controlado e a comunidade em si lhes "diga" alguma coisa. Somente assim podem ser construídos sistemas de documentação adequados à comunidade "ela mesma" e não apenas adequados à opinião dos documentalistas sobre quais seriam as necessidades informacionais de uma comunidade, opinião que pode ser incorreta.

Na medida em que comunidades são dinâmicas, já que seus membros estão em um processo constante de transformação em seu estar-lançado, o processo de análise de comunidade deve acontecer periodicamente, de modo a que o sistema de documentação esteja a par das necessidades informacionais da comunidade, necessidades que estão em constante transformação. Desse modo, o processo de análise de comunidade e avaliação de necessidades pode ser visto como um processo circular e infindo de compreensão e interpretação.

Uma vez que uma comunidade é analisada e suas necessidades informacionais avaliadas, o sistema de documentação pode proceder ao desenvolvimento de suas coleções.

\subsection{Desenvolvimento de coleções}

Uma vez que uma comunidade é analisada e suas necessidades informacionais são estabelecidas, um sistema de documentação procede ao desenvolvimento de uma coleção de documentos que são considerados relevantes para as necessidades informacionais dessa comunidade. O processo é inerentemente dependente do conhecimento que se tem da comunidade e de suas necessidades, pois a seleção e subsequente aquisição de novos documentos, a avaliação da coleção e o desbaste são atividades executadas tendo-se como objetivo o atendimento das necessidades informacionais da comunidade.

O desenvolvimento de coleções é um processo sistêmico e cíclico, pressupondo planejamento e o estabelecimento de critérios e políticas de desenvolvimento de coleções que sejam adequados às especificidades do sistema de documentação. O processo deve ser 
cíclico porque pressupõe a avaliação constante da coleção em relação às necessidades informacionais da comunidade. Assim, concordamos com Buckland $(1989,1995)$, para quem o processo de desenvolvimento de coleções é responsável pela mediação entre o universo de documentos existente e o usuário do serviço de informação.

Nos apropriando da ideia de que "a contribuição que a hermenêutica pode fazer é sempre essa transferência de um mundo para outro, do mundo dos deuses para o dos homens, do mundo de uma língua estrangeira para o mundo da língua própria" (GADAMER, 2011b, p. 112), podemos dizer que o processo de desenvolvimento de coleções é um processo hermenêutico semelhante, uma vez que ele transfere um documento de um mundo para outro. O documento deixa o mundo onde foi produzido e é transferido para o mundo do sistema de documentação através de sua seleção e aquisição, ou ele é transferido do sistema de documentação para o mundo exterior por meio do processo de avaliação e desbaste.

Essas atividades exigem que o documentalista realize a interpretação e compreensão dos documentos com os quais ele se depara. Como visto anteriormente, o sistema de documentação deve compartilhar com a comunidade uma rede de significados, que pode ser entendida como parte do horizonte de compreensão do documentalista que realiza a interpretação do documento, seja esta interpretação para que novos documentos sejam adicionados à coleção, ou para que documentos que não atendem mais às necessidades informacionais da comunidade sejam removidos da coleção.

O horizonte de compreensão do documentalista, no entanto, não se limita à estrutura de significação que ele compartilha com o mundo da comunidade, uma vez que o sistema de documentação pode ser considerado como um mundo em si, dotado de um horizonte de compreensão próprio formado a partir de padrões normativos de interpretação e conduta do fazer profissional dos documentalistas, padrões prescritos pela tradição teórica e prática desenvolvida pela disciplina da Ciência da Informação.

É possível dizer então que o horizonte de compreensão do documentalista é o resultado da fusão do horizonte de compreensão da comunidade com o horizonte de compreensão teórico e prático da Ciência da Informação. É este novo horizonte que permite o planejamento e o estabelecimento de critérios e políticas de desenvolvimento de coleções específicos para um sistema de documentação particular.

A interpretação do documento acontece através do processo circular de compreensão discutido no capítulo anterior. Aplicando-o ao contexto do desenvolvimento de coleções, 
podemos dizer que o documentalista projeta uma expectativa de sentido ao documento com base no planejamento e nos critérios e políticas de desenvolvimento de coleções, projeto que ele continua revisando e corrigindo até compreender se o documento pode atender às necessidades informacionais da comunidade.

Ao interpretar um documento, o documentalista deve guiar-se pelo documento "ele mesmo", não buscando confirmar sua antecipação de sentido, mas sendo consciente desta para a controlar, deixando assim que o documento "ele mesmo" mostre através do processo de interpretação se ele atende ou não às necessidades da comunidade. Portanto, deixar que a interpretação seja guiada pelo documento "ele mesmo" é deixar que o documento revele seu potencial informativo para uma comunidade sem que a projeção de sentido prévia do documentalista determine o destino do documento sem que este tenha sido interpretado por "ele mesmo". Ou seja, o documentalista está sujeito a errar por causa de suas opiniões prévias, que podem não se confirmar no documento "ele mesmo".

Sabe-se, contudo, que o documento só pode mostrar algo a partir da situação hermenêutica na qual o documentalista se encontra e de seu horizonte de compreensão. Em princípio, a situação hermenêutica e o horizonte de compreensão do documentalista devem ser os mesmos que os do sistema de documentação. No entanto, o documentalista é também ele presença lançada no mundo e possui seu próprio Umwelt, de modo que sua situação hermenêutica e seu horizonte de compreensão são únicos e eles influenciam a interpretação que esse documentalista realiza no seu contexto de trabalho. O documentalista deve, portanto, buscar interpretar um documento com uma consciência metodológica, ou seja, tendo consciência de qual é sua situação hermenêutica e seu horizonte de compreensão próprios e de como eles podem interferir em sua atividade profissional.

Na medida em que horizontes de compreensão estão em constante transformação, sejam estes horizontes profissionais ou horizontes de um Umwelt particular, e na medida em que situações hermenêuticas são sempre variadas e variáveis, documentalistas diferentes podem divergir em relação ao destino de um documento, se este deve ser adicionado ou não à coleção ou se ele deve ser removido ou não da coleção, o mesmo ocorrendo quando um mesmo documentalista interpreta um documento em momentos distintos.

O processo de interpretação de um documento por um documentalista não visa a que esse profissional enquanto presença se oriente em seu estar-lançado. Este processo de interpretação visa à compreensão do potencial informativo de um documento para uma 
comunidade, ou seja, ele visa à compreensão do potencial de um documento para que a presença de outrem se oriente em seu estar-lançado. Desse modo, o processo de interpretação que um documentalista realiza no contexto do desenvolvimento de uma coleção não visa à aquisição de horizontes e ao desenvolvimento de seu Umwelt, mas visa permitir que outros o façam.

Uma vez que o processo de desenvolvimento de coleções é de caráter sistêmico e cíclico, seleção, aquisição, análise e desbaste devem ser atividades periódicas que devem ter como referência os critérios e as políticas de desenvolvimento de coleções, os quais também devem ser constantemente revisados e atualizados, de modo a sempre atender às necessidades informacionais da comunidade, que estão sempre em transformação. Desse modo, o processo de desenvolvimento de coleções, assim como o processo de análise de comunidade e avaliação de necessidades, pode ser visto como um processo circular e infindo de compreensão e interpretação.

Uma vez que uma coleção é criada ou novos documentos the são adicionados, procede-se ao processo de organização desses documentos através da análise e representação documentária, as quais serão discutidas a seguir.

\subsection{Análise e representação documentária}

O próximo processo no estabelecimento de um sistema de documentação é a organização dos documentos para que eles possam ser recuperados e utilizados. Essa organização é executada mediante a análise e representação dos documentos.

É comum na Ciência da Informação entender que os documentos analisados são representados de duas maneiras: descritiva e tematicamente. Segundo Ortega (2011, p. 45), "os termos representação descritiva e representação temática são adotados para indicar [...] etapas distintas e complementares". O termo "representação descritiva refere-se aos aspectos da descrição formal dos documentos, o que inclui a descrição física e a descrição dos elementos para identificação dos mesmos" (ORTEGA, 2011, p. 45). O termo "representação temática, por sua vez, refere-se à atribuição de assuntos aos documentos" (ORTEGA, 2011, p. 45).

A separação da representação documentária em uma etapa de representação da "forma" e uma etapa de representação do "conteúdo" do documento pode ser entendida 
como um resultado da tradição filosófica criticada por Heidegger, a mesma tradição criticada pela Neo-Documentação, onde conteúdo é sinônimo de informação, aquela que Buckland (1991, 2017) chama de informação-como-conhecimento, e "que incorpora conotações de nobreza e transferibilidade em sua significação, de modo que parece certo que o conteúdo será preservado intacto quando seus suportes material e social forem retirados"239 (NUNBERG, 1996, p. 107). Podemos entender que essa é a concepção do paradigma físico e em certa medida do paradigma cognitivo da Ciência da Informação, mas essa concepção não é aquela do paradigma hermenêutico. No paradigma hermenêutico o documento é visto como uma totalidade de significância que resulta não apenas do domínio cognitivo teóricoconceitual, mas também do domínio da ocupação no manuseio e uso, que em sua conjugação determinam o potencial informativo dos documentos, os significados por eles evocados. $\mathrm{Na}$ medida em que não é apenas aquilo que está "dentro" do documento que informa, não é justificável haver a separação entre a representação da "forma" e a representação do "conteúdo" de um documento. Não é apenas a representação temática que indica o potencial informativo de um documento, não é apenas ela que indica os significados que um documento evoca. A representação descritiva também indica o potencial informativo de um documento, os significados por ele evocados.

Os procedimentos de análise documentária são a seleção e condensação dos significados que um documento evoca tanto no domínio cognitivo teórico-conceitual como no domínio da ocupação no manuseio e uso no contexto específico de um sistema de documentação, ou seja, estes procedimentos devem, portanto, levar em consideração não apenas o documento, mas também suas condições de produção e consumo, fazendo deles procedimentos intrinsecamente hermenêuticos.

Na perspectiva da hermenêutica, o processo de interpretação e compreensão é a primeira atividade de análise de qualquer documento. Apesar das especificidades de cada tipo de documento, quando o documentalista se depara com qualquer ente potencialmente informativo, ele busca identificar quais significados o documento evoca para a comunidade à qual o sistema de documentação serve. Com esta identificação, o documentalista pode elaborar produtos que permitam que um usuário do sistema de documentação recupere esse documento e, por conseguinte, os significados que ele evoca, seu potencial informativo.

\footnotetext{
239 [...] a term that incorporates assumptions of nobility and transferability in its meaning, so that it seems foregone that content will be preserved intact when its material and social supports are stripped away.
} 
Aplicando o círculo hermenêutico ao contexto da análise documentária, podemos dizer que o documentalista projeta uma expectativa de sentido ao documento com base em seu horizonte de compreensão profissional, que, como visto anteriormente, resulta da fusão do horizonte de compreensão da comunidade com o horizonte de compreensão teórico e prático da Ciência da Informação. Essa expectativa de sentido prévia é revisada e corrigida até que o documentalista compreenda os significados que esse documento evoca para a comunidade.

Mais uma vez o documentalista deve ser guiado pelo documento "ele mesmo" durante o processo de interpretação, buscando ser consciente de sua antecipação de sentido não com o objetivo de a confirmar, mas sim de ser ciente de sua expectativa de sentido para a controlar, deixando que o documento "ele mesmo" mostre por meio do processo de interpretação quais os significados que ele evoca para a comunidade.

Como visto, em todo processo de interpretação anteriormente descrito, um documento só pode revelar o que ele significa a partir da situação hermenêutica e do horizonte de compreensão do documentalista. Já vimos que, em princípio, essa situação e esse horizonte devem ser os mesmos que os do sistema de documentação, mas que de fato eles podem ser impactados pela condição individual do documentalista enquanto presença, ser-no-mundo, ser-com que está lançado no mundo e possui um Umwelt próprio. Assim sendo, o documentalista deve procurar interpretar um documento com uma consciência metodológica, ou seja, tendo consciência de quais são sua situação hermenêutica e seu horizonte de compreensão próprios.

Como ressalvado quando discutimos o processo de desenvolvimento de coleções, o processo de interpretação de um documento por um documentalista não visa a que o profissional enquanto presença se oriente em seu estar-lançado. Este processo de interpretação visa à compreensão dos significados que um documento evoca para uma comunidade, ou seja, ele visa à compreensão dos significados que um documento evoca para que uma presença na comunidade, ao utilizá-lo, possa se orientar em seu estar-lançado. Assim, o processo de interpretação que um documentalista realiza durante a análise documentária não visa à aquisição de horizontes e ao desenvolvimento de seu Umwelt, mas visa permitir que alguém na comunidade adquira horizontes de compreensão e desenvolva seu Umwelt. 
Portanto, no contexto da análise documentária, deixar que a interpretação seja guiada pelo documento "ele mesmo" é deixar que o documento mostre os significados que ele evoca para a comunidade sem que a projeção de sentido prévia do documentalista determine os significados que o documento evoca para a comunidade. Ou seja, mais uma vez o documentalista está sujeito a errar por causa de suas opiniões prévias, que podem não se confirmar no documento "ele mesmo".

O produto do processo de análise documentária é a representação documentária. Segundo Lara (2009, p. 37), a representação documentária "é uma construção [...], que tem em vista objetivos pragmáticos de facilitar a organização e a recuperação da informação", ou, na nomenclatura que adotamos, a organização e recuperação de documentos. Esta é uma representação que apresenta "sob forma condensada, os textos submetidos à análise que integram um sistema documentário" (LARA, 2009, p. 37) e é "um tipo de representação construída com a finalidade de substituir um texto num sistema documentário-informacional ou dar acesso a ele por meio de indicadores" (LARA, 2009, p. 40). Apesar de Lara (2009) mencionar especificamente a representação de textos em sua definição, texto deve ser aqui entendido de modo amplo - como visto no capítulo anterior com McKenzie (1999) -, a própria autora fazendo referência a imagens e dados estatísticos como textos (2011). Portanto, entendemos que qualquer tipo de documento é representado de forma condensada com o fim de ser substituído em um sistema de documentação ou dar acesso a ele por meio de indicadores.

O documento deve ser representado de modo a que qualquer aspecto que ele apresente como potencialmente informativo esteja descrito no sistema de documentação, aspectos potencialmente informativos no domínio cognitivo teórico-conceitual, no domínio da ocupação no manuseio e uso e nas relações entre esses domínios. Assim, qualquer aspecto do documento que evoque um significado para a comunidade deve ser representado no sistema.

A representação documentária é o culminar do processo de interpretação e compreensão do documento e, na medida em que "todo ser-aí [presença] compreende-se a partir de seu mundo circundante e de sua vida cotidiana, articulando-se na forma linguística em que se movimenta" (GADAMER, 2012a, p. 75), representações documentárias são produzidas por meio da linguagem, mais especificamente por meio da linguagem documentária, "a linguagem especialmente construída para organizar e facilitar o acesso e a 
transferência da informação" (LARA, 2004, p. 231), ou, na nomenclatura que adotamos, organizar e facilitar o acesso aos documentos e a transferência dos significados que eles evocam.

Segundo Svenonius (2000, p. 53), as linguagens documentárias, que a autora chama de linguagens bibliográficas, funcionam "como uma ponte conectando a linguagem dos documentos àquela dos usuários que os procuram" 240 . Uma linguagem documentária "é uma linguagem artificial que, purgada das anomalias da linguagem natural, é capaz de prover acesso sistemático, em oposição ao acesso incerto, à informação registrada" 241 (SVENONIUS, 2000, p. 53). Isto significa que a linguagem natural "pertence ao grupo social e apresenta uma organização de tal complexidade, que foge ao controle individual", enquanto a "linguagem documentária, ao contrário, deve ser uniforme", cabendo "a um grupo determinar a sua forma de organização interna" (TÁLAMO, 1987, p. 93). Segundo Cintra:

\begin{abstract}
As LD [linguagens documentárias] têm um propósito específico de organização de funções e por isso mesmo pode-se dizer que são governadas por regras de 'JURE', ou seja, por regras estabelecidas por um indivíduo ou grupo que cria o sistema. A LN [linguagem natural], entretanto, embora portadora de organização, apresenta uma complexidade tal, que suas funções são governadas por regras de 'FATO', não de direito, na medida em que não são criadas no todo por um indivíduo, mas atendem às diversas necessidades de comunicação do grupo social (CINTRA, 1983, p. 10).
\end{abstract}

Assim, "define-se linguagem documentária (LD) como uma linguagem construída, oposta à natural, portanto, que tem como objetivo específico tratar a informação para fins de recuperação" (TÁLAMO, 1994, p. 10), ou, na nomenclatura que adotamos, tratar o documento para fins de recuperação.

Para Svenonius (2000) as linguagens documentárias podem ser divididas naquelas que descrevem atributos intelectuais de um documento, como autor, título e assunto, e naquelas que descrevem o documento em sua concretude, como dados de publicação e atributos físicos - tamanho, cor e etc. A divisão realizada por Svenonius (2000) é fundamentada na tradição dos paradigmas físico e cognitivo da Ciência da Informação, já discutida anteriormente em oposição ao paradigma hermenêutico. Contudo, chamamos a atenção para o fato de que Svenonius (2000) considera toda linguagem utilizada para representar um documento em

\footnotetext{
240 [...] as a bridge connecting the language of documents with that of the users who seek them.

241 [...] is an artificial language that, purged of the anomalies of natural language, is capable of providing systematic, as opposed to chancy, access to information in recorded form.
} 
qualquer um de seus diversos aspectos como uma linguagem documentária, enquanto a literatura da Ciência da Informação tradicionalmente considera como linguagem documentária apenas a linguagem que representa o assunto do documento, que, sob a ótica da hermenêutica, é apenas um dos aspectos do documento capaz de evocar significados.

$\mathrm{Na}$ medida em que sob a ótica da hermenêutica o documento é visto como uma totalidade de significância, não sendo justificável a separação entre a representação da "forma" e a representação do "conteúdo" de um documento, entendemos de modo semelhante a Svenonius (2000) que toda linguagem utilizada para representar os significados que um documento evoca é uma linguagem documentária. Cada aspecto do documento que é representado é articulado linguisticamente de acordo com uma linguagem documentária que é criada e organizada de acordo com as necessidades de representação desse aspecto específico do documento que é considerado como evocador de significados para a comunidade que o sistema de documentação atende.

Segundo Cintra et al., as linguagens documentárias são

\begin{abstract}
instrumentos intermediários, ou instrumentos de comutação, através dos quais se realiza a 'tradução' da síntese dos textos e das perguntas dos usuários. Esta 'tradução' é feita em unidades informacionais ou conjunto de unidades aptas a integrar sistemas documentários. A formalização das perguntas dos usuários é feita na linguagem do próprio sistema. É por esta razão que as LDs [linguagens documentárias] podem ser concebidas como instrumentos de comutação documentária (CINTRA et al., 2002, p. 34-35).
\end{abstract}

Cintra et al. (2002) se referem às linguagens documentárias para a representação de assunto, mas entendemos que as linguagens utilizadas para representar qualquer outro aspecto de um documento são igualmente caracterizadas. Qualquer aspecto de um documento que é representado em um sistema de documentação foi descrito linguisticamente de modo a funcionar como um instrumento intermediário, ou de comutação, que substitui o próprio documento no sistema de documentação. Qualquer significado que qualquer dos aspectos do documento evoque precisa ser "traduzido" para a linguagem do sistema.

Gadamer frequentemente discute o processo de interpretação utilizando o exemplo da tradução de um idioma para o outro. Podemos analisar o que ele diz e realizar uma comparação com o processo de representação documentária. Para o autor 
o tradutor precisa transpor o sentido a ser compreendido para o contexto em que vive o outro interlocutor. Mas é claro que isso não significa que possa falsear o sentido que o outro tem em mente. Ao contrário, o sentido precisa ser mantido, mas como ele deve ser compreendido num novo universo de linguagem, precisa ganhar validez de outra maneira. Por isso, toda tradução já é interpretação. Podemos dizer, inclusive, que ela é sempre a consumação da interpretação que o tradutor deu à palavra que lhe foi proposta (GADAMER, 2015, p. 498).

Entendemos que o processo descrito acima é semelhante ao processo de representação realizado por um documentalista. $O$ significado que um documento evoca deve ser entendido no contexto do sistema de documentação, que por sua vez deve ser entendido no contexto da comunidade servida. Desse modo, o significado que um documento evoca deve ser preservado dentro do mundo linguístico condensado do sistema de documentação, que deve estabelecer sua validade em relação ao mundo linguístico da comunidade. Portanto, quando um documento tem o significado que evoca representado pela linguagem documentária do serviço de documentação, ocorre a consumação da interpretação do documentalista.

Segundo Gadamer:

O caso da tradução, portanto, nos faz tomar consciência do caráter de linguagem como o medium do acordo, pois este medium deve ser produzido artificialmente através de uma mediação expressa. De certo que essa elaboração artificial não é o caso normal de uma conversação. Tampouco a tradução é o caso normal de nosso comportamento frente a uma língua estrangeira. Antes, o fato de depender da tradução é uma espécie de tutela por parte do interlocutor. Quando a tradução é necessária, não há outro remédio a não ser adequar-se à distância entre o espírito da literalidade originária do que é dito e sua reprodução, distância que nunca chegamos a superar completamente. Nesses casos o acordo não se dá realmente entre os companheiros de diálogo mas entre os intérpretes, que estão realmente aptos a se encontrar num mundo comum (GADAMER, 2015, p. 498).

Entendemos que o mesmo ocorre no contexto do sistema de documentação. Representações documentárias são mediações expressas onde documento e usuário prescindem de sua "independência" no processo de interpretação; o documento prescinde da possibilidade de ser interpretado por "ele mesmo" e o usuário da possibilidade de dar significado ao documento diretamente a partir de seu horizonte de compreensão pessoal, de seu Umwelt. Existe uma distância entre o documento "ele mesmo" e a representação documentária. Portanto, o processo de recuperação de um documento armazenado em um sistema de documentação não acontece pela interpretação direta do documento, mas pela 
interpretação da interpretação do documento realizada por um documentalista de acordo com o horizonte de compreensão do sistema de documentação.

Segundo Gadamer (2015, p. 499), “depender da tradução de um intérprete é um caso extremo que reduplica o processo hermenêutico". A dependência da representação documentária pode ser vista como um caso de reduplicação do processo hermenêutico, no entanto, entendemos que essa dependência é uma característica intrínseca daquilo que Day (2016) chama de comunidade documentária compartilhada.

Uma vez que, segundo Frohmann (2004), são práticas documentárias, tais como contexto de produção e uso, institucionalização e historicidade, que determinam a informatividade de um documento, que tornam um documento informativo, é possível que um documento armazenado em um sistema de documentação, um documento que não pode ser recuperado sem a mediação de sua representação, tenha adquirido informatividade apenas porque foi institucionalizado. Ou seja, sem as práticas de representação documentária, sem a reduplicação do processo hermenêutico, não haveria documento para evocar significados.

Uma outra questão que se levanta em relação à representação documentária é o fato de que, segundo Buckland (2012a), ela é por definição para uso futuro, para a recuperação de um documento no futuro. Isto requer que o documentalista pense sobre necessidades informacionais prováveis e represente um documento pensando em sua recuperação futura. Entretanto, "significados são estabelecidos pelo uso e, portanto, são sempre extraídos do passado"242 (BUCKLAND, 2012a, p. 156).

Segundo Gadamer (2011c, p. 173), uma característica do ser humano sob o ponto de vista da hermenêutica é a de ele ter "um sentido para o futuro". Em sua condição lançada, a presença sempre compreende o mundo a partir de horizontes de compreensão formados no passado, seja porque são os padrões normativos de interpretação e conduta da cultura na qual ela está lançada, ou seja, da tradição na qual ela se insere, ou porque foram adquiridos ao longo de sua experiência de vida. No entanto, a presença se orienta para o futuro, pois seu modo de ser é a compreensão, um processo de projeção de suas possibilidades que dá “caráter futuro" à presença (GADAMER, 2015, p. 25). É possível concluir assim que o modo de

\footnotetext{
242 Meanings are established by usage, and so always draw on the past.
} 
ser da representação documentária se assemelha ao modo de ser da presença, que é a existência "entre duas obscuridades, o futuro e a proveniência" (GADAMER, 2012a, p. 75).

Transformações no sistema de documentação e na comunidade que ele atende levam a que essa representação fique obsoleta, algo que sob a ótica da hermenêutica pode ser entendido como uma consequência do fato de que "a linguagem tem sua própria historicidade" (GADAMER, 2011e, p. 71). Em uma situação ideal, representações são revistas periodicamente de modo a representarem uma nova totalidade de significações. Assim, o processo de reanálise e "rerepresentação" pode ser entendido como uma nova etapa do círculo hermenêutico de interpretação e compreensão, onde o documento tem seu sentido aprofundado e ampliado de acordo com a mudança no contexto da comunidade documentária compartilhada.

Realizado o processo de análise e representação documentária os documentos podem ser recuperados e utilizados, como veremos a seguir.

\subsection{Busca e recuperação de documentos, serviço de referência e relevância}

Como visto no capítulo anterior, a presença sente uma necessidade informacional quando se depara em seu estar-lançado "com algo estranho, provocante e desorientador" (GADAMER, 2011d, p. 218), algo que cria uma situação na qual ela não pode mais avançar, de modo que ela busca um conhecimento mais profundo para poder seguir em frente. Vimos também que a presença pode suprir sua necessidade informacional de diversas formas, uma delas sendo a busca de documentos potencialmente informativos em um sistema de documentação.

Executar uma busca em um sistema de documentação é uma atividade hermenêutica que pressupõe que a presença compreenda o funcionamento do sistema de documentação de modo geral, assim como o funcionamento do sistema específico de busca e recuperação de documentos. A compreensão destes dois processos apresenta tanto uma dimensão cognitiva teórico-conceitual como uma dimensão de ocupação, de contextos e envolvimentos práticos através de manuseio e uso. Uma vez que a presença tenha compreendido como ela deve executar uma busca nessas duas dimensões e em suas inter-relações, ela pode partir para esta execução em si. 
De modo geral, segundo Hjørland (1998, p. 16), o processo de busca e recuperação de documentos pode ser entendido como "o processo no qual usuários colocam questões aos sistemas de informação [ou, na nomenclatura que adotamos, sistemas de documentação] e consequentemente obtêm algumas respostas"243. Para o autor, "no nível mais elementar, esta interação consiste de 1) uma pergunta 2) algumas representações de textos 3) alguma técnica de correspondência"244. Segundo Buckland (2017) e Buckland e Plaunt (1994), é possível entender o sistema que executa este processo como um sistema de seleção, uma vez que ele realiza a correspondência entre uma pergunta e representações documentárias de modo a selecionar os documentos armazenados no sistema de documentação que têm o potencial de responder à pergunta feita pelo usuário.

A busca em um sistema de seleção pressupõe que a pergunta que o usuário quer fazer passe por um processo de formalização que a adéque à linguagem do sistema. Frases interrogativas precisam ser transformadas em descritores, o que exige um esforço de conceptualização e "tradução", que são processos de interpretação e compreensão.

Gadamer (2011b, p. 139) afirma que "todo esforço de conceitualização persegue, de princípio, o consenso possível, o acordo possível, devendo basear-se já num acordo vinculante, quando se quer chegar a um entendimento", afinal "onde não há vínculo, também não pode haver diálogo". É possível entender a transformação da pergunta do usuário como um esforço de conceptualização que objetiva criar um acordo que vincule a pergunta do usuário ao sistema de documentação, de modo que possam ser recuperados documentos que respondam à pergunta feita. Nesse sentido, só pode haver um "diálogo" entre usuário e sistema quando há um "entendimento" entre eles, quando a pergunta do usuário é formalizada em um descritor formalmente utilizado pelo sistema nas suas representações documentárias. $\mathrm{O}$ processo de busca é um processo onde a necessidade informacional deve ser analisada e representada para que a busca ocorra, esta representação devendo ser feita especificamente na linguagem utilizada pelo sistema para que a recuperação possa ocorrer.

Com a pergunta traduzida para a linguagem do sistema de documentação, ela pode ser inserida no sistema de seleção, de modo a que representações documentárias sejam recuperadas. A lista recuperada presume que a presença interprete e compreenda a

\footnotetext{
243 [...] the process in which users put questions to information systems and consequently get some answers [...].

${ }^{244}$ At the most elementary level, this interaction consists of 1 ) a query 2) some text representations 3 ) some matching technique.
} 
representação de acordo com sua situação hermenêutica e seu horizonte de compreensão, de modo a que possa identificar através da representação se o documento ao qual esta se refere tem potencial informativo para o seu ser-no-mundo.

O processo de interpretação e compreensão de uma representação documentária é um processo que também está sujeito ao círculo hermenêutico. $O$ usuário ser-no-mundo tem uma expectativa de sentido quando recupera uma representação e, baseado no processo de interpretação e compreensão, buscará acesso ao documento em si para que sua necessidade de informação seja suprida.

A própria interpretação e compreensão da recuperação não se dá apenas quando o usuário tem acesso à representação documentária, mas também no processo de chegar a essa representação. A interpretação e compreensão de uma lista de resultados em uma base de dados é um primeiro passo para a chegada à representação em si. O mesmo acontece com catálogos online ou até mesmo com fichários.

Caso a presença não consiga ou não queira fazer sozinha uso do sistema de seleção de representações documentárias, ela irá ao encontro do serviço de referência, onde um profissional deverá entrar em um processo de diálogo com a presença, de modo a interpretar e compreender o que ela busca, onde mais uma vez se coloca em prática o círculo hermenêutico. As atividades conduzidas pelo serviço de referência podem ser descritas da seguinte maneira:

\begin{abstract}
Antes de iniciar uma busca em resposta a uma questão, o bibliotecário [ou documentalista] de referência conduz uma entrevista de referência para desenvolver uma compreensão mais completa da necessidade de informação do usuário. Interações de referência bem-sucedidas requerem uma variedade de habilidades além de questionamento eficaz. Bibliotecários [ou documentalistas] deveriam ter um interesse genuíno nas necessidades informacionais dos usuários, uma habilidade de estabelecer confiança e segurança, flexibilidade no desenvolvimento de estratégias de busca e conhecimento das fontes de referência ${ }^{245}$ (SMITH, 2017, p. 3912)
\end{abstract}

O documentalista projetará um sentido à pergunta do usuário e irá ampliando e aprofundando esse sentido conforme dialogar com o usuário e interpretar o que ele lhe diz.

\footnotetext{
245 Prior to initiating a search in response to a question, the reference librarian conducts a reference interview to develop a more complete understanding of the user's information need. Successful reference interactions require a variety of skills in addition to effective questioning. Librarians should have a genuine interest in users' information needs, an ability to establish trust and confidence, flexibility in developing search strategies, and knowledge of reference sources.
} 
Neste momento, o documentalista deve buscar interpretar a pergunta "ela mesma". Aqui o documentalista interpreta a pergunta do usuário através do seu horizonte de compreensão profissional, formado pela totalidade de significações da comunidade e pela conduta de trabalho. Novamente o documentalista deve balancear seu horizonte de compreensão profissional com seu horizonte de compreensão individual.

Uma vez que o documentalista compreenda o que o usuário busca, ele procede à tradução da necessidade de informação à linguagem do sistema, de modo que o sistema de seleção recupere os documentos que podem responder à informação que o usuário está buscando. Contudo, a relevância de um documento para um usuário pode apenas ser determinada pelo próprio usuário de acordo com aquilo que o permite lidar com seu estarlançado.

Segundo Saracevic (2016), existem duas manifestações básicas de relevância: relevância para o usuário e relevância para o sistema, cada uma delas envolvendo diferentes relações. Aqui não entendemos a relevância no sentido da recuperação de representações documentárias pelo sistema de seleção, mas sim como a relevância para o ser-no-mundo que obteve um documento. A detecção da relevância do documento também responde ao círculo hermenêutico e o documento somente é relevante se ele permitir ao ser-no-mundo que este se responsabilize por si mesmo.

Segundo Buckland (2017, p. 155), a relevância se encontra "na natureza evidencial dos documentos e nas necessidades cognitivas relativas a esse papel evidencial"246. Sob uma perspectiva hermenêutica, estas necessidades cognitivas não se referem apenas a necessidades de conhecimento entendido como conhecimento perceptivo, da tradição filosófica, mas se referem a necessidades de conhecimento entendido como tudo aquilo que permite à presença enquanto ser-no-mundo lidar com seu estar-lançado.

Ainda segundo Buckland:

Relevância é altamente situacional, dependendo do que o inquiridor já sabe. E relevância é instável porque o inquiridor está, ou deveria estar, aprendendo ativamente, de modo que o próprio fato de recuperar documentos informativos deveria mudar a condição de relevância dos documentos para o buscador ${ }^{247}$ (BUCKLAND, 2017, p. 160).

\footnotetext{
$246[. .$.$] in the evidential nature of documents and the cognitive needs relative to that evidential role.$

247 Relevance is highly situational, depending on what the inquirer already knows. And relevance is unstable because the inquirer is, or should be, actively learning, so the very fact of retrieving informative documents should change the relevance status of documents for the searcher.
} 
Assim, a relevância não é binária, ou seja, um documento não é relevante ou não relevante: "na prática, documentos provavelmente são um tanto relevantes, parcialmente relevantes, marginalmente relevantes ou de relevância incerta"248, a relevância sendo diferente dependendo de quem a avalia e de quando no tempo uma mesma pessoa a avalia (BUCKLAND, 2017, p. 160-161). Ou seja, a relevância depende da situação hermenêutica e do horizonte de compreensão do usuário.

Portanto, "relevância é subjetiva, idiossincrática, difícil de prever e instável"249 (BUCKLAND, 2017, p. 161).

\subsection{Infraestrutura}

Segundo Star e Ruhleder (1996, p. 112), “infraestrutura é algo que emerge para pessoas na prática, conectada a atividades e estruturas" 250 . Para as autoras $(1996$, p. 112) a infraestrutura é comumente entendida como um substrato, isto é, como "algo sobre o qual alguma outra coisa 'funciona' ou 'opera', tal como um sistema de trilhos de trem sobre o qual vagões ferroviários rodam"251. Ver a infraestrutura desta forma é vê-la "como algo que é construído e mantido e que então submerge em um plano de fundo invisível. É algo que somente está lá, à mão, completamente transparente"252 (STAR; RUHLEDER, 1996, p. 112).

Para Larkin:

Infraestruturas são redes construídas que facilitam o fluxo de bens, pessoas ou ideias e permitem sua troca através do espaço. Como formas físicas elas moldam a natureza de uma rede, a velocidade e direção de seu movimento, sua temporalidade e sua vulnerabilidade a danos. Elas incluem a arquitetura para circulação, literalmente fornecendo a fundação das sociedades modernas, e geram o meio ambiente da vida diária ${ }^{253}$ (LARKIN, 2013, p. 328).

\footnotetext{
248 In practice, documents are more likely to be somewhat relevant, partially relevant, marginally relevant, or of uncertain relevance.

249 [...] relevance is subjective, idiosyncratic, hard to predict, and unstable.

$250[. .$.$] infrastructure is something that emerges for people in practice, connected to activities and structures.$

251 [...] something upon which something else "runs" or "operates," such as a system of railroad tracks upon which rail cars run.

252 [...] as something that is built and maintained, and which then sinks into an invisible background. It is something that is just there, ready-to-hand, completely transparent.

253 Infrastructures are built networks that facilitate the flow of goods, people, or ideas and allow for their exchange over space. As physical forms they shape the nature of a network, the speed and direction of its movement, its temporalities, and its vulnerability to breakdown. They comprise the architecture for circulation, literally providing the undergirding of modern societies, and they generate the ambient environment of everyday life.
} 
No contexto dos sistemas de documentação, infraestrutura é aquilo sobre o qual são construídos sistemas de armazenamento, organização e recuperação de documentos, mas que eventualmente são invisíveis para aqueles que armazenam, organizam e recuperam documentos. A infraestrutura dos sistemas de documentação permite que os significados evocados pelos documentos fluam e sejam trocados através do sistema de documentação e para dentro e para fora dele. Ela molda a natureza do sistema de documentação, a velocidade em que os significados evocados pelos documentos alcançam uma comunidade, a direção em que esses significados vêm para e saem de uma comunidade, as restrições de tempo da circulação desses significados e a vulnerabilidade do sistema. A infraestrutura de cada sistema de documentação varia, geralmente abrangendo edifícios, mobília, água e encanamento, eletricidade, a estrutura material de catálogos e bases de dados - como hardware e software de computadores, mas não exclusivamente -, dispositivos para a leitura de documentos leitores de microformas, disquetes, CD-ROMs e etc. -, e tudo mais que dê apoio ao armazenamento, organização e recuperação de documentos. Além disso, pessoas também são cruciais para a infraestrutura:

Pessoas não foram meras beneficiárias de infraestrutura; elas realmente serviram como elos integrais dentro daquelas redes infraestruturais, fornecendo mão de obra para extração material ou para serviços de entrega, por exemplo, ou substituindo com suas próprias mãos bombas e canos e portais quando estes falham ou, como é o caso em bolsões particularmente desempossados do mundo, quando aquele andaime está simplesmente ausente ${ }^{254}$ (MATTERN, 2018, p. 321, grifo da autora).

Apesar de a infraestrutura submergir em um plano de fundo invisível, sendo um substrato, ela também faz parte do mundo, de uma rede estruturada de significância, sendo inerentemente constituída com significado, de modo que a presença se relaciona com a infraestrutura não apenas de modo causal, mas também simbolicamente. Segundo Larkin,

infraestruturas também existem como formas separadas de seu funcionamento puramente técnico e precisam ser analisadas como veículos concretos semióticos e estéticos orientados para destinatários. Elas emergem de e armazenam dentro de si formas de desejo e fantasia e podem assumir aspectos de fetiche que às vezes podem ser totalmente independentes de sua função técnica. Focando na questão da forma, ou na poética da infraestrutura, nos permite compreender como o político

\footnotetext{
${ }^{254}$ People have not been mere beneficiaries of infrastructure; they have actually served as integral links within those infrastructural networks, providing labor for material extraction or service delivery, for instance, or filling in with their own hands when the pumps and pipes and portals fail or, as is the case in particular disenfranchised pockets of the world, when that scaffolding is simply absent.
} 
pode ser constituído através de diferentes meios. Isso aponta para o senso de desejo e possibilidade [...]. Isso também significa estar vivo para as dimensões formais das infraestruturas, compreendendo que tipo de objetos semióticos elas são e determinando como elas se endereçam a e constituem sujeitos, assim como suas operações técnicas ${ }^{255}$ (LARKIN, 2013, p. 329).

Para Star e Ruhleder (1996, p. 113) a "infraestrutura é um conceito fundamentalmente relacional. Ela se torna infraestrutura em relação a práticas organizadas" 256 . Segundo as autoras (1996, p. 113, grifo nosso), "na análise histórica, a política, a voz e a autoria embutidas nos sistemas [de infraestrutura] são reveladas-não como motores de mudança, mas como componentes articulados do sistema que está sob exame. Substrato se torna substância" 257 . Seguindo a mesma ideia, Larkin afirma que:

\begin{abstract}
Infraestruturas são matéria que possibilita o movimento de outra matéria. Sua ontologia particular jaz no fato de que elas são coisas e de que elas também são a relação entre coisas. Como coisas elas estão presentes para os sentidos, mas elas também estão deslocadas do foco da matéria ao redor do qual elas se movem. [...] Contudo, a dualidade das infraestruturas indica que quando elas operam sistematicamente elas não podem ser teorizadas em termos do objeto sozinho. 0 que distingue infraestruturas de tecnologias é o fato de que elas são objetos que criam as bases nas quais outros objetos operam, e quando elas o fazem elas operam como sistemas $^{258}$ (LARKIN, 2013, p. 329).
\end{abstract}

Percebemos assim que a infraestrutura, mais do que pertencer ao domínio cognitivo teórico-conceitual, pertence ao domínio da ocupação no manuseio e uso. Na medida em que todos os processos anteriormente discutidos neste capítulo dependem de infraestrutura,

\footnotetext{
255 [...] infrastructures also exist as forms separate from their purely technical functioning, and they need to be analyzed as concrete semiotic and aesthetic vehicles oriented to addressees. They emerge out of and store within them forms of desire and fantasy and can take on fetish-like aspects that sometimes can be wholly autonomous from their technical function. Focusing on the issue of form, or the poetics of infrastructure, allows us to understand how the political can be constituted through different means. It points to the sense of desire and possibility [...]. It also means being alive to the formal dimensions of infrastructures, understanding what sort of semiotic objects they are, and determining how they address and constitute subjects, as well as their technical operations.

${ }^{256}[\ldots .$.$] infrastructure is a fundamentally relational concept. It becomes infrastructure in relation to organized$ practices.

${ }^{257}$ In the historical analysis, the politics, voice and authorship embedded in the systems are revealed-not as engines of change, but as articulated components of the system under examination. Substrate becomes substance.

${ }^{258}$ Infrastructures are matter that enable the movement of other matter. Their peculiar ontology lies in the facts that they are things and also the relation between things. As things they are present to the senses, yet they are also displaced in the focus on the matter they move around. [...] Yet the duality of infrastructures indicates that when they operate systemically they cannot be theorized in terms of the object alone. What distinguishes infrastructures from technologies is that they are objects that create the grounds on which other objects operate, and when they do so they operate as systems [...].
} 
todos eles sendo processos hermenêuticos de interpretação e compreensão, sua realização é intrinsecamente ligada à infraestrutura do sistema de documentação, sendo dependente do domínio da ocupação no manuseio e uso para sua execução.

\subsection{Sistemas de documentação sob a ótica da hermenêutica}

A Ciência da Informação objetiva a construção de sistemas de documentação, isto é, sistemas de coleção, armazenamento e organização de documentos que sejam dotados de significado e permitam a recuperação desses documentos para que seu potencial informativo, os significados que eles evocam, sirva de auxílio à presença que objetiva se responsabilizar por si mesma e se fundamentar no mundo em seu estar-lançado. Buscar contribuir para a sistematização de uma metateoria hermenêutica da Ciência da Informação através do levantamento de elementos teórico-conceituais de cunho geral que sirvam de base para essa sistematização pressupõe que o funcionamento desses sistemas de documentação seja analisado sob a perspectiva da hermenêutica, que foi o que objetivamos neste capítulo.

Aqui analisamos conceitos fundamentais às atividades de armazenamento, organização e recuperação de documentos sob a ótica da hermenêutica, mostrando o caráter intrinsecamente hermenêutico dos sistemas de documentação. Segundo Heidegger (1971, 1985, 2003), aquilo que é hermenêutico é aquilo que traz mensagens, mensagens estas que precisam ser preservadas, conservadas, guardadas para serem transmitidas. Na medida em que sistemas de documentação colecionam, armazenam e organizam documentos evocadores de significados para que estes significados sejam transmitidos, concluímos que sistemas de documentação e os processos e atividades desenvolvidos para sua criação e manutenção podem ser entendidos como tendo uma natureza hermenêutica.

Com o levantamento de elementos teórico-conceituais de cunho geral referentes aos modos como os documentos são tratados para que possam ser recuperados e utilizados pelos indivíduos, ou seja, referentes ao armazenamento, organização e recuperação de documentos sob a ótica hermenêutica que foram apresentados neste capítulo, pudemos cumprir nosso segundo objetivo de pesquisa.

Passamos agora à conclusão de nossa pesquisa de doutorado. 


\section{Conclusão}

Esta pesquisa de doutorado surgiu da seguinte pergunta: como seria possível a sistematização do corpo teórico-conceitual da Ciência da Informação? Ao investigarmos a literatura sobre a epistemologia da disciplina para chegarmos a uma resposta, verificamos que cada um dos paradigmas de desenvolvimento da Ciência da Informação possui suas bases teórico-conceituais próprias, de modo que identificamos ser necessário definir o paradigma a partir do qual buscar a sistematização do corpo teórico-conceitual da disciplina. Determinando que nosso foco seria o paradigma hermenêutico da Ciência da Informação, formulamos as seguintes hipóteses em resposta à nossa pergunta de pesquisa:

a) ao articularmos Ciência da Informação e hermenêutica, esta serviria de base para a sistematização do corpo teórico-conceitual específico do paradigma hermenêutico da disciplina;

b) seria possível sistematizar o corpo teórico-conceitual do paradigma hermenêutico da Ciência da Informação através da sistematização de sua metateoria.

De forma a verificarmos essas hipóteses, formulamos como objetivo geral de nossa pesquisa levantar elementos teórico-conceituais de cunho geral que sirvam de base para a sistematização futura de uma metateoria hermenêutica da Ciência da Informação e como objetivos específicos:

a) levantar elementos teórico-conceituais de cunho geral referentes ao comportamento informacional sob a ótica hermenêutica;

b) levantar elementos teórico-conceituais de cunho geral referentes ao armazenamento, organização e recuperação de documentos sob a ótica hermenêutica.

Nosso levantamento, revisão e análise da literatura da hermenêutica e sua articulação a elementos teórico-conceituais referentes à relação entre indivíduo e informação, bem como aos referentes aos modos como os documentos são tratados para que possam ser recuperados e utilizados pelos indivíduos, confirmou nossa hipótese de que a hermenêutica 
serviria de base para a sistematização do corpo teórico-conceitual específico do paradigma hermenêutico da Ciência da Informação. Ao articularmos elementos teórico-conceituais da Ciência da Informação à hermenêutica pudemos verificar que os fundamentos da hermenêutica perpassam toda a Ciência da Informação, servindo assim de base para a sistematização do corpo teórico-conceitual do paradigma hermenêutico da disciplina.

Ainda que a sistematização de uma metateoria completa esteja além do escopo de uma única pesquisa de doutorado, concluímos que nossa segunda hipótese poderia ser verificada através do objetivo ao qual nos propusemos, pois entendemos que o levantamento por nós realizado se configura como um delineamento inicial de uma perspectiva teórica abrangente à toda a disciplina da Ciência da Informação. Nossa pesquisa nos levou a concluir que os pontos centrais ao redor dos quais se estrutura a Ciência da Informação sob uma perspectiva hermenêutica são o indivíduo que busca informação e dela faz uso e o documento capaz de informar, pontos estes que foram individualmente explorados em nossa pesquisa. Portanto, concluímos que nosso levantamento se configura como um delineamento inicial para o desenvolvimento de uma metateoria da Ciência da Informação.

$\mathrm{Na}$ medida em que nosso objetivo era levantar elementos teórico-conceituais de cunho geral que sirvam de base para a sistematização futura de uma metateoria hermenêutica da Ciência da Informação, metateoria aqui entendida como uma perspectiva que se sobrepõe à teoria da disciplina, estávamos cientes dos problemas identificados por Ritzer (1991) com relação a este tipo de metateorização, de modo a que nossa pesquisa pudesse efetivamente contribuir para com a sistematização do corpo teórico-conceitual da Ciência da Informação.

O primeiro problema apontado por Ritzer (1991) é a tendência dos metateóricos de argumentar que sua perspectiva teórica abrangente é a única correta e que todas as outras estão erradas. Como dissemos no capítulo sobre nosso percurso teórico-metodológico, jamais tivemos a pretensão de que os elementos levantados sejam utilizados para a sistematização da única metateoria "correta" da disciplina e que todas as outras estariam "erradas". Partimos da compreensão de que não existe uma única possibilidade global e totalitária de sistematização do corpo teórico-conceitual da Ciência da Informação, o que faria da metateoria a ser desenvolvida a partir dos elementos que levantamos uma metateoria específica a partir da ótica da hermenêutica. Após concluirmos nossa pesquisa, mantemos nosso entendimento de que a metateoria a ser sistematizada a partir dos elementos que 
levantamos é apenas uma dentre as metateorias possíveis, uma metateoria que visará sistematizar o paradigma hermenêutico da Ciência da Informação.

O segundo problema indicado por Ritzer (1991) é o de que perspectivas abrangentes seriam imprecisas, ou seja, não definiriam claramente seus conceitos e suas inter-relações. Em nosso levantamento buscamos a precisão e clareza na exposição dos conceitos levantados e de suas inter-relações, já que nosso problema de pesquisa é justamente a falta de estruturação do corpo teórico-conceitual da Ciência da Informação. Entendemos que tivemos sucesso em evitar este problema, pois os conceitos que levantamos e suas inter-relações se articulam adequadamente e apresentam consistência interna.

O terceiro problema ao qual Ritzer (1991) se refere é o de que metateorias não auxiliam o trabalho teórico e tampouco o trabalho empírico. Em nosso levantamento buscamos obter um nível de generalidade que auxiliasse tanto o trabalho teórico como o trabalho empírico dentro da disciplina, já que a detecção de nosso problema de pesquisa indicou que a falta de um corpo teórico-conceitual sistematizado traz problemas tanto aos desenvolvimentos teóricos como aos desenvolvimentos empíricos da Ciência da Informação. Concluímos que nosso levantamento procurou ser suficientemente abrangente, de modo a auxiliar tanto os desenvolvimentos teóricos como empíricos da disciplina.

Em nossa ótica, pudemos cumprir o objetivo ao qual nos propusemos, confirmando nossas hipóteses de que a hermenêutica serve de base para a sistematização do corpo teóricoconceitual do paradigma hermenêutico da Ciência da Informação e de que é possível sistematizar o corpo teórico-conceitual do paradigma hermenêutico da disciplina através da sistematização de sua metateoria.

Como pudemos mostrar nesta tese, interpretação e compreensão são processos infinitos. Interpretar e compreender a hermenêutica como a base que perpassa toda a Ciência da Informação é, portanto, um trabalho infinito, assim como é infinito o processo de sistematização de uma metateoria da disciplina. Esta constatação significa que temos a possibilidade de continuar explorando as relações entre a hermenêutica e a Ciência da Informação, sendo que a cada revisão que façamos de nossa compreensão dessas relações estaremos aprofundando e ampliando seu sentido, o que possibilita a melhor compreensão constante das limitações e possibilidades da disciplina.

Em seu estar-lançado a presença está continuamente se projetando para o futuro. Assim, em nosso próprio estar-lançado estamos nos projetando para um futuro de 
possibilidades de desenvolvimento de pesquisas onde as relações entre Ciência da Informação e hermenêutica serão exploradas. 


\section{Referências}

ABDALLA, Raquel B.; KOBASHI, Nair Y. (2012). Ciência da informação: reflexões sobre a constituição de um campo científico. In: GUIMARÃES, José A. C.; DODEBEI, Vera L. D. L. M. (orgs.). Desafios e perspectivas científicas para a organização e representação do conhecimento na atualidade. Marília: ISKO-Brasil; FUNDEPE. (Estudos Avançados em Organização e Representação do Conhecimento, v. 1). p. 54-58.

ADRIAANS, Pieter W. (2018). Information. In: ZALTA, Edward N. (ed.). The Stanford Encyclopedia of Philosophy. Winter 2018 Edition. Disponível em: https://plato.stanford.edu/archives/win2018/entries/information/. Acesso em: 13 jan. 2019.

ANDERSON, Kimberly. (2013). The footprint and the stepping foot: archival records, evidence, and time. Archival Science, [Dordrecht], v. 13, n. 4, p. 349-371.

ARAÚJO, Paula C.; GUIMARÃES, José A. C.; TENNIS, Joseph. (2017). Metatheory and Knowledge Organization. In: NORTH AMERICAN SYMPOSIUM ON KNOWLEDGE ORGANIZATION, 6., 2017, Champaign. Proceedings [...]. Champaign: University of Illinois at Urbana-Champaign. p. 173-181. Disponível em: https://journals.lib.washington.edu/index.php/nasko/article/view/15238. Acesso em: 22 dez. 2018.

ARAÚJO, Paula C.; TENNIS, Joseph. (2018). Influence of metatheoretical research in Knowledge Organization. In: INTERNATIONAL ISKO CONFERENCE: CHALLENGES AND OPPORTUNITIES FOR KNOWLEDGE ORGANIZATIONIN THE DIGITAL AGE, 15., 2018, Porto. Proceedings [...]. Porto: University of Porto. p. 273-281.

ÁREAS do Conhecimento - Ciências Sociais Aplicadas. [2018]. In: DIRETÓRIO de Grupos de Pesquisa no Brasil. [Brasília, DF: Conselho Nacional de Desenvolvimento Científico e Tecnológico]. Disponível em: http://lattes.cnpq.br/web/dgp/ciencias-sociais-aplicadas. Acesso em: 17 dez. 2018.

BARRetO, Aldo A. (1994). A questão da informação. São Paulo em Perspectiva, [São Paulo], v. 8 , n. 4, p. 3-8.

BARRETO, Aldo A. (1998). O rumor do conhecimento. São Paulo em Perspectiva, [São Paulo], v. 12, n. 4 , p. 69-77.

BARRON, Daniel; CURRAN, Charles. (1981). A look at community analysis: some myths and some realities. Public libraries, Chicago, v. 20, p. 29-30.

BATES, Marcia J. (1999). The invisible substrate of Information Science. Journal of the American Society for Information Science, [Washington], v. 50, n. 12, p. 1043-1050. 
BATES, Marcia J. (2005). An introduction to metatheories, theories, and models. In: FISHER, Karen. E., ERDELEZ, Sandra; MCKECHNIE, Lynne (eds.). Theories of information behavior. Medford, NJ: Information Today. p. 1-24.

BATES, Marcia J. (2006). Fundamental Forms of Information. Journal of the American Society for Information Science and Technology, [New York], v. 57, n. 8, p. 1033-1045.

BATES, Marcia J. (2017). Information Behavior. In: McDONALD, John D.; LEVINE-CLARK, Michael (eds.). Encyclopedia of Library and Information Sciences. 4. ed. Boca Raton: CRC Press. p. 2074-2085.

BAUMAN, Zygmunt. (1978). Hermeneutics and social science. New York: Columbia University Press.

BERGER, Peter L.; LUCKMANN, Thomas. (2004). A construção social da realidade: tratado de sociologia do conhecimento. 24. ed. Petrópolis: Vozes.

BRÄSCHER, Marisa; CAFÉ, Lígia. (2010). Organização da Informação ou Organização do Conhecimento? In: LARA, Marilda L. G.; SMIT, Johanna W. (orgs.). Temas de pesquisa em Ciência da Informação no Brasil. São Paulo: Escola de Comunicações e Artes/USP. p. 85-103.

BRIET, Suzanne. (2016). O que é a documentação? Brasília: Briquet de Lemos.

BROOKES, Bertram C. (1980). The foundations of Information Science: part I, philosophical aspects. Journal of Information Science, [Amsterdam], v.2, n. 3-4, p.125-133.

BUCKLAND, Michael K. (1989). The roles of collections and the scope of collection development. Journal of Documentation, [London], v. 45, n. 3, p. 213-226.

BUCKLAND, Michael K. (1991). Information as thing. Journal of the American Society for Information Science, [Washington], v. 42, n. 5, p. 351-360.

BUCKLAND, Michael K. (1995). What will collection developers do? Information Technology and Libraries, [Chicago], v. 14, n. 3, p. 155-159.

BUCKLAND, Michael K. (1999). The landscape of Information Science: the American Society for Information Science at 62. Journal of American Society for Information Science, [Washington], v. 50, n. 11, p. 970-974.

BUCKLAND, Michael K. (2011). Information schools: a monk, library science, and the information age. In: Hauke, Petra. (ed.). Bibliothekswissenschaft - quo vadis? / Library science - quo vadis?: eine Disziplin zwischen Traditionen und Visionen: Programme Modelle - Forschungsaufgaben / a discipline between challenges and opportunities: programs - models - research assignments. Berlin: De Gruyter. p. 19-32.

BUCKLAND, Michael K. (2012a). Obsolescence in subject description. Journal of Documentation, [Bingley], v. 68, n. 2, p. $154-161$. 
BUCKLAND, Michael K. (2012b). What kind of a science can Information Science be? Journal of the American Society for Information Science and Technology, [New York], v. 63, n. 1, p. 1-7.

BUCKLAND, Michael K. (2013). The quality of information in the web. BiD: textos universitaris de biblioteconomia i documentació, Barcelona, n. 31. Disponível em: http://bid.ub.edu/en/31/buckland3.htm. Acesso em: 15 jan. 2014.

BUCKLAND, Michael K. (2017). Information and Society. Cambridge, MA: MIT Press.

BUCKLAND, Michael K. (2018). Document Theory. Knowledge Organization, [Würzburg], v. 45, n. 5 , p. 425-436.

BUCKLAND, Michael K.; LIU, Ziming. (1995). History of Information Science. Annual Review of Information Science and Technology, [Medford], v. 30, p. 385-416.

BUCKLAND, Michael K.; PLAUNT, Christian J. (1994). On the construction of selection systems. Library Hi Tech, [Ann Arbor], v. 12, n. 4, p. 15-28.

BUNNIN, Nicholas; YU, Jiyuan. (2004). The Blackwell Dictionary of Western Philosophy. Malden: Blackwell.

BUTLER, Tom. (1998). Towards a hermeneutic method for interpretive research in information systems. Journal of Information Technology, [London], v. 13, n. 4, p. 285-300.

CAPURRO, Rafael. (1978). Information: ein Beitrag zur etymologischen und ideengeschichtlichen Begründung des Informationsbegriffs. München: Saur Verlag.

CAPURRO, Rafael. (2007). Epistemología y ciencia de la información. Enl@ce: revista venezolana de información, tecnología y conocimiento, [Maracaibo], v. 4, n. 1, p. 11-29.

CAPURRO, Rafael. (2008). Pasado, presente y futuro de la noción de información. In: ENCUENTRO INTERNACIONAL DE EXPERTOS EN TEORÍAS DE INFORMACIÓN: UN ENFOQUE INTERDISCIPLINAR, 1., 2008, León. Actas [...]. León: Universidad de León. p. 1-26.

CAPURRO, Rafael; HJ $\varnothing$ RLAND, Birger. (2003). The concept of information. Annual Review of Information Science and Technology, [Medford], v. 37, p. 343-411.

CINTRA, Anna M. M. (1983). Elementos de linguística para estudos de indexação. Ciência da Informação, Brasília, v. 12, n. 1, p. 5-22.

CINTRA, Anna M. M. et al. (2002). Para entender as linguagens documentárias. 2. ed. rev. ampl. São Paulo: Polis. (Coleção Palavra-Chave, 4).

CLANCHY, Michael T. (2013). From Memory to Written Record: England 1066-1307. 3. ed. Chichester: Wiley-Blackwell. 
CUADRA, Carlos A. (1964). Identifying key contributions to information science, American Documentation, [Washington], v. 15, p. 289-295.

CUNHA, Isabel M. R. F. (1987). Análise documentária. In: SMIT, Johanna W. (coord.). Análise documentária: a análise da síntese. Brasília: IBICT. p. 37-60.

DAHLSTROM, Daniel O. (2013). The Heidegger Dictionary. London: Bloomsbury Academic. (Bloomsbury philosophy dictionaries).

DAY, Ronald E. (2001). The modern invention of information: discourse, history, and power. Carbondale: Southern Illinois University Press.

DAY, Ronald E. (2011). Death of the user: reconceptualizing subjects, objects, and their relations. Journal of American Society for Information Science, [New York], v. 62, n. 1, p. 7888.

DAY, Ronald E. (2014). Indexing it all: the subject in the age of documentation, information, and data. Cambridge, MA: MIT Press.

DAY, Ronald E. (2016). All that is the case: documents and Indexicality. Scire: Representación y Organización del Conocimiento, [Zaragoza], v. 22, n. 1, p. 57-63.

DERVIN, Brenda. (1976). Information: an answer for every question? A solution for every problem? Journal of Broadcasting, [Washington], v. 20, n. 3, p. 323-333.

DOW, John T. (1977). A Metatheory for the Development of a Science of Information. Journal of American Society for Information Science, [Washington], v. 28, n. 6, p. 323-332.

DREYFUS, Hubert L.; WRATHALL, Mark A. (2005). Martin Heidegger: an introduction to his thought, work, and life. In: DREYFUS, Hubert; WRATHALL, Mark (eds.). A companion to Heidegger. Malden: Blackwell. (Blackwell companions to philosophy). p. 1-15.

DUGUID, Paul. (2015). The ageing of information: from particular to particulate. Journal of the History of Ideas, [Baltimore], v. 76, n. 3, p. 347-368.

EGAN, Margaret E. (1951). Bibliographic development in the social sciences. American Documentation, [Washington], v. 2, n. 1, p. 11-18.

EGAN, Margaret E. (1953). The use of social data by business, finance, and industry. American Documentation, [Washington], v. 4, n. 4, p. 147-154.

EGAN, Margaret E. (1955). The library and social structure. The Library Quarterly, [Chicago], v. 25, n. 1 , p. $15-22$.

EGAN, Margaret E. (1956). Librarian's dilemma. The Saturday Review, [New York], December 1, p. 72-73. 
EGAN, Margaret E.; SHERA, Jesse H. (1952). Foundations of a theory of Bibliography. The Library Quarterly, [Chicago], v. 22, n. 2, p. 125-137.

FERNEDA, Edberto. (2003). Recuperação da Informação: análise sobre a contribuição da Ciência da Computação para a Ciência da Informação. 2003. Tese (Doutorado em Ciências da Comunicação) - Escola de Comunicações e Artes, Universidade de São Paulo, São Paulo.

FROHMANN, Bernd. (1995). Taking information policy beyond Information Science: applying the actor network theory. In: ANNUAL CONFERENCE OF THE CANADIAN ASSOCIATION FOR INFORMATION SCIENCE, 23., 1995, Edmonton. Proceedings [...]. Edmonton: University of Alberta. p. 19-28.

FROHMANN, Bernd. (2001). Discourse and documentation: some implications for pedagogy and research. Journal of Education for Library and Information Science, [State College, PA], v. 42 , n. 1 , p. $12-26$.

FROHMANN, Bernd. (2004). Documentation Redux: Prolegomenon to (Another) Philosophy of Information. Library Trends, [Urbana], v. 52, n. 3, p. 387-407.

FROHMANN, Bernd. (2007). Multiplicity, materiality, and autonomous agency of documentation. In: SKARE, Roswitha; LUND, Niels W.; VÅRHEIM, Andreas (eds.). A document (re)turn: contributions from a research field in transition. Frankfurt: Peter Lang. p. 27-39.

FROHMANN, Bernd. (2008). O caráter social, material e público da informação. In: FUJITA, Mariângela S.; MARTELETO, Regina M.; LARA, Marilda L. G. (orgs.). A dimensão epistemológica da ciência da informação e suas interfaces técnicas, políticas e institucionais nos processos de produção, acesso e disseminação da informação. São Paulo: Cultura Acadêmica; Marília: Fundepe. p. 19-34. Disponível em: http://repositorios.questoesemrede.uff.br/repositorios/handle/123456789/829. Acesso em: 26 jan. 2019.

GADAMER, Hans-Georg. (2011a). Hermenêutica. In: GADAMER, Hans-Georg. Verdade e método II: complementos e índice. 6. ed. Petrópolis: Vozes; Bragança Paulista: Editora Universitária São Francisco. p. 494-508.

GADAMER, Hans-Georg. (2011b). Hermenêutica clássica e hermenêutica filosófica. In: GADAMER, Hans-Georg. Verdade e método II: complementos e índice. 6. ed. Petrópolis: Vozes; Bragança Paulista: Editora Universitária São Francisco. p. 111-142.

GADAMER, Hans-Georg. (2011c). Homem e linguagem. In: GADAMER, Hans-Georg. Verdade e método II: complementos e índice. 6. ed. Petrópolis: Vozes; Bragança Paulista: Editora Universitária São Francisco. p. 173-182.

GADAMER, Hans-Georg. (2011d). Linguagem e compreensão. In: GADAMER, Hans-Georg. Verdade e método II: complementos e índice. 6. ed. Petrópolis: Vozes; Bragança Paulista: Editora Universitária São Francisco. p. 216-233. 
GADAMER, Hans-Georg. (2011e). O que é a verdade? In: GADAMER, Hans-Georg. Verdade e método II: complementos e índice. 6. ed. Petrópolis: Vozes; Bragança Paulista: Editora Universitária São Francisco. p. 57-71.

GADAMER, Hans-Georg. (2011f). Sobre o círculo da compreensão. In: GADAMER, HansGeorg. Verdade e método II: complementos e índice. 6. ed. Petrópolis: Vozes; Bragança Paulista: Editora Universitária São Francisco. p. 72-81.

GADAMER, Hans-Georg. (2011g). A universalidade do problema hermenêutico. In: GADAMER, Hans-Georg. Verdade e método II: complementos e índice. 6. ed. Petrópolis: Vozes; Bragança Paulista: Editora Universitária São Francisco. p. 255-270.

GADAMER, Hans-Georg. (2012a). Hermenêutica e diferença ontológica. In: GADAMER, HansGeorg. Hermenêutica em retrospectiva. 2. ed. Petrópolis: Vozes. p. 68-81.

GADAMER, Hans-Georg. (2012b). No rastro da hermenêutica. In: GADAMER, Hans-Georg. Hermenêutica em retrospectiva. 2. ed. Petrópolis: Vozes. p. 161-188.

GADAMER, Hans-Georg. (2015). Verdade e método I: traços fundamentais de uma hermenêutica filosófica. 15. ed. Petrópolis: Vozes; Bragança Paulista: Editora Universitária São Francisco.

GOMES, Henriette Ferreira. (2001). Interdisciplinaridade e Ciência da Informação: de característica a critério delineador de seu núcleo principal. Datagramazero, [Rio de Janeiro], v. 2, n. 4. Disponível em:

basessibi.c3sl.ufpr.br/brapci/_repositorio/2010/01/pdf_a5768c4b85_0007441.pdf. Acesso

em 9 ago. 2017.

GOODY, Jack. (2000). The power of the written tradition. Washington: Smithsonian Institution Press.

GORICHANAZ, Tim. (2016). How the document got its authority. Journal of Documentation, [Bingley], v. 72, n. 2, p. $299-305$.

GRENERSEN, Geir; KEMI, Kjell; NILSEN, Steinar. (2016). Landscapes as documents: the relationship between traditional Sámi terminology and the concepts of document and documentation. Journal of Documentation, [Bingley], v. 72, n. 6, p. 1181-1196.

HAVELOCK, Eric A. (1986). The muse learns to write: reflections on orality and literacy from antiquity to the present. New Haven: Yale University Press.

HEIDEGGER, Martin. (1971). On the way to language. New York: Harper \& Row.

HEIDEGGER, Martin. (1985). Unterwegs zur Sprache. Frankfurt am Main: Vittorio Klostermann. (Gesamtausgabe, Bd. 12). 
HEIDEGGER, Martin. (2003). A caminho da linguagem. Petrópolis: Vozes; Bragança Paulista: Editora Universitária São Francisco.

HEIDEGGER, Martin. (2008). Introdução à filosofia. São Paulo: Martins Fontes.

HEIDEGGER, Martin. (2013). Ontologia: (hermenêutica da facticidade). Petrópolis: Vozes.

HEIDEGGER, Martin. (2015). Ser e Tempo. 10. ed. Petrópolis: Vozes; Bragança Paulista: Editora Universitária São Francisco.

HEKMAN, Susan J. (1986). Hermeneutics and the Sociology of Knowledge. Notre Dame: University of Notre Dame Press.

HJØRLAND, Birger. (1998). Theory and metatheory of Information Science: a new interpretation. Journal of Documentation, London, v. 54, n. 5, p. 606-621.

HJØRLAND, Birger. (2008). What is Knowledge Organization (KO)? Knowledge Organization, [Würzburg], v. 35, n. 2/3, p. 86-101.

HJØRLAND, Birger. (2012). Knowledge Organization = Information Organization? In: INTERNATIONAL ISKO CONFERENCE: CATEGORIES, CONTEXTS AND RELATIONS IN KNOWLEDGE ORGANIZATION, 13., 2012, Mysore. Proceedings [...]. Würzburg: Germany: Ergon. p. 8-14.

HJ ØRLAND, Birger. (2014). Theoretical development of information science: a brief history. Journal of Information Science, [London], [pre-referee version], p. 1-17. Disponível em: https://doi.org/10.1177/0165551510000000. Acesso em: 15 jun. 2014.

HJØRLAND, Birger. (2016). Knowledge Organization (KO). Knowledge Organization, [Würzburg], v. 43, n. 6, p. 474-484.

HOUAISS, Antônio; VILLAR, Mauro de Salles. (2009). Dicionário Houaiss da língua portuguesa. Rio de Janeiro: Objetiva.

JAEGER, Paul T. (2010). Education, adoption, and development: building a culture of social theory in LIS. The Library Quarterly, Chicago, v. 80, n. 3, p. 203-209.

KELLY, Thomas. (2016). Evidence. In: ZALTA, Edward N. (ed.). The Stanford Encyclopedia of Philosophy. Winter 2016 Edition. Disponível em:

https://plato.stanford.edu/archives/win2016/entries/evidence/. Acesso em: 12 jan. 2019.

KOBASHI, Nair Y. (1994). A elaboração de informações documentárias: em busca de uma metodologia. 1994. Tese (Doutorado em Ciências da Comunicação) - Escola de Comunicações e Artes, Universidade de São Paulo, São Paulo. 
KOBASHI, Nair Y. (1996). Análise Documentária e representação da informação. Informare: Cadernos do Programa de Pós-Graduação em Ciência da Informação, Rio de Janeiro, v. 2, n. 2, p. 5-27.

KOBASHI, Nair Y.; TÁLAMO, Maria F. G. M. (2003). Informação: fenômeno e objeto de estudo da sociedade contemporânea. Transinformação, Campinas, v. 15, n. 3, p. 7-21. Edição especial.

KOUTROUFINIS, Spyridon. (2016). Animal and Human "Umwelt" (Meaningful Environment)Continuities and Discontinuities. Balkan Journal of Philosophy, [Sofia], v. 8, n. 1, p. 49-54.

KULL, Kalevi. (1998). On semiosis, Umwelt, and semiosphere. Semiotica, Berlin, v. 120, n. 3/4, p. 299-310.

LAFONT, Cristina. (2005). Hermeneutics. In: DREYFUS, Hubert; WRATHALL, Mark (eds.). A companion to Heidegger. Malden: Blackwell. (Blackwell companions to philosophy). p. 265284.

LARA, Marilda L. G. (1993). A representação documentária: em jogo a significação. 1993. Dissertação (Mestrado em Ciências da Comunicação) - Escola de Comunicações e Artes, Universidade de São Paulo, São Paulo.

LARA, Marilda L. G. (2004). Linguagem documentária e terminologia. Transinformação, Campinas, v. 16, n. 3, p. 231-240.

LARA, Marilda L. G. (2009). Linguística documentária: seleção de conceitos. 2009. Tese (Livre Docência) - Escola de Comunicações e Artes, Universidade de São Paulo, São Paulo.

LARA, Marilda L. G. (2011). Conceitos de Organização e Representação do Conhecimento na ótica das reflexões do Grupo TEMMA. Informação \& Informação, Londrina, v. 16, n. 3, p. 92121.

LARA, Marilda L. G.; ORTEGA, Cristina D. (2012). Para uma abordagem contemporânea do documento na Ciência da Informação. In: CONGRESO ISKO, 10., 2011, Ferrol. Actas [...]. A Coruña: Universidade da Coruña. p. 371-387.

LARKIN, Brian. (2013). The politics and poetics of infrastructure. Annual Review of Anthropology, [Palo Alto], v. 42, p. 327-343.

LÓPEZ YEPES, José. (1997). Reflexiones sobre el concepto de documento ante la revolución de la información: ¿Un nuevo profesional del documento? Scire: representación y organización del conocimiento, [Zaragoza], v. 3, n. 1, p. 11-29.

LÓPEZ YEPES, José. (2015). La ciencia de la información documental: el documento, la disciplina y el profesional en la era digital. Ciudad de México: Universidad Panamericana. 
LUND, Niels W. (2004). Documentation in a complementary perspective. In: RAYWARD, W. Boyd (ed.). Aware and responsible: papers of the Nordic-International Colloquium on Social and Cultural Awareness and Responsibility in Library, Information, and Documentation Studies (SCARLID). Lanham: Scarecrow. p. 93-102.

LUND, Niels W. (2009). Document theory. Annual Review of Information Science and Technology, [Medford], v. 43, p. 399-432.

LUND, Niels W. (2010). Document, text and medium: concepts, theories and disciplines. Journal of Documentation, [Bingley], v. 66, n. 5, p. 734-749.

LUND, Niels W.; SKARE, Roswitha (2017). Document theory. In: McDONALD, John D.; LEVINECLARK, Michael (eds.). Encyclopedia of Library and Information Sciences. 4. ed. Boca Raton: CRC Press. p. 1372-1380.

MACHLUP, Fritz; MANSFIELD, Una (eds.). [1983]. The study of information: interdisciplinary messages. New York: Wiley.

MALPAS, Jeff. (2018). Hans-Georg Gadamer. In: ZALTA, Edward N. (ed.). The Stanford Encyclopedia of Philosophy. Fall 2018 Edition. Disponível em:

https://plato.stanford.edu/archives/fall2018/entries/gadamer/. Acesso em: 23 jan. 2019.

MANTZAVINOS, Chrysostomos. (2016). Hermeneutics. In: ZALTA, Edward N. (ed.). The Stanford Encyclopedia of Philosophy. Winter 2016 Edition. Disponível em: https://plato.stanford.edu/archives/win2016/entries/hermeneutics/. Acesso em: 13 dez. 2018.

MATTERN, Shannon. (2018). Scaffolding, hard and soft: media infrastructures as critical and generative structures. In: SAYERS, Jentery (ed.). The Routledge Companion to Media Studies and Digital Humanities. London: Routledge. p. 318-326.

McCLEER, Adriana. (2013). Knowing communities: a review of community assessment literature. Public Library Quarterly, [New York], v. 32, n. 3, p. 263-274.

McKENZIE, Donald F. (1999). Bibliography and the Sociology of Texts. Cambridge: Cambridge University Press.

MENDES, Luciana C. (2014). Do tecer do algodão ao tecer da informação: organizando a explosão informacional do século XIX. 2014. Dissertação (Mestrado em Ciência da Informação) - Escola de Comunicações e Artes, Universidade de São Paulo, São Paulo.

MEYRIAT, Jean. (2016). Documento, documentação, documentologia. Perspectivas em Ciência da Informação, [Belo Horizonte], v. 21, n. 3, p. 240-253.

MIJAILOV, A. I.; CHERNII, A. I.; GUILIAREVSKII, R. S. (1973). Fundamentos de la Informática. Moscú: Nauka; La Habana: Academia de Ciencias de Cuba, Instituto de Documentación e Información Científica y Técnica. 2 v. 
MIKHAILOV, A. I.; CHERNYI, A. I.; GILYAREVSKYI, R. S. (1980). Estrutura e principais propriedades da informação científica: a propósito do escopo da informática. In: GOMES, Hagar E. (org.). Ciência da Informação ou Informática? Rio de Janeiro: Calunga. p. 71-89.

MIKHAILOV, A. I.; GILAREVSKIJ, R. S. (1971). An Introductory Course on

Informatics/Documentation. The Hague: International Federation for Information.

MUELLER-VOLLMER, Kurt. (1989). Introduction: Language, mind, and artifact: an outline of hermeneutic theory since the Enlightenment. In: MUELLER-VOLLMER, Kurt. (ed.). The Hermeneutics reader: texts of the German tradition from the Enlightenment to the present. New York: Continuum. p. 1-53.

NOTAS explicativas. (2015). In: HEIDEGGER, Martin. Ser e Tempo. 10. ed. Petrópolis: Vozes; Bragança Paulista: Editora Universitária São Francisco. p. 561-582.

NUNBERG, Geoffrey. (1996). Farewell to the Information Age. In: NUNBERG, Geoffrey. (ed.). The future of the book. Berkeley: University of California Press. p. 103-138.

OLSEN, Bernt I. et al. (2012). Document theory for the design of socio-technical systems: a document model as ontology of human expression. Journal of Documentation, [Bingley], $v$. 68 , n. 1 , p. $100-126$.

ONG, Walter J. (2002). Orality and literacy: the technologizing of the word. 2. ed. New York: Routledge.

$\varnothing$ ROM, Anders. (2007). The concept of information versus the concept of document. In: SKARE, Roswitha; LUND, Niels W.; VÅRHEIM, Andreas (eds.). A document (re)turn: contributions from a research field in transition. Frankfurt: Peter Lang. p. 53-72.

ORTEGA, Cristina D. (2004). Relações históricas entre Biblioteconomia, Documentação e Ciência da Informação. Datagramazero, [Rio de Janeiro], v. 5, n. 5. Disponível em: http://www.dgz.org.br/out04/Art_03.htm. Acesso em: 14 mar. 2012.

ORTEGA, Cristina D. (2009a). A Documentação como uma das origens da Ciência da Informação e base fértil para sua fundamentação. Brazilian Journal of Information Science, [Marília], v. 3, n. 1, p. 3-35.

ORTEGA, Cristina D. (2009b). Surgimento e consolidação da Documentação: subsídios para compreensão da história da Ciência da Informação no Brasil. Perspectivas em Ciência da Informação, [Belo Horizonte], v. 14, número especial, p. 59-79.

ORTEGA, Cristina D. (2011). Do princípio monográfico à unidade documentária: exploração dos fundamentos da Catalogação. Liinc em Revista, Rio de Janeiro, v. 7, n. 1, p. 43-60.

OTLET, Paul. (2018). Tratado de documentação: o livro sobre o livro: teoria e prática. Brasília: Briquet de Lemos. 
PAGÈS, Robert. (1948). Transformations documentaires et milieu culturel (Essai de documentologie). Reveu de la documentation, La Haye, v. 15, n. 3, p. 53-64.

PALMER, Richard E. [2006]. Hermenêutica. Lisboa: Edições 70. (O saber da filosofia, 15).

PETERS, John D. (1988). Information: notes toward a critical history. Journal of

Communication Inquiry, [Thousand Oaks], v. 12, n. 9, p. 9-23.

RABELLO, Rodrigo. (2009). A face oculta do documento: tradição e inovação no limiar da Ciência da Informação. 2009. Tese (Doutorado em Ciência da Informação) - Faculdade de Filosofia e Ciências, Universidade Estadual Paulista, Marília.

RABELLO, Rodrigo. (2011). A dimensão categórica do documento na Ciência da Informação. Encontros Bibli, Florianópolis, v. 16, n. 31, p. 131-156.

RADFORD, Gary P. (1991). Hermeneutics: an intellectual tradition for communication studies. Occasional Papers in Communication, Information, and Library Studies, New Brunswick, v. 1, p. 6-27. Disponível em: http://www.theprofessors.net/hermen.html. Acesso em: 26 jan. 2017.

RAYWARD, W. Boyd. [1983]. Library and Information Sciences: disciplinary differentiation, competition, and convergence. In: MACHLUP, Fritz; MANSFIELD, Una (eds.). The study of information: interdisciplinary messages. New York: Wiley. p. 343-363.

RAYWARD, W. Boyd. (1985). Library and Information Science: an historical perspective. Journal of Library History, [Tallahassee], v. 20, n. 2, p.120-136.

RIOUX, Kevin. (2010). Metatheory in Library and Information Science: a nascent social justice approach. Journal of Education for Library and Information Science, [State College, PA], v. 51 , n. 1, p. 9-17.

RITZER, George. (1991). Metatheorizing in sociology. Lexington: Lexington Books.

SANTOS, Boaventura S. (2010). Um discurso sobre as ciências. 16. ed. Porto: Afrontamento.

SARACEVIC, Tefko. (2016). Relevance: in search of a theoretical foundation. In:

SONNENWALD, Diane H. (ed.). Theory development in the information sciences. Austin: University of Texas Press. p. 141-163.

SCHRADER, Alvin M. (1984). In search of a name: Information Science and its conceptual antecedents. Library and Information Science Research, Norwood, v. 6, n. 3, p. 227-271.

SCHUBACK, Márcia Sá Cavalcante. (2015). A perplexidade da presença. In: HEIDEGGER, Martin. Ser e Tempo. 10. ed. Petrópolis: Vozes; Bragança Paulista: Editora Universitária São Francisco. p. 15-32. 
SCHUM, David A. (1994). Evidential Foundations of Probabilistic Reasoning. New York: John Wiley \& Sons. (Wiley Series in Systems Engineering).

SHAPIRO, Fred R. (1995). Coinage of the term Information Science. Journal of the American Society for Information Science, [Washington], v. 46, n. 5, p. 384-385.

SHAW, Ryan. (2013). Information organization and the philosophy of history. Journal of the American Society for Information Science and Technology, [New York], v. 64, n. 6, p. 10921103.

SHERA, Jesse H. (1967). Librarians against machines. Science, [Washington], v. 156, n. 3776, p. 746-750.

SHERA, Jesse H. (1971). The sociological relationships of Information Science. Journal of the American Society for Information Science, [Washington], v. 22, n. 2, p. 76-80.

SHERA, Jesse H. (1973). Toward a theory of Librarianship and Information Science. Ciência da Informação, Rio de Janeiro, v. 2, n. 2, p. 87-97.

SHERA, Jesse H. (1974). Mechanization, Librarianship, and the bibliographic enterprise. Journal of Documentation, [London], v. 30, n. 2, p. 153-169.

SHERA, Jesse H. (1977). Epistemologia Social, Semântica Geral e Biblioteconomia. Ciência da Informação, Rio de Janeiro, v. 6, n. 1, p. 9-12.

SHERA, Jesse H. (1980). Sobre Biblioteconomia, Documentação e Ciência da Informação. In: GOMES, Hagar Espanha (org.). Ciência da Informação ou Informática? Rio de Janeiro: Calunga. p. 91-105.

SHERA, Jesse H. [1983]. Librarianship and Information Science. In: MACHLUP, Fritz; MANSFIELD, Una (eds.). The study of information: interdisciplinary messages. New York: Wiley. p. 379-388.

SHERA, Jesse H.; CLEVELAND, Donald B. (1977). History and foundations of Information Science. Annual Review of Information Science and Technology, [White Plains], v. 12, p. 249-275.

SILVA, Armando M.; RIBEIRO, Fernanda. (2012). Documentation/Information and their paradigms: characterization and importance in research, education, and professional practice. Knowledge Organization, [Würzburg], v. 39, n. 2, p. 111-124.

SMIT, Johanna W. (1987). Introdução. In: SMIT, Johanna W. (coord.). Análise documentária: a análise da síntese. Brasília: IBICT. p. 5-10.

SMIT, Johanna W. (2003). Arquivologia/biblioteconomia: interfaces das ciências da informação. Informação \& Informação, Londrina, v. 8, n. 2. Disponível em: 
http://www.uel.br/revistas/uel/index.php/informacao/article/download/1713/1464. Acesso em: 05 jul. 2014.

SMIT, Johanna W. (2009). Novas abordagens na organização, no acesso e na transferência da informação. In: SILVA, Helen C.; BARROS, Maria H. T. C. (orgs.). Ciência da Informação: múltiplos diálogos. Marília: Oficina Universitária Unesp. p. 57-66.

SMIT, Johanna W. (2012). A informação na Ciência da Informação. InCID: Revista de Ciência da Informação e Documentação, Ribeirão Preto, v. 3, n. 2, p. 84-101.

SMIT, Johanna W.; BARRETO, Aldo A. (2002). Ciência da Informação: base conceitual para a formação do profissional. In: VALENTIM, Marta Lígia Pomim (org.). Formação do profissional da informação. São Paulo: Polis. p. 9-23.

SMIT, Johanna W.; TÁLAMO, Maria F. G. M.; KOBASHI, Nair Y. (2004). A determinação do campo científico da Ciência da Informação: uma abordagem terminológica. Datagramazero, [Rio de Janeiro], v. 5, n. 1. Disponível em: http://www.dgz.org.br/fev04/Art_03.htm. Acesso em: 12 abr. 2012.

SMITH, Linda C. (2017). Reference Services. In: McDONALD, John D.; LEVINE-CLARK, Michael (eds.). Encyclopedia of Library and Information Sciences. 4. ed. Boca Raton: CRC Press. p. 3912-3919.

SOUND. (2015). In: LAW, Jonathan; RENNIE, Richard (eds.). A Dictionary of Physics. 7. ed. Oxford: Oxford University Press. Disponível em:

http://www.oxfordreference.com/view/10.1093/acref/9780198714743.001.0001/acref9780198714743-e-2840?rskey=KAyUTx\&result=1. Acesso em: 13 set. 2018.

STAR, Susan L.; RUHLEDER, Karen. (1996) Steps toward an ecology of infrastructure: design and access for large information spaces. Information Systems Research, [Providence], v. 7, n. 1, p. 111-134.

SUMMERS, Ron et al. (1999). Information Science in 2010: A Loughborough University View. Journal of the American Society for Information Science, [Washington], v. 50, n. 12, p. 1153- 1162.

SVENONIUS, Elaine. (2000). The intellectual foundation of information organization. Cambridge, MA: The MIT Press.

TÁLAMO, Maria F. G. M. (1987). A definição semântica para a elaboração de glossários. In: SMIT, Johanna W. (coord.). Análise documentária: a análise da síntese. Brasília: IBICT. p. 8798.

TÁLAMO, Maria F. G. M. (1994). Linguagem documentária. São Paulo: APB. (Ensaios APB, n. 45). 
TÁLAMO, Maria F. G. M.; SMIT, Johanna W. (2007). Ciência da Informação: pensamento informacional e integração disciplinar. Brazilian Journal of Information Science, [Marília], v. 1, n.1, p. 33-57.

TENNIS, Joseph T. (2005). Conceptions of subject analysis: a metatheoretical investigation. 2005. $180 \mathrm{f}$. Dissertation (Doctor of Philosophy) - The Information School, University of Washington, Seattle.

TENNIS, Joseph T. (2008). Epistemology, Theory, and Methodology in Knowledge Organization: Toward a Classification, Metatheory, and Research Framework. Knowledge Organization, [Würzburg], v. 35, n. 2/3, p. 102-112.

TURNER, Deborah A. (2007). Conceptualizing oral documents. Information Research, Borås, v. 12, n. 4. Disponível em: http://www.informationr.net/ir/12-4/colis/colis32.html. Acesso em: 14 jan. 2019.

TURNER, Deborah A. (2009). Conceptualizing oral documents. 2009. Dissertation (Doctor of Philosophy) - The Information School, University of Washington, Seattle.

TURNER, Deborah A. (2010). Can a Document be Oral? In: HAWAII INTERNATIONAL CONFERENCE ON SYSTEM SCIENCES, 43., 2010, Honolulu. Proceedings [...] Los Alamitos: IEEE Computer Society. p. 1-8. Disponível em: https://ieeexplore.ieee.org/document/5428332. Acesso em: 14 jan. 2019.

TURNER, Deborah A. (2012a). Oral documents in concept and in situ, part I: grounding an exploration of orality and information behaviour. Journal of Documentation, [Bingley], v. 68, n. 6, p. 852-863.

TURNER, Deborah A. (2012b). Oral documents in concept and in situ, part II: managerial decrees. Journal of Documentation, [Bingley], v. 68, n. 6, p. 864-881.

TURNER, Deborah A; ALLEN, Warren. (2011). Materiality and Oral Documents. In: iCONFERENCE, 2011, Seattle. Proceedings [...]. New York: ACM. p. 56-62.

UEXKÜLL, Jakob J. von. (2010). Foray into the worlds of animals and humans: with a theory of meaning. Minneapolis: University of Minnesota Press.

VAKKARI, Pertti. (1997). Information seeking in context: a challenging metatheory. In: VAKKARI, Pertti; SAVOLAINEN, Reijo; DERVIN, Brenda (eds.). Information seeking in context: proceedings of an international conference on research in information needs, seeking and use in different context. London: Taylor Graham. p. 451-464.

VEGA-ALMEIDA, Rosa L.; FERNÁNDEZ-MOLINA, J. Carlos; LINARES, Radamés. (2009). Coordenadas paradigmáticas, históricas y epistemológicas de la Ciencia de la Información: una sistematización. Information Research, Borås, v. 14, n. 2. Disponível em: http://informationr.net/ir/14-2/paper399.html. Acesso em: 7 maio 2012. 
VESSEY, David. (2009). Gadamer and the fusion of horizons. International Journal of Philosophical Studies, [London], v. 17, n. 4, p. 531-542.

VICKERY, Brian. (1997). Metatheory and Information Science. Journal of Documentation, London, v. 53, n. 5, p. 457-476.

WAGNER, David G.; BERGER, Joseph. (1985). Do sociological theories grow? American Journal of Sociology, Chicago, v. 90, n. 4, p. 697-728.

WERSIG, Gernot. (1993). Information science: the study of postmodern knowledge usage. Information Processing \& Management, [Oxford], v. 29, n. 2, p. 229-239.

WERSIG, Gernot; HENNINGS, Ralf-Dirk. (1984). The intellectual architecture of information systems: a broad range research agenda. In: DIETSCHMANN, Hans J. (ed.). Representation and exchange of knowledge as a basis of information processes. Amsterdam: North Holland. p. 7-30.

WERSIG, Gernot; NEVELING, Ulrich. (1975). The phenomena of interest to Information Science. The Information Scientist, [London], v. 9, n. 4, p. 127-140.

WERSIG, Gernot; WINDEL, Gunther. (1985). Information Science needs a theory of 'information actions'. Social Science Information Studies, [Borough Green], v. 5, n. 1, p. 1123.

WILSON, Thomas D. (1981). On user studies and information needs. Journal of Documentation, [London], v. 37, n. 1, p. 3-15.

WILSON, Thomas D. (2000). Human information behavior. Informing Science, [Santa Rosa], v. 3, n. 2, p. 49-55.

YEO, Geoffrey. (2007). Concepts of record (1): evidence, information, and persistent representations. The American Archivist, [Chicago], v. 70, n. 2, p. 315-343. 